NBER WORKING PAPER SERIES

\title{
WHO SOLD DURING THE CRASH OF 2008-9? EVIDENCE FROM TAX-RETURN DATA ON DAILY SALES OF STOCK
}

\author{
Jeffrey Hoopes \\ Patrick Langetieg \\ Stefan Nagel \\ Daniel Reck \\ Joel Slemrod \\ Bryan Stuart \\ Working Paper 22209 \\ http://www.nber.org/papers/w22209
NATIONAL BUREAU OF ECONOMIC RESEARCH
1050 Massachusetts Avenue
Cambridge, MA 02138
April 2016

We thank John Friedman, Clemens Sialm, Andrei Shleifer, Chris Williams, Stefan Zeume, and participants at the University of Michigan Public Finance seminar, the 2015 National Tax Association meetings, the NBER Behavioral Finance Meeting, the US Treasury Office of Tax Analysis, and the University of North Carolina Annual Tax Symposium for helpful discussion and comments. We also thank John Guyton of the Research, Analysis, and Statistics Division of the Internal Revenue Service for help with using the IRS administrative data. The views expressed here are those of the authors alone, and do not necessarily reflect the views of the Internal Revenue Service or the National Bureau of Economic Research.

At least one co-author has disclosed a financial relationship of potential relevance for this research. Further information is available online at http://www.nber.org/papers/w22209.ack

NBER working papers are circulated for discussion and comment purposes. They have not been peer-reviewed or been subject to the review by the NBER Board of Directors that accompanies official NBER publications.

(C) 2016 by Jeffrey Hoopes, Patrick Langetieg, Stefan Nagel, Daniel Reck, Joel Slemrod, and Bryan Stuart. All rights reserved. Short sections of text, not to exceed two paragraphs, may be quoted without explicit permission provided that full credit, including $(\odot)$ notice, is given to the source. 
Who Sold During the Crash of 2008-9? Evidence from Tax-Return Data on Daily Sales of Stock

Jeffrey Hoopes, Patrick Langetieg, Stefan Nagel, Daniel Reck, Joel Slemrod, and Bryan Stuart NBER Working Paper No. 22209

April 2016

JEL No. G01,G11,G12

\section{ABSTRACT}

We examine individual stock sales from 2008 to 2009 using population tax return data. The share of sales by the top 0.1 percent of income recipients and other top income groups rose sharply following the Lehman Brothers bankruptcy and remained elevated throughout the financial crisis. Sales by top income and older age groups were relatively more responsive to increased stock market volatility. Volatility-driven sales were not concentrated in any one sector, but mutual fund sales responded more strongly to increased volatility than stock sales. Additional analysis suggests that gross sales in tax return data are informative about unobserved net sales.

Jeffrey Hoopes

Ohio State University

448 Fisher Hall

2100 Neil Avenue

Columbus, $\mathrm{OH} 43210$

hoopes@fisher.osu.edu

Patrick Langetieg

Internal Revenue Service

Patrick.T.Langetieg@irs.gov

Stefan Nagel

Ross School of Business and

Department of Economics

University of Michigan

701 Tappan Street

Ann Arbor, MI 48109

and NBER

stenagel@umich.edu
Daniel Reck

University of Michigan

Economics Department

238 Lorch Hall, 611 Tappan Street

Ann Arbor, MI 48109-1220

dreck@umich.edu

Joel Slemrod

University of Michigan Business School

701 Tappan Street

Room R5396

Ann Arbor, MI 48109-1234

and NBER

jslemrod@umich.edu

Bryan Stuart

Department of Economics

University of Michigan

611 Tappan St.

Lorch Hall

Ann Arbor, MI 48109-1220

bastuart@umich.edu 


\section{Introduction}

Periods of turmoil in stock markets—-such as September 2008 in the wake of the Lehman Brothers bankruptcy_are associated with large declines in prices, abnormally high intra-day price volatility, and high trading volume. Market commentary often characterizes these periods as "sell-offs." As always, there is a buyer for every seller, so investors as a group cannot all be sellers. What may be happening instead during these instances is that some investors sell out, leaving the remaining investors to bear the risk of stock ownership. Such a reallocation of asset ownership among heterogeneous investors is consistent with the high level of trading activity observed during such periods. Little is known, however, about the characteristics of the investors that are prone to sell in the midst of market turmoil. This paper uses administrative data from the Internal Revenue Service, consisting of billions of third-party reports on all sales of stock in United States taxable individual accounts, to understand which individuals sold stock during the tumultuous market events of 2008 and 2009. Our main finding is that investors at the very top of the income distribution—both the top 1 percent and even the top 0.1 percent—are, along with older investors, much more likely to sell stock during times of market tumult than other investors.

A number of factors can cause certain investors to be relatively sensitive to market tumult. Some investors may be forced to sell due to constraints on their risk-bearing capacity (e.g., leverage constraints, liquidity shocks), some may be less tolerant of short-run risk than the average investor (e.g., close to retirement), some may perceive themselves to be better informed than others and anticipate a further price decline, and some investors may lose trust in the stock market altogether and perceive it as a rigged game. While some of these reasons for selling could 
apply equally to both institutional and individual investors, others are primarily relevant for individual investors (and the flows they direct in and out of institutional investment products).

Understanding heterogeneity in investors' propensity to sell sheds light on several key questions in finance and macroeconomics, including the mechanisms that give rise to elevated premia for bearing risk (Bollerslev and Todorov 2011; Martin 2015) and for providing liquidity (Nagel 2012) following market tumult episodes. If part of the investor population has a tendency to sell during times of market turmoil, this leaves a smaller set of investors holding aggregate stock market risk. They must be enticed to do so by a higher risk premium and by greater compensation for absorbing the liquidity demand of those who want to sell. Empirical evidence on such episodic shifts in stock ownership has so far remained largely elusive due to lack of data.

In this paper, we study this set of questions with a unique new data set that allows us to track, at a daily frequency, sales of stocks and mutual fund shares in the population of U.S. taxable individual investors. The data are extracted from the universe of (anonymized) tax returns filed with the Internal Revenue Service (IRS), and allow us to match asset sales reported for capital gains taxation purposes with some demographic information on each taxpayer. While we do not observe asset purchases in these tax records, we present indirect evidence from dividend receipts and a supplementary brokerage account data set suggesting that individuals with high levels of gross sales are also, to a substantial extent, net sellers of stocks.

We focus our analysis on 2008 and 2009, and further zoom in on the period immediately following the bankruptcy of Lehman Brothers in September 2008. We find that, starting in September 2008, the share of sales volume attributed to the top 0.1 percent of income recipients rises sharply until the beginning of 2009. More generally, we find that high-income taxpayers have a greater propensity to sell during periods of market tumult. In regression analysis, we 
measure tumult with lagged one-day changes in the VIX index. The VIX index is a measure of (risk-adjusted) expected market volatility and it is commonly used as a proxy for market tumult and as a crisis indicator (see Adrian and Shin 2010; Longstaff 2010; Nagel 2012). Stock market returns are typically negative on days when the VIX rises. We find that sales volume rises much more strongly with lagged VIX changes for the top 95-99, 99-99.9, and 99.9-100 income percentiles than for other income groups over the period 2008 to 2009. In multi-dimensional analysis, both high income and age over 60 are associated with a strongly positive sales volumeVIX relationship, as are income and receipt of Social Security income.

The greater sensitivity of older investors is consistent with the idea that investors close to retirement (with less opportunity to make up losses through future labor income) should be particularly sensitive to a perceived rise in risk (Chai et al. 2011). The tendency of high-income investors to sell in high-volatility episodes could be a consequence of their tendency to pay greater attention to their portfolios (Sicherman et al. 2016) and it could indicate that financially more sophisticated investors perceive themselves better able to time the market. ${ }^{1}$ Another possibility is that high-income investors are more likely to own stocks on margin. As a consequence, a fall in asset prices or a rise in risk leads them to delever their portfolio by through sales of risky assets (Kimball et al. 2011). A third potential explanation that could explain both the age- and income-related findings is that selling during tumultuous periods interacts with the disposition effect, i.e., the tendency of investors to avoid selling stocks with accumulated losses (Shefrin and Statman 1985; Odean 1998). Prior evidence in Dhar and Zhu (2006) and Calvet, Campbell, and Sodini (2009) indicates that the disposition effect is stronger for younger investors and those with lower wealth. This reluctance to realize losses among the young and less

\footnotetext{
${ }^{1}$ Recent work by Moreira and Muir (2016) suggests that temporarily reducing stock market exposure following burst of high volatility may in fact be a utility-improving timing strategy.
} 
wealthy could be the reason why their sales volume is less sensitive to market tumult. ${ }^{2}$ Other demographic characteristics of investors-gender, marital status, region and state of residence, presence and amount of a mortgage interest deduction, and 2007 zip-code-level house price growth-are not related to the volatility sensitivity of stock sales.

We also analyze separately the sales volume of individual stocks and mutual funds. Taxpayers' mutual fund sales volume is more sensitive to changes in the VIX than is sales volume of individual stocks. This also parallels findings for the disposition effect. Chang, Solomon, and Westerfield (2016) show that the disposition effect is present for non-delegated assets such as individual stocks, but not for delegated assets such as mutual funds. Thus, the disposition effect could have a dampening effect on tumult-driven selling of individual stocks. For delegated assets, Chang, Solomon, and Westerfield argue that cognitively dissonant investors blame managers for stock market losses and withdraw their funds in response. A related notion is that investors lose trust in financial intermediaries in response to market turmoil (Dorn and Weber 2013). Although sales in financial stocks clearly respond to specific events, we find no evidence that sales in finance responded more strongly to changes in the VIX than sales in most other sectors.

The data we analyze are, in a number of ways, substantially better than the data sets that have been studied up to now. Existing studies of investor responses to market movements and changes in risk use data either from investor surveys (Guiso et al. 2013; Hudomiet et al. 2011; Shiller 1987), from non-randomly selected samples of portfolio holdings data (Dorn and Weber 2013; Hoffmann et al. 2013; Weber et al. 2012; Barrot et al. 2016), administrative data from Sweden that are available only at annual frequency (Calvet et al. 2009), or data on institutional

\footnotetext{
${ }^{2}$ While the literature on the disposition effect focuses on the cross-section of individual stock trades, our results show that the findings in this literature may also be relevant for understanding individuals' reaction to market tumult.
} 
investor portfolios (see Ben-David, Franzoni, and Moussawi (2012); Cella et al. (2013) for the crisis in 2008; see Brunnermeier and Nagel (2004); Griffin et al. (2011) for the Nasdaq crash in 2000). Our data let us investigate, for the first time, the population of U.S. taxable investors as a whole at a daily frequency.

The data set is not perfect, though. The data set covers only reported taxable sales, but not purchases of stocks and mutual funds. Additional analyses show, however, that there is a strong relationship between gross selling, which we observe, and net selling (i.e., sales minus purchases), which we do not observe. First, we examine data from a discount brokerage that reports both gross and net sales (Barber and Odean 2000). We find a very strong positive relationship between gross and net sales. Furthermore, net sales of brokerage customers rise with changes in the VIX in similar ways as the gross sales of taxpayers in our data. Second, in the IRS data, we examine changes in dividend income reported on individual tax returns. Here we find a strong negative relationship between gross sales in a given year (e.g. 2008) and the change in dividend income from the previous year (2007) to the subsequent year (2009). Despite coming from different sources and time periods, the quantitative results from discount brokerage data and from changes in dividend income on tax returns are highly consistent with one another, suggesting that $\$ 1$ of gross sales corresponds to about $\$ 0.33$ in net sales.

Another shortcoming of the data set is that we do not observe sales in non-taxable accounts, such as Individual Retirement Accounts. We analyze data from the 2007-2009 panel of the Survey of Consumer Finance, which contains data on wealth in taxable and non-taxable accounts, including pensions and trusts. We find that the share of wealth in taxable accounts is relatively higher for individuals at the top of the income distribution, and for older individuals. These facts rule out the concern that our main findings are driven by older and higher-income 
people holding a disproportionately small share of their equities in taxable accounts. Additionally, net sales in taxable accounts between the 2007 and 2009 waves of the survey are strongly related to total net sales, suggesting that our analysis of sales in taxable accounts are informative about total asset holdings.

Our study connects to a number of recent papers that have started to shed light on the reaction of different types of investors to the market turmoil during the financial crisis. The evidence from existing studies is mixed, possibly because samples used in these studies are small and selective. Dorn and Weber (2013) find that customers of a large German retail bank kept their overall equity allocations quite stable, but they withdrew from actively managed mutual funds, which could be related to our finding that U.S. taxpayer mutual fund sales volume is more sensitive to changes in VIX than stock sales are. Barrot et al. (2016) find that customers of a French brokerage customers also withdrew from mutual funds, but they increased their exposure to directly held stocks. Hoffmann et al. (2013) find that the brokerage customers in their sample did not reduce the risk of their portfolios during the height of the crisis, even though, temporarily, their risk tolerance dropped and they expected lower returns and higher risk. In contrast, Weber et al. (2012) find substantial changes in risk taking associated with changes in subjective perceptions of risk and return during this period in a survey of U.K. online brokerage customers. Similarly, Guiso et al. (2013) find that both a qualitative and a quantitative surveybased measure of risk aversion increased following the experience of the crisis, but they do not find much predictable cross-sectional heterogeneity in the change in risk aversion. Although certainly of interest, the small and selected nature of the samples in these studies limits the extent to which one can learn about heterogeneity between demographic groups and how much one can 
generalize from these findings. We turn now to describe the much more comprehensive data we examine, our research design and its theoretical underpinning, and finally our results.

\section{Data}

This section describes the confidential administrative data and publicly available data we use, and provides summary statistics and match rates across different data sources.

\subsection{Tax Return Data}

We use two types of tax-return data on U.S. individuals trading in taxable accounts. The primary source of data is third-party information assembled by brokerages and provided to the IRS and taxpayers on Form 1099-B. ${ }^{3}$ The raw data set contains all Form 1099-B's for trades occurring between January 1, 2000 and December 31, 2012. For any covered financial asset sold in this period, Form 1099-B provides the sale price and date, the Committee on Uniform Security Identification Procedures (CUSIP) number identifying the asset, an anonymized version of the taxpayer identification number (TIN), which for an individual seller is a Social Security number, along with several less relevant items. ${ }^{4}$

The second source of information we can link to asset sales is demographic information from individual income tax returns (Forms 1040) and other records. These include, among other details, age and gender (from Social Security records), number of dependents, whether the individual takes a mortgage interest deduction, and the ZIP code of the filing address. We also observe a variety of income measures, including wages and salaries, dividends, interest payments, retirement benefits, and net income from self-employment, many of which are supported by third-party information.

\footnotetext{
${ }^{3}$ For a current year 1099-B, see www.irs.gov/pub/irs-pdf/f1099b.pdf.

${ }^{4}$ For some assets acquired after January 1, 2011, Form 1099-B also lists the date of acquisition, the cost basis, the capital gain or loss, and whether the capital gain is short-term or long-term. We do not use this information in this paper.
} 
Our data set offers several important advantages over existing work. We have daily transaction data, as do Odean (1998) and Hoffman et al. (2013). However, our enormous sample size permits estimation of trading behavior at a daily frequency with substantial precision. Our data are unique in measuring activity across all taxable accounts; the aforementioned studies use data from a single brokerage house. Our data are also unique in containing several incomesource variables, as well as many other taxpayer characteristics.

Because we only observe activity in individual taxable accounts, if individuals' propensity to sell off assets during times of turmoil systematically differs between non-taxable retirement accounts and taxable accounts, our results will be limited in scope, because they are only informative about the latter. Second, we observe gross sales, but not purchases, so we cannot provide direct evidence on "net sales;" we do, however, observe annual dividend income, which is related to stock ownership. We address these issues at length in Section 5. We also do not have information on traders' market perceptions, risk attitudes, or emotional states, which limits our ability to explore the precise motivation for selling. Absent high frequency time-series data about people's underlying motivation for selling stock, we instead analyze how sales by traders with various characteristics are correlated with reasonable measures of "tumult" in the market, focusing on price volatility.

\subsection{Match Rates and Aggregate Statistics}

Table 1 provides details of our data selection process and sample statistics. We start with the population of 1.4 billion 1099-B's in tax years 2008 and 2009, representing $\$ 37$ trillion in total trading volume. There were about 22 million distinct taxpayers (individuals and institutions) in 2008, and about 21 million distinct taxpayers in 2009. After eliminating nontrading days and partial trading days, negative trade amounts and seemingly erroneous and very 
large trades, we are left with 1.4 billion 1099-Bs and $\$ 36$ trillion of volume. ${ }^{5}$ Next, we keep only sales related to individual taxpayers, substantially reducing our sample to 870 million transactions and $\$ 9.6$ trillion in volume; the excluded trades are largely executed by entities such as partnerships, corporations, and trusts. ${ }^{6}$ Of these 1099-Bs that have a valid Social Security Number as a TIN (individual taxpayers), we discard trades entered into by minors (those under 18), leaving 861 million 1099-Bs in the sample, representing $\$ 9.5$ trillion in volume. Although many different assets are subject to 1099-B reporting, we focus on stocks and stock mutual funds, represented by 273 million 1099-Bs and $\$ 6.8$ trillion in trading volume. Until Section 6.2, when we examine differences in selling behavior between stock shares and mutual funds, we refer to individual stocks and stock mutual funds collectively as stocks. Finally, because our main income measure derives from average income over the period 2000 to 2007, we retain only transactions in 2008 and 2009 for taxpayers who appear as the taxpayer or spouse on at least one Form 1040 from 2000 to 2007. This leaves us with a final sample of $\$ 6.8$ trillion in trading volume across 2008 and 2009— $\$ 3.7$ trillion in 2008, and \$3.1 trillion in 2009. Our total trading volume of $\$ 3.8$ trillion in 2008 compares to the estimate of $\$ 2.2$ trillion from the Sales of Capital Assets (SOCA) sample in 2008 (Wilson and Liddell 2013). ${ }^{7}$ Additional summary statistics on the final sample are presented in Appendix Table A.1.

\footnotetext{
${ }^{5}$ Specifically, we discard data from a trivial number of 1099-Bs (under 10) that are clearly errors (single sales of stock in the tens of billions of dollars) and several large sales apparently related to a single event in a single state. Many large trades remain in our sample; from 2007 to 2009, there are over 13,000 sales over $\$ 10$ million and over 140 sales over $\$ 100$ million. We verified as valid by hand a random set of these transactions.

${ }^{6}$ If a demographic group is unusually likely to execute trades through such entities, we might be mis-stating the relative sensitivity of these groups' overall sales. Cooper at al. (2015) provide evidence about the ultimate owners of pass-through entities, suggesting that they are substantially more concentrated among high earners.

${ }^{7}$ See https://www.irs.gov/pub/irs-soi/08in03soca.xls. A number of factors might account for the difference between the universe of 1099-B transactions and the sample in the SOCA data assembled by the Statistics of Income Division of the IRS. For 2008, SOCA estimates are based on a sample of 58,521 taxpayers (Wilson and Liddell 2013). Further, based on conversations with IRS staff, we believe that the data in the SOCA is based on when a return is filed, as opposed to when a trade is executed. Further, the SOCA study only records a limited number of short-term trades (500) per taxpayer, due to the costliness of transcribing Schedule D data.
} 


\subsection{Market Turmoil and the Financial Crisis}

To proxy for market tumult, we use the Chicago Board Options Exchange Volatility Index (VIX), obtained from the Center for Research in Security Prices (CRSP). The VIX index measures the implied volatility of stock prices based on option contracts sold on the S\&P 500 stock index with a one-month maturity. ${ }^{8}$ Because it is based on option prices, it is a forwardlooking measure of investor uncertainty. It reflects the expected S\&P 500 stock-index return volatility at a one-month horizon as well as the risk premium that investors are willing to pay to insure against shocks to volatility over this horizon. The VIX is widely used in academic studies as a measure of tumult in stock markets and the financial system more generally (see, for example, Adrian and Shin (2010), Longstaff (2010), and Nagel (2012)). ${ }^{9}$ For purposes of presentation, we divide VIX by 100 throughout and make any transformations on this re-scaled variable, and often analyze the logarithm of the VIX. Unless noted otherwise, we examine behavior only on full trading days. ${ }^{10}$

Figure 1 plots the evolution of the VIX at a daily frequency. In Panel A of Figure 1, we plot the VIX, in logs and levels, from 2008 to 2009. Until mid-2008, the VIX was low relative to levels seen during the crisis. Starting in the second week of September 2008, the VIX increased dramatically, from 0.23 on September 8 to 0.80 on October $27 .{ }^{11}$ Panel B of Figure 1 displays the VIX from September to November 2008. On the day of the Lehman Brothers

\footnotetext{
${ }^{8}$ The VIX calculated based on the S\&P 500 is highly correlated with reasonable alternatives such as the VIX based on the Dow Jones Industrial Average or the NASDAQ, with rank correlations in excess of 0.95 between each pair of these measures over our sample period.

${ }^{9}$ The VIX is, to be sure, not the only reasonable measure of market tumult, one alternative being the lagged negative market return. Below we show that our qualitative conclusions about investor heterogeneity in their response to market tumult are preserved if we use this alternative measure.

${ }^{10}$ For 2008-2009, the half-trading days are 7/3/2008, 11/28/2008, 12/24/2008, 12/26/2008, 7/2/2009, 11/27/2009, and 12/24/2009. The market is fully closed on weekends and holidays. See http://www1.nyse.com/pdfs/closings.pdf. ${ }^{11}$ A VIX value of 23 (scaled to 0.23 ) means that option prices imply that a one standard deviation movement in the S\&P 500 is 23 percent of the current index level over the next year, and 6.6 percent $(=23 / \sqrt{12})$ over the next month.
} 
bankruptcy (September 15, 2008), the VIX increased by 24 percent. $^{12}$ The following day, American International Group (AIG) avoided bankruptcy after receiving an $\$ 85$ billion loan from the Federal Reserve Bank of New York. The next major increase in the VIX occurred on September 29, the day on which Citigroup agreed to purchase Wachovia, the Federal Open Market Committee (FOMC) expanded swap lines with several other central banks, and the U.S. House of Representatives rejected legislation from Treasury on the purchase of troubled assets. On October 14, Treasury announced the Troubled Asset Relief Program (TARP), and VIX increased considerably on the following day. Ten days later, VIX reached a new peak, when National City Bank was purchased by PNC. Almost a month later, on November 18, executives of three large U.S. auto companies testified before Congress and requested TARP funds, triggering an increase in the VIX that began to turn around only on November 21 . The VIX peaked on November 20 (at 0.81 ), and then began to decrease toward pre-crisis levels.

\subsection{Aggregate Measures of Sales Volume}

To gain a sense of the usefulness and limitations of the data we examine in the main part of the analysis, Figure 2 compares the share of total sales volume reported on matched Form 1099-B's to total sales volume as measured by CRSP. ${ }^{13}$ Panel A plots logged trading volume from these two sources over time, and Panel B depicts matched 1099-B sales as a fraction of CRSP sales volume. The total volume coverage rate does not vary substantially with market

\footnotetext{
${ }^{12}$ This narrative is based on the account in https://www.stlouisfed.org/financial-crisis/full-timeline.

${ }^{13}$ The positive relationship between market sales volume and volatility is well documented in the literature; see the survey by Karpoff (1987) for references to classic studies on this topic. In our sample period, a one standard deviation increase in the log VIX difference is associated with a 3.7 percent increase in market sales volume, significant at the one-percent level. Sales volume from matched Form 1099-B's is slightly less strongly associated: a one standard deviation increase in the log VIX difference is associated with a 2.4 percent increase in 1099-B sales volume. Appendix Table A.1 provides summary statistics and Appendix Table A.2 provides details of these regressions.
} 
volatility. ${ }^{14}$ This share increases modestly throughout 2009 . We also see large increases in the matched 1099-B shares during the very last days of 2008 and 2009. This phenomenon is likely at least partly attributable to the well-known tendency of individual investors to rebalance their portfolio at year-ends, including their tendency to "harvest" capital losses for tax purposes (Hoopes et al. 2015; Poterba and Weisbenner 2001). Opportunities for loss harvesting were especially abundant at the end of 2008 and 2009 because of the crisis. When we later examine heterogeneity in the propensity to sell assets, we use day fixed effects to control for these types of behaviors.

On average, 1099-B sales volume amounts to about 6 percent of CRSP sales volume in a day; the median coverage rate is similar. Given estimates that about 73 percent of U.S. equity trading in our sample period is done by computer-driven, high-frequency (HF) traders, ${ }^{15}$ a 6 percent coverage rate implies that our data covers the sales volume of a substantial fractionabout 22 percent - of non-HF trading. Because HF traders typically close their positions at the end of each day, they are better viewed as intermediaries that hold temporary positions rather than investors that add risk-bearing capacity to the market. For a study like ours that focuses on who is ultimately bearing stock market risk, the sales volume of HF traders is not particularly relevant. The non-HF part of sales volume of course also includes the sales volume of mutual funds, hedge funds, and other non-HF institutional investors. We are therefore likely capturing a substantial part of individual investors' sales volume.

Figure 3 examines the number of transactors and the sales volume per transactor. Panel A plots the total sales volume and the number of individual investors selling stocks (the number of transactors) from our Form 1099-B data. The number of transactors on a given day ranges from

\footnotetext{
${ }^{14} \mathrm{~A}$ one standard deviation increase in the lagged difference of log VIX is associated with a 0.08 percentage point decrease in the total coverage rate. See column 3 of Appendix Table A.2.

${ }^{15}$ See MacKenzie (2009), which references estimates by the Tabb Group, a consulting firm.
} 
294,000 to 773,000 . The two series, total sales volume and number of transactors, exhibit a strong correlation (0.69) during our sample period. Panel B displays the average daily sales volume per transactor, which ranges from $\$ 16,000$ to $\$ 46,000$ dollars. The increase in sales volume after an increase in VIX appears to be driven mostly by an increase in sales volume per transactor, rather than by an increase in the number of transactors. ${ }^{16}$

\section{A Model of Who Sells}

We hypothesize that there is heterogeneity in the willingness of different groups of investors to hold on to stocks during times of turmoil. To investigate this hypothesis, we begin by developing an analytical framework, which we draw on to guide our empirical analysis and to address two important questions. First, to what extent can we use data on stock and mutual fund gross sales to infer the unobserved net trades (sales minus purchases)? Second, how does market clearing — that is, the fact that the average investor can neither buy nor sell on net—affect our analysis?

Conceptually, we split investors' trades into two categories with different trading motivation: (i) "reallocation" trades that aim to change the overall wealth allocation to stocks, and (ii) "selection" trades that aim to change the composition of the stock portfolio, but not the overall wealth allocation to stocks. If we could observe net trades, we would not have to worry about the selection trades, because they cancel when netting purchases and sales.

Consider individual $i$ in investor group $g$. We assume that the dollar amounts of shares bought or sold by this individual on trading day $t$ for reallocation and selection reasons can be

\footnotetext{
${ }^{16}$ Column (5) of appendix Table A.2 shows that a one standard deviation increase in log VIX (of 0.068) corresponds to a 1.5 percent increase in the average volume per transactor, significant at the one-percent level. In column (4) the same increase in $\log$ VIX leads to a 0.9 percent increase in the number of transactors, although this is statistically indistinguishable from zero. Appendix Table A.3 provides the correlations of 1-day lagged log VIX differences, going back ten days; there is a significant negative correlation, of between -0.173 and -0.179 , of the one-day-apart differences and, somewhat surprisingly, of from -0.106 to -0.108 of five-day-apart differences.
} 
represented by four independent Poisson random variables with the following time-varying intensities:

Reallocation Selection

$\begin{array}{lcc}\text { Sales }\left(S_{i t}\right) & \sigma_{\lambda} \lambda_{t} W_{i} & \sigma_{\eta} \eta_{t} W_{i} \\ \text { Purchases }\left(B_{i t}\right) & \sigma_{\lambda} \lambda_{t}^{-1} W_{i} & \sigma_{\eta} \eta_{t} W_{i}\end{array}$

where $\lambda_{t}$ and $\eta_{t}$ are positive random variables with unit time-series mean and variance; $\sigma_{\lambda}$ and $\sigma_{\eta}$ are constants. Conditional on the intensities, the four types of trades are independent. Over time, however, they can be correlated if $\lambda_{t}$ and $\eta_{t}$ have correlated time-variation. The same factors that drive sales also generally drive purchases, but the effects are in the same direction for selection trades (hence they offset when netting) and in the opposite direction for reallocation trades (hence they add when netting). All intensities are proportional to the investor's wealth $W_{i}$ to capture the fact that wealthier investors are likely to trade higher dollar amounts. We view $W_{i}$ as slowly moving relative to the time-variation in trading intensities, so that we can think of it as roughly constant for the purposes here. Wealth and the intensities can differ across investor groups, but to reduce clutter we do not use a $g$-subscript.

Aggregating across a large number of individuals within some group, with $S_{t} \equiv \sum_{i} S_{i t}$, $B_{t} \equiv \sum_{i} B_{i t}$, and $W \equiv \sum_{i} W_{i}$, and, in the case of purchases, applying a first-order Taylor approximation around the (unit) mean of $\lambda_{t}$ yields ${ }^{17}$

$$
\begin{aligned}
& S_{t} / W \approx \sigma_{\lambda} \lambda_{t}+\sigma_{\eta} \eta_{t}, \\
& B_{t} / W \approx 2 \sigma_{\lambda}-\sigma_{\lambda} \lambda_{t}+\sigma_{\eta} \eta_{t} .
\end{aligned}
$$

We can express net sales, $T_{t}=S_{t}-B_{t}$, as

\footnotetext{
${ }^{17}$ We use the fact that the sum of Poisson random variables is also Poisson with intensity equal to the sum of the intensities. Further, for a large intensity $\psi$, the Poisson distribution is approximated very well with a lognormal distribution with parameters $\mu=\log \psi$ and $\sigma=1 / \psi$. In our case, by summing across a very large number of individuals the intensity is so big that the variance is negligibly small relative to the mean. Stochastic variation in trading volume therefore originates only from stochastic variation in the intensities.
} 


$$
T_{t} / W \approx 2 \sigma_{\lambda}\left(\lambda_{t}-1\right)
$$

Thus, sensibly, a higher $\lambda_{t}$ implies higher net sales, while $\eta_{t}$ has no impact on net sales. Taking expectations,

$$
\begin{aligned}
& \mathrm{E}\left[S_{t} / W\right]=\mathrm{E}\left[B_{t} / W\right]=\sigma_{\lambda}+\sigma_{\eta}, \\
& \mathrm{E}\left[T_{t} / W\right]=0 .
\end{aligned}
$$

The sum $\sigma_{\lambda}+\sigma_{\eta}$ therefore represents average trading volume measured as a percentage of wealth.

We specify intensities as follows. The intensity of reallocation trades on day $t$ depends on two factors: First, it depends on changes in the investor's risk aversion, pessimism, or "panic" since the previous day, which we summarize in $\Delta x_{t}$. Second, it depends on $\Delta p_{t}$, the log change in the value of the stock market index. More precisely,

$$
\lambda_{t}=\exp \left(b \Delta x_{t}+d \Delta p_{t}\right) \approx 1+b \Delta x_{t}+d \Delta p_{t}
$$

where $\mathrm{E}\left[\Delta x_{t}\right]=0$ and $\mathrm{E}\left[\Delta p_{t}\right]=0$ and the second (approximate) equality follows from a first-order Taylor approximation around these expected values. The inclusion of the $\Delta p_{t}$ term allows the model to account for that part of an individual's desired change in the allocation to stocks due to price changes rather than trading that changes the quantities of assets held. In eq. (6), the $b \Delta x_{t}$ term reflects the trades the individual would want to undertake if prices remained unchanged and the $d \Delta p_{t}$ term reflects the offset due to price changes. We use $\Delta p_{t}$ here to capture two effects associated with price changes that work in the same direction: A decline in stock prices reduces the investor's share of wealth allocated to stocks and it may be associated with a rise in expected returns. Both imply a reduced inclination to sell.

For the market to clear in aggregate, $T_{t}$ must sum to zero in the investor population. Our empirical study focuses on individual investors, and for this sub-group, $T_{t}$ can be non-zero. For the investor population as a whole, however, the market-clearing condition combined with (3) 
and (6) requires that $\Delta p_{t}=-(B / d) \Delta x_{t}$, where $B$ is the $\sigma_{\lambda} W$-weighted average of $b$ in the investor population.

Because we do not observe $T_{i t}$ in the tax-return data, we work with data on gross sales. Taking logs of (1), applying a first-order approximation around the means of $\lambda_{t}$ and $\eta_{t}$, combining with (6), and using our result $\Delta p_{t}=-(B / d) \Delta x_{t}$, we obtain

$$
\log \left(S_{t}\right) \approx \mu+\sigma_{\lambda}\left(\sigma_{\lambda}+\sigma_{\eta}\right)^{-1}(b-B) \Delta x_{t}+\sigma_{\eta}\left(\sigma_{\lambda}+\sigma_{\eta}\right)^{-1}\left(\eta_{t}-1\right),
$$

where $\mu=\log (\mathrm{W})+\log \left(\sigma_{\lambda}+\sigma_{\eta}\right)$.

This model clarifies a few important points. First, as eq. (7) shows, an individual investor sells if his or her inclination to reduce stock holdings in response to tumult is stronger than for the average investor, i.e., $b>B$. In contrast, for the average investor, adjustment can only take place through changes in prices and equilibrium expected returns rather than adjustment of quantities. As a consequence, we cannot identify the level of $b$, but rather only cross-sectional differences $b-B$. In other words, we can identify the extent to which a subset of the investor population reacted more strongly or more weakly than did the average investor. For example, if we look at the taxpayers in our sample as a whole, we can identify the extent to which they reacted differently from the average investor in the entire investor population.

Second, going from a dependent variable expressed as fraction of wealth as in (1) to a dependent variable expressed in logs, the coefficients get scaled by $\left(\sigma_{\lambda}+\sigma_{\eta}\right)^{-1}$, i.e., by the reciprocal of expected trading volume (in terms of fraction of wealth traded). Thus, multiplying the effect of $\Delta x_{t}$ on $\log \left(S_{t}\right)$ with an estimate of average trading volume yields an estimate, to a first-order approximation, of the effect on $S_{t} / W$.

Third, since we do not observe whether a sale of a stock is a selection trade or a reallocation trade, we have to leave $\eta_{t}$ as unobserved in the residual. To the extent that $\Delta x_{t}$ and $\eta_{t}$ 
are positively correlated (e.g., during times of tumult investors' reduce their stock holdings overall, but they also re-shuffle the composition of their stock portfolio more than they do in times of calm markets), this will make the coefficient in a regression of $\log S_{t}$ on $\Delta x_{t}$ an upward biased estimate of the effect on net sales. Ideally, we would like to estimate the (infeasible) regression of $T_{t} / W$ on $\Delta x_{t}$. In Section 5 , we use the brokerage account data of Barber and Odean (2000) to estimate the effect of using gross sales rather than net sales. We find that gross sales and net sales are strongly positively correlated and the coefficient in regressions of $S_{t} / W$ on $\Delta x_{t}$ is about three times higher than the coefficient in a regression of $T_{t} / W$ on $\Delta x_{t}$. Thus, our estimates based on gross sales from tax return data should be adjusted downward by a factor of three if one wants to estimate the likely effect on net sales. Section 5 also presents an analysis of dividend receipts, which provides additional indirect evidence of a link between gross sales and net sales.

In our baseline specification, we proxy for changes in investors' desire to sell stock, $\Delta x_{t}$, with $\Delta V_{t-1}$, the change in the log of the VIX index from day $t-2$ to $t-1$. Let $\Delta x_{t}=\Delta V_{t-1}+u_{t}$, where $u_{t}$ represents other unobserved components of $\Delta x_{t}$ that are orthogonal to $\Delta V_{t-1}$. Projecting $\log$ gross sales from (7) on $\Delta V_{t-1}$, we get

$$
\log \left(S_{g t}\right)=\beta_{g} \Delta V_{t-1}+\alpha_{g}+\delta_{t}+\varepsilon_{g t}
$$

where $\varepsilon_{\mathrm{gt}}$ is a composite residual that contains a $u_{t}$-related component as well as the part of the $\eta_{t^{-}}$ related term in (7) that is orthogonal to $\Delta V_{t-1}$; we add $g$-subscripts to emphasize that we are looking at a sub-group of investors.

We estimate (8) with ordinary least squares. The key parameter of interest is $\beta_{g}$, which measures how gross sales of group $g$ respond to the lagged change in log VIX. As discussed above, estimates of $\beta_{g}$ likely reflect the response of reallocation as well as selection trades. We include group fixed effects, $\alpha_{g}$, to absorb time-invariant differences in $\mu$ across groups, and we 
include date fixed effects, $\delta_{t}$, to absorb sales determinants that affect all groups. Because we include date fixed effects, we normalize $\beta_{g}$ to equal zero for one group of taxpayers in each regression. Throughout, we use Newey-West standard errors that allow for autocorrelation in the residual $\varepsilon_{g t}$ up to a maximum of 10 days.

\section{Evidence on Investor Selling Behavior}

This section presents the main results on investor heterogeneity in the propensity to sell stock during periods of high market volatility. We present graphical evidence on the shares of sales-as a fraction of total sales volume reported on Form 1099-B-attributable to particular groups of taxpayers. We also examine these phenomena in a regression context, estimating regressions based on equation (8).

We begin by establishing basic facts about the relationship between aggregate sales behavior and volatility. As discussed in Section 3, because net sales must add up to zero for all investors in aggregate, the higher the aggregation level that we use, the less likely it is that the observed stock sales reflect net sales (that reduce investors' stock holdings) rather than selection trades (that change the composition of investors' stock portfolios). However, individual taxpayers do not constitute the entire investor population. For example, endowments, pension funds, or mutual funds that have flexibility to alter their stock market exposure could take the other side of individual taxpayer stock sales.

Table 2 presents the results of regressing the log of the amount of stocks sold on changes in lagged log VIX, both for 2008 and 2009 and separately for September through November of 2008. In columns 1 and 3, we examine only the one-day lag, while in columns 2 and 4 we report the sum of the estimated coefficients on the first ten lags of log VIX. Over the 2008-2009 period, a ten-percent increase in the VIX (i.e., an increase in log VIX of 0.0953) is associated with 3.3 
percent more selling the next day, and 47.3 percent more over the next ten trading days. Focusing on the three months from September to November 2008 during which the financial turmoil peaked, the one-day effect is very similar, and the ten-day is almost one and a half times as large. As columns 2 and 4 show, the ten lags of log VIX also explain a substantial portion of the time-variation in log sales volume, especially during the height of the financial crisis: In the September to November 2008 time window, the R-squared is $54 \%$.

This initial analysis shows that market tumult, as measured by the VIX index, induces individual taxpayers to engage in a substantial amount of stock sales during the following days. To understand the reasons for these stock sales, we now look at the data in a more disaggregated way and study heterogeneity in selling behavior.

\subsection{Heterogeneity by Quantiles of Pre-Crisis Average Adjusted Gross Income}

We first examine how the propensity to sell assets during the crisis relates to traders' income. We focus on average adjusted gross income (AGI) over the eight years prior to the period we study, from 2000 to 2007 . We do not use income from 2008 onwards because it can be influenced by sales of stock in the period we are studying. ${ }^{18}$ We divide the population of individual tax return filers into five groups to study heterogeneity by pre-2008 average AGI. We select groups such that each group accounts for a roughly similar share of total sales volume in the 1099-B data. The precise quantiles used to generate the groups should not substantially affect the results. More broadly, though, this approach implies that we are focusing much more on differences in trading behavior between individuals in the top percentiles of AGI than on differences between individuals in the "middle class" part of the AGI distribution. For example,

\footnotetext{
${ }^{18}$ In cases where taxpayers did not file a tax return in a given year (if, for example, the taxpayer has very low income)-we use income only in the years it is available. We use AGI rather than taxable income because the latter subtracts below-the-line deductions that are arguably better thought of as consumption expenditures (i.e., itemized deductions such as charitable contributions and home mortgage interest payments, personal and dependency exemptions, etc.). AGI does subtract "above-the-line" deductions such as alimony payments.
} 
our bottom group contains individuals all the way up to the $75^{\text {th }}$ percentile of AGI and this group's sales volume is most strongly influenced by its relatively wealthier members close to the $75^{\text {th }}$ percentile cutoff than by those lower down the AGI ranks who tend to hold smaller portfolios. Since our focus is on understanding the contribution of various demographic groups to aggregate sales volume, this tilt towards higher-income taxpayers is appropriate.

Figure 4 presents the main results for heterogeneity by income in stock sales during the sample period. Panel A depicts the daily share of total 1099-B sales volume attributable to each group, for 2008 and 2009. Panel B normalizes the shares from Panel A by their average value from 2008 to 2009 in order to facilitate visual interpretation of how the shares change over time. For the most part, the shares are stable until September of 2008. Starting in September, though, the share of sales volume attributed to the top 0.1 percent of income recipients rises sharply until the beginning of 2009 , at which time the top-income share drops continuously through midMarch, when it levels out. As must be true mechanically, the behavior of the other shares on average mirrors these patterns, with the most striking behavior among the lowest of the income groups, those below the $75^{\text {th }}$ percentile. Plainly, sales by the top 0.1 and top $0.1-1$ percent responded more strongly to the events of the financial crisis than sales by other groups. We also observe an increase in the top 0.1 percent share during the very last days of 2008 , which we attribute to a greater propensity of these individuals to "harvest" capital losses to offset realized capital gains. These observations are consistent with our proposed explanation for the structural change occurring at the beginning of 2009: having sold large amounts of stock during the crisis and the loss-harvesting period at the end of 2008, very-high-income traders had sold a significant amount of their stock in individual taxable accounts by 2009. As a result, their share of sales 
volume fell, and did not recover until the last quarter of 2009, when the time series in Panel B of Figure 4 converge back to their pre-crisis (normalized) values.

Regression analysis tells a similar story. Table 3 presents the results of regression analyses of the association between sales volumes of these income groups with measures of volatility using the methodology described above, for several alternative measures of volatility. Specifically, we report the estimated $\beta_{g}$ coefficients from eq. (8), where $g$ denotes an AGI group. The left-out group in these regressions is sales by individuals in the bottom 75 percent of the income distribution, so these coefficients are estimates of the degree to which traders in a given AGI group tend to sell more than the bottom 75 percent in periods of higher tumult. As suggested by Figure 4, these coefficients are largest in magnitude, positive, and strongly statistically significant for the top 0.1 percent group. The share of stock sales by the top income group move up when the lagged change in VIX rises, relative to the lowest income group. The results are qualitatively similar when examining all of the trading days in 2008 and 2009 (columns 1 and 2) or focusing on just September through November of 2008 (columns 3 and 4): the estimated coefficients are positive and significant, although smaller in magnitude. They are even smaller and difficult to distinguish statistically from zero for the other two groups. Table A.4 shows that the results are quantitatively similar when we use the change in log VIX or the change in VIX as our measure of volatility, and Table A.5 shows the results are similar if we use the negative market return as a measure of market tumult.

Heterogeneous responsiveness to volatility by income persists well beyond the first day after an increase in volatility. Columns 2 and 4 of Table 3 show the sum of the estimated coefficients on the first ten lagged differences of VIX. Indeed, the 10-day effect is approximately ten times larger than the one-day-after effect, suggesting no let-up in the effect over the first two weeks. 
Appendix Table A.6 provides more detail on the lag structure, showing the differential effect on the top 0.1 percent income group gradually weakening in magnitude after ten trading days, but remaining statistically significant for more than twenty days; a similar pattern appears for the next two highest income groups.

To get a sense of the magnitude of the effects documented in Table 3, consider the following exercise. The estimate for the top 0.1 percent in column 1 suggests that a $10 \log$ point (or 10.5 percent) increase in the VIX on date $t$ is associated with a 3.3 percent increase in sales volume for the top 0.1 percent of earners relative to the bottom 75 percent. ${ }^{19}$ The 25 percent increase in the VIX on the day of the Lehman Brothers collapse is therefore associated with a change in sales volume of the top 0.1 percent of 7.9 percent more than the change for the bottom 75 percent. When we account for the typical dollar amounts of sales volume in the top 0.1 percent, this effect corresponds roughly to $\$ 142$ million $(0.079 * \$ 1.8$ billion) more stock sales by this group on September 15, 2008 alone. Proceeding similarly, the results from the ten-day specification in column 2 of Table 3 suggest that the Lehman collapse led roughly to $\$ 1.7$ billion more gross stock sales by the top 0.1 percent than the bottom 75 percent over the ten days following collapse. Next, we scale these numbers by a factor of three to convert gross sales to net sales (see Section 5). We finally obtain that the elevated sensitivity of the top 0.1 percent relative to the bottom 75 percent corresponds to net sales by the top 0.1 percent of $\$ 47$ million one day after the Lehman collapse and $\$ 567$ million over the ten-day period following the collapse.

\subsection{Heterogeneity by Age and Retirement Status}

In this section, we report results for heterogeneity by characteristics related to aging and retirement. First, we consider age. Figure 5 depicts shares of sales in a fashion similar to Figure

\footnotetext{
${ }^{19}$ Appendix Table A.1 provides the summary statistics used in this calculation.
} 
4, dividing taxpayers into age groups rather than income groups. We define age as of December 31, 2008 for all individuals in the 1099-B sales data, based on records from the Social Security Administration. Panel A depicts shares of sales for selected age groups. Panel B normalizes these shares for ease of visual comparison. We observe that older individuals, especially those over the age of 60 , were substantially more prone to sell during the crisis. In the regression analysis by age, tabulated in Table 4, we observe that individuals over the age of 60 are more likely to sell following increases in the VIX, both over the full two-year period (columns 1 and 2) and September to November 2008 (columns 3 and 4). The coefficients for the 60+ age group in columns 1 through 4 of Table 4 are statistically significant, and roughly comparable in magnitude to the coefficients for the top 0.1 percent AGI group in Table 3, although the persistence over a ten-day period is less marked for the age 60+ group than it is for the top 0.1 percent income group.

Figure 6 examines whether retirees are more prone to selling in times of tumult than nonretirees, where we proxy for retirement status by whether any Social Security income is reported on individuals' tax returns. It plots the share of sales by individuals with retirement income, relative to total sales reported on Form 1099-B — note that because there are only two groups in this analysis, one share completely characterizes the heterogeneity. Regression results in Table 5 indicate that households with retirement income were significantly more likely to sell assets during the crisis in late 2008 and 2009 than were households without retirement income.

\subsection{Heterogeneity by Selected Other Household Characteristics}

Figure 7 reports shares of asset sales by percentiles of the dividend income distribution. We use the same percentile categories $(0-75,75-95$, etc.) we used for the AGI distribution, but we do not split individuals in the top 0.1 percent of the distribution out from everyone else to 
facilitate the visual comparisons. Panel A depicts the shares themselves; the shares are roughly comparable although, because dividend income is more unequally distributed than AGI, the share of sales is shifted towards the top of the dividend income distribution relative to AGI. Panel B depicts normalized shares, revealing a higher tendency to sell during the crisis among individuals in the top 1 percent of the dividend income distribution, and to a lesser degree the top 5 percent. Table 6 reports the coefficients for the regression version of this analysis. The VIX interaction coefficients on the top 1 percent and the top 1-5 percent are statistically significant and quite large, and indeed are larger than the estimated coefficients on top AGI percentiles in Table 3.

Figure 8 and Table 7 report results using as a measure of financial sophistication whether an individual had positive partnership or S-corporation income prior to 2008 (whether they have positive income reported on Line 32 of Schedule E). We observe that the share of sales by these individuals increases significantly during the crisis, and that it is significantly more responsive to changes in VIX. However, the relationship between market tumult and sales by sophisticated individuals is weaker than many others studied here, and not significantly different from sales by others during the narrower period of September-November 2008.

\subsection{Heterogeneity Non-findings}

We also investigated whether the relationship of volatility varied by other aspects of investors: gender, marital status, region, state, presence and amount of a mortgage interest deduction, and 2007 zip-code level house price growth. No noteworthy effects were detected. Appendix Tables A.7 through A.13 provide the details of these exercises.

\subsection{Multi-Dimensional Heterogeneity: Income and Age}


A natural question is whether the strong association of volatility sensitivity to income is at least partly reflecting other investor characteristics that are correlated with income. To examine this, we define group-day volume by income and one of several other characteristics, and estimate the coefficient on the interaction between our measure of lagged change in VIX and an indicator for the income-by-other characteristic group. We also include income-by-other characteristic fixed effects and date fixed effects.

The results suggest that our two most striking findings, those involving income and age, are statistically distinct from one another. Table 8 presents results for average AGI and age. Panel A examines trades from 2008-2009, and Panels B presents results for September to November 2008 only. The coefficients from Panel A are plotted graphically in Figure 9. In general, we find that the responsiveness to tumult increases in AGI for each age group, and increases in age for each AGI group.

\section{Evidence that Gross Sales are Informative about Net Sales}

So far we have interpreted the evidence from gross sales volume in taxable accounts as indicative of a likely similar (although quantitatively perhaps accentuated) behavior of net sales across all accounts. This section presents evidence in support of this assumption using three supplemental data sets. To examine whether gross sales track net sales, we use detailed daily trading data from discount brokerage accounts, and we examine the evolution of dividend income in tax-return data. To examine whether sales in taxable accounts track total sales of equities, we use detailed wealth data in the Survey of Consumer Finance.

\subsection{Gross and Net Sales in Discount Brokerage Data}


We begin by analyzing the Barber and Odean (2000) data set of daily trades in a discount brokerage account from 1991 to $1996 .{ }^{20}$ In the brokerage account data, we can observe both gross sales and net sales (i.e., gross sales minus purchases). We eliminate option trades and trades in fixed-income mutual fund shares. The resulting sample largely comprises trades in domestic common stock and equity mutual fund shares, but it also includes small amounts of trades in such assets as ADRs, Canadian stocks, REITs, and preferred shares. This sample contains roughly 1,000 individual trades per day.

For each trading day, we calculate two aggregate sales numbers for the whole brokerage account sample. The first is the amount of net sales, $T_{g t}$, which is simply the aggregate dollar amount (positive for sales, negative for purchases) added across all brokerage customers each day. The second is the amount of gross sales, $S_{g t}$, which includes only the dollar amount of sales across all brokerage customers. The latter gross sales number corresponds to the sales numbers that we get from the tax-return data. We further observe the aggregate value of brokerage customers' portfolios at the beginning of each month (including all assets, not just stocks and stock mutual funds), and we express $T_{g t}$ as a percentage of this aggregate portfolio value. ${ }^{21}$

We first replicate our baseline regressions with the brokerage account data. Column 1 in Table 9 shows the results from a regression of log gross sales volume in taxable accounts-the equivalent to 1099-B sales volume in the tax-return data—on the change in the log VIX index. In addition to the lagged one-day change in the log VIX index, we also include the contemporaneous change. In the tax-return data, the contemporaneous change in log VIX is not significantly related to sales volume but, as Table 9 shows, brokerage account customer sales are

\footnotetext{
${ }^{20}$ We thank Terry Odean for allowing us to access these data.

${ }^{21}$ We take the absolute value of each position in the calculation of the portfolio value; that is, short positions enter with a positive value. We do this because we want to scale trading activity variables with the gross size of an investor's portfolio rather than the net equity of the portfolio.
} 
strongly related to both the contemporaneous and lagged change in log VIX. The magnitude of the combined effect is about 4-to-5 times as big as the effect in the tax return data. Both of these findings are sensible: discount-brokerage customers are more likely to react to same-day news and trade more actively than the average taxpayer is. For our purposes, the relevant take-away is that the tax return data and the brokerage account data tell the same story about the direction and the order of magnitude of the relationship between changes in log VIX and gross sales volume.

Column 2 presents the most important piece of evidence from the brokerage account data. Here we use net sales (which we do not observe in the tax-return data) as the dependent variable and gross sales (which we do observe in the tax-return data) as the explanatory variable, both expressed as a percentage of the portfolio value. The results show that there is a very strong relationship between these two variables. A gross sale of one percent of the portfolio value is associated with a net sale of 0.34 percent. The adjusted $\mathrm{R}^{2}$ of approximately 27 percent also indicates that there is a strong relationship between gross sales and net sales.

Columns 3 and 4 compare regressions on log VIX changes with gross sales and net sales as dependent variables, both expressed as a percentage of portfolio value. As we discussed in Section 3, a comparison of the estimates from these two regressions can help us estimate to what extent a rise of gross sales in times of market tumult also implies a rise in net sales. We find that the coefficient estimates with gross sales are about two to three times as big as with net sales. This finding is the basis for our suggestion in Section 4 that one can get a rough estimate of the effect on net sales by dividing the coefficient in the gross sales regression by three. More broadly, the estimates in columns 2 to 4 suggest that the gross sales from the tax return data are informative about the unobserved net sales. 
Unlike the tax-return data, the brokerage account data also contains trades in non-taxable (IRA and Keogh) accounts. This allows us to check whether in tumultuous times the behavior of investors in non-taxable accounts is fundamentally different. We find that they are not. The results reported in column 5 are quite similar to the results for taxable accounts in column 1 . Thus, it seems that the results from our analysis of taxable trades in tax-return data could also carry over to some extent to non-taxable accounts.

Finally, column 6 looks at the taxable accounts restricted to customers with large portfolios, defined as those above the $80^{\text {th }}$ portfolio value percentile. This is an imperfect way to approximate the high-AGI sample in the tax-return data. Based on the point estimates, the relationship with the VIX index changes is slightly stronger than in column 1, but the difference is not statistically significant and the magnitude of the difference is much smaller than in our AGI-based sample splits in the tax return data. Part of the reason could be that the value of the brokerage-house portfolio is not as good a measure of wealth and income as is AGI in the taxreturn data. Moreover, the brokerage customers are a rather special selected sample that likely differs from the average taxpayer on a number of dimensions. We also repeated the regressions in column 3 and 4 with the large-portfolio sample (untabulated). We find that the estimated coefficients on log VIX changes are slightly higher than those reported in columns 3 and 4 .

\subsection{Changes in Dividend Income}

Next we present evidence that annual gross sales by a given individual are associated with decreases in dividend income reported on that individual's tax return (Form 1040 Schedule B). Intuitively, one can think of qualified ${ }^{22}$ dividend income as a rough proxy for the amount of

\footnotetext{
22 A qualified dividend is one that is taxed at the preferential lower tax rate. Regular dividends paid out to shareholders of for-profit U.S. companies are usually qualified. There are minimum holding periods around exdividend days, and dividends paid out by, for example, real estate investment trusts and master limited partnerships do not qualify.
} 
stocks held in an individual's portfolio. If gross sales are associated with net sales, then an individual's portfolio should contain less stock after a year of high gross sales, and thus the individual's dividend income should decrease.

We run simple regressions of the change in dividend income from year $t-1$ to year $t+1$ on gross sales in year $t$, where $t$ is either 2008 or $2009 .{ }^{23}$ We restrict the sample to individuals receiving dividends in year $t$-1, and we winsorize gross sales and dividend income changes at the 1 and 99 percent levels to eliminate the effect on the results of some obvious data errors. ${ }^{24}$

Table 10 reports the results of this analysis. In columns (1) and (2), we document a statistically significant relationship between gross sales and decreases in dividend income. To assess whether the coefficient we estimate is reasonable and consistent with the analysis of the discount brokerage data in Table 9 , consider $\$ 1$ of gross sales on some day. The earlier analysis suggested that $\$ 1$ of gross sales corresponds on average to $\$ 0.33$ of net sales on the same day. Suppose that the $\$ 0.33$ reallocated from stocks on that day is not reallocated back to stocks within one year. Then the decrease in dividend income will be roughly $\$ 0.33$ times the dividend yield in the individual's portfolio. For the average individual, we expect the dividend yield to be somewhere near the S\&P 500 dividend yield of 2 percent. In this case the drop in gross sales would be about $\$ 0.33 * 0.02=\$ 0.0066$. This number is nearly identical to our estimated coefficients, which are 0.0065 and 0.0068 .

A number of assumptions are implicit in the above reasoning. Our interpretation requires that changes in dividend yields from $t-1$ to $t+1$ should be reasonably unrelated to gross sales, and to the share of gross sales that pass through to net sales. For example, the first condition fails if

${ }^{23}$ We have also estimated regression specifications with transformed versions of the same dependent and independent variables, including logarithmic specifications and those in which all variables are scaled by adjusted gross income. In all instances, the qualitative results are the same. We prefer the specifications reported here because their interpretation is relatively straightforward.

${ }^{24}$ The results are nearly identical if we also exclude individuals with zero gross sales in the given year. 
individuals disproportionately sell dividend-paying stocks, and the second fails if individuals' selection trades transfer assets away from high-dividend-paying stocks and towards low-dividend paying stocks. While this analysis is an imperfect test of the relationship between gross and net sales for the reasons described above, we believe the most plausible explanation for the strong negative association between gross sales in year $t$ and changes in dividend income from $t-1$ to $t+1$ is that gross sales are associated with net sales, especially given that the magnitude of the coefficients so closely aligns with this interpretation.

We also use changes in dividend income to test an implicit assumption above, that the relationship between gross sales to net sales is invariant across groups. Specifically, if this implicit assumption is satisfied, the relationship between dividend income changes and gross sales should be roughly constant across groups. Columns (3) and (4) of Table 10 report the results of this test for AGI groups: we interact the specification in columns (1) and (2) with the AGI groups used in Section 4. The negative coefficients on the interaction between gross sales and high-AGI group membership suggests that individuals in the higher-AGI groups have a higher rate of pass-through from gross to net sales than people in the bottom 75 percent of the income distribution. While there may be heterogeneity in pass-through rates, heterogeneity of the kind suggested by these results would actually strengthen our interpretation of the results in Section 4 that high-income groups disproportionately sold out of the stock market during the financial crisis. The interpretation of the regressions in columns (3) and (4) in terms of passthrough rates from gross to net sales is subject to similar caveats about dividend yields described in the previous paragraph.

\subsection{Taxable and Non-Taxable Accounts}


We next provide suggestive evidence that our inability to observe activity in non-taxable accounts does not confound the qualitative results described in Section 4, using data from the 2007-2009 panel of the Survey of Consumer Finances. This data set contains detailed information on wealth for 3,857 households interviewed in late 2007 and late 2009, and the survey deliberately oversamples high-wealth individuals (see Bricker et al, (2011) for an overview). Importantly, the data allow us to examine separately wealth in taxable accounts, which includes directly held stock, mutual funds, and hedge funds, and wealth in non-taxable accounts, where the latter includes tax deferred retirement accounts, trusts, other managed assets, and annuities. ${ }^{25}$ Using this data, we construct measures of 1) equities held in taxable accounts, 2) equities in all accounts, 3) net sales or purchases of equities in taxable accounts, and 4) net sales or purchases of equities in all accounts. ${ }^{26}$

How might our inability to observe non-taxable accounts influence our results? The percent change in an individual or group's overall equity holdings sold in response to an uptick in volatility (our principal parameter of interest) depends on (1) the percent change in their taxable equities, (2) the share of overall equities held in taxable accounts, and (3) the relative intensity of their stock trading in taxable accounts. Our main results suggest that (1) is higher for highincome groups. A comparison of (1) alone, however, could be misleading if higher-income individuals hold a smaller share of wealth in taxable accounts and/or they execute more of their equity sales in their taxable accounts.

Figure 10 plots the share of wealth held in taxable accounts by income group (Panel A) and age group (Panel B). We use similar group definitions as elsewhere in the paper, but because of data limitations we use income in 2007 rather than average AGI from 2000-2007 and, due to

\footnotetext{
${ }^{25}$ The data do not include wealth held by foundations controlled by an individual.

${ }^{26}$ To be comparable with the IRS data, we consider a transaction in the SCF to be taxable if it would lead to a reported sale on a 1099-B linked to an individual taxpayer.
} 
power concerns, we group the top 0.1 percent of the income distribution with the rest of the top 1 percent. Examining these graphs rules out the first potential pitfall, that higher income individuals hold a smaller share of wealth in their taxable accounts. Indeed, the opposite is true: high-income people hold a higher share of their wealth in taxable accounts, perhaps due to the limits on contributions to tax-deferred retirement accounts. The same is true of older individuals, as shown Panel B of Figure 10. These facts on their own suggest that the heterogeneity in responses to volatility is higher than what we document.

Although our results are clearly not driven by differences in the share of wealth held in taxable accounts, it could still be the case that higher-income individuals conduct much more of their volatility-driven net sales in taxable accounts, while lower-income individuals mix their activity between taxable and non-taxable accounts. This could cause our results to be misleading, as the overall sales of lower-income individuals would be higher than what we measure, and maybe not that different from the high-income individuals.

To address this second problem, we regress across the individuals in the SCF the change in total stock holdings between 2007 and 2009 on the change in stock holdings in taxable accounts, with and without an interaction with income group indicators. When calculating these changes, we adjust the stock holdings in 2009 for the change in the Wilshire 5000 Total Market Stock Index between the survey dates in 2007 and 2009. The remaining change in stock holdings equals approximately the amount of stocks bought or sold. This exercise is similar in spirit to the regression comparing gross and net sales in Table 9 (column 2), but we here compare net taxable sales and total net sales. If individuals conduct all their trading in taxable accounts and no trading in non-taxable accounts, or if trading in non-taxable accounts is uncorrelated with trading in taxable accounts, the slope coefficient in such a regression would be around one: a dollar in net 
taxable sales is associated with a dollar in total sales. If selling in taxable and non-taxable accounts is positively correlated, this coefficient would be larger than one. Another possibility is that individuals tend to sell in taxable accounts when they buy in non-taxable accounts, in which case the coefficient would be less than one. The main caveat to this approach is that not all variation in net sales in these data is a response to market tumult, although to be sure a large amount of activity between 2007 and 2009 was driven by the tumult of the financial crisis.

Table 11 reports the results of the regression. The slope coefficient is 0.92 ; this estimate is statistically different from zero $(p<0.001)$ but not from one $(p \approx 0.37)$. When we include interactions for income groups in column 2, we find that the group interaction terms are all statistically insignificant, and the point estimates are relatively small relative to the overall effect. ${ }^{27}$ Thus, we find no evidence that the relative trading activity in taxable versus non-taxable accounts confounds our main results. These results also rule out that gross sales in taxable accounts over this period were primarily due to shifting assets from taxable to non-taxable accounts (in which case the estimated coefficient would be zero). To be sure, this exercise is suggestive rather than dispositive, as due to data limitations it does not directly analyze the response of equity holdings in various accounts to volatility, but rather the overall variation in equity holdings.

\section{Which Stocks Were Sold?}

Thus far, we have focused on heterogeneity in individual investors in the propensity to sell corporate stock during times of crisis. In this section, we add another dimension to the analysis: the propensity of investors to sell off different assets during times of crisis.

${ }^{27}$ If we include interactions for age groups, the point estimates for interactions are also small and statistically insignificant. 
To perform this analysis, we group sales from the Form 1099-B microdata based on the reported CUSIP number of the asset sold, and the date of sale. We restrict ourselves, as before, to sales by individuals, using the TIN on the 1099-B and on individual tax returns. The result is a CUSIP-day panel dataset. To preserve anonymity, we exclude CUSIP-days on which fewer than ten individuals sold a particular asset, which eliminates just under 0.1 percent of the total sales volume in the original dataset. We add to the dataset information on these assets from Wharton Research Data Services, including stock returns, Standard Industrial Classification (SIC) codes, CRSP sales volume, and the S\&P 500 VIX used throughout the paper. The methods we use to analyze this data are similar to the ones employed in Section 4, except that we examine heterogeneity by asset characteristics instead of by taxpayer characteristics.

As a check on the quality of the CUSIP-day panel dataset, we estimated a regression of logged individual sales volume from 1099-B data for a given CUSIP-day on logged CRSP volume for that CUSIP-day, including stock fixed effects. The estimated coefficient on logged CRSP volume was roughly 0.81 , suggesting that a ten percent increase in CRSP volume for a given CUSIP is associated on average with an 8.1 percent increase in taxable individual sales for that CUSIP.

\subsection{Sector}

We first focus on the sector of the companies whose stock was sold. We use the FamaFrench 12-industry (FF12) classification system, which classifies each stock into one of 12 sectors based on the Standard Industrial Classification (SIC) code (Fama and French, 1997). We aggregate sales in these 12 sectors and then depict the evolution over time of shares of total individual sales in various sectors, as we did in Figures 4 through 8 . Given the nature of the financial crisis, we are interested particularly in the sales of stock of firms in the financial sector. 
We thus disaggregate sales in the financial sector into finer groups at times, using the FamaFrench 48-industry classification system, in order to focus on more narrowly defined sectors in finance.

Figure 11 depicts the evolution of shares of sales within selected sectors. Panel A depicts the share of total individual sales in each of the FF12 sectors. The two largest sectors are finance, with 46 percent of total sales on average over the two-year period, and business equipment, with 20 percent. The share of sales in the finance sector increases markedly during March of 2008, during which Bear Stearns nearly failed and subsequently was bought out by JPMorgan Chase with the assistance of the Federal Reserve Bank of New York. The finance-sector share falls following the Bear Stearns acquisition, but increases shortly thereafter and remains elevated until the end of 2009. We observe a marked short-term increase in the finance share during the height of the crisis in September 2008.

The definition of the finance sector we use in Panel A is broad, grouping together firms in banking and trading as well as insurance. In Panels B and C, we report shares of sales volume using sector definitions that separate firms in banking and trading firms from those in insurance. ${ }^{28} \mathrm{We}$ also include manufacturing and consumer durables, two sectors that reflect firms in the so-called "Main Street" part of the economy, as opposed to the "Wall Street" firms in finance. The evolution of shares using these groupings is depicted in Panel B of Figure 11. The banking and trading subset of the finance sector is much larger than the insurance subset, but both exhibit elevated sales shares relative to non-finance stocks around key dates like the Bear Stearns acquisition and the Lehman Brothers collapse. The overall share of sales in banking and

\footnotetext{
${ }^{28}$ The FF12 Finance sector also includes a very small number of firms in the real estate sector, consisting of less than one percent of total sales in the FF12 Finance category. Note that prominent firms such as Merrill Lynch and Lehman Brothers are (were) classified as trading firms.
} 
trading remains elevated from the last quarter of 2008 to the end of 2009, likely due to the uncertainty created by the financial crisis.

In Panel $\mathrm{C}$ of Figure 11 we plot the shares from Panel $\mathrm{B}$, normalized according to the mean share from 2008-2009 in each sector. The large differences in scale between sectors means that some caution is warranted in interpreting this figure: our normalization will cause changes in shares that constitute a smaller share of overall sales to appear more volatile when we plot normalized shares. We observe, in addition to the response of the financial shares to the collapse or near-collapse of several large firms mentioned above, an elevated share of sales in consumer durables throughout the last three quarters of 2009 , elevation in the share of sales in insurance in fall of 2008, and another jump in the share of sales in insurance in late August through midSeptember of 2009. This pattern is also apparent if we just plot sales in these sectors on their own, but it is masked in the previous figures due to the relatively small shares of trading in these categories. We attribute the increase in the consumer durables share to the market's increasing concern that the financial crisis might have a very large effect on Main Street. The fall 2008 spike in sales of insurance companies' shares is likely related to the woes of AIG, which in its second quarter filing on August 6 updated its total losses to $\$ 26.2$ billion and aggregate collateral to $\$ 16.5$ billion, and on September 15 had its credit rating downgraded, forcing another $\$ 14.5$ billion in collateral. On September 16, the Federal Reserve authorized the New York Fed to lend AIG up to $\$ 85$ billion through a revolving credit facility in return for a 79.9 percent equity stake.

We next examine whether individual sales of stock in different sectors respond differently to overall market tumult using regressions similar to those in Section 4, but with an asset characteristic as the "group" variable in the regressions instead of a taxpayer characteristic. Table 12 reports the results of this analysis. We document little sectoral heterogeneity in the 
responsiveness of sales to tumult using just one lagged difference in log VIX, with the possible exception of sales in chemicals, energy, and utility. However, examining 10 days of lagged differences uncovers significant heterogeneity by sector, with business equipment, chemicals, consumer non-durables, energy, finance, and utilities all much more responsive to tumult than consumer durables (the left-out industry). Although sales in financial stocks clearly respond to specific events and are strongly related to tumult, we find no evidence that sales in finance respond significantly more strongly to changes in the overall VIX than sales in many other sectors.

\subsection{Mutual Funds versus Individual Shares}

Here, we compare the relationship of sales of stock with that of sales of assets in mutual funds. ${ }^{29}$ We are motivated in part by the finding of Chang, Solomon, and Westerfield (2016), who find that the disposition effect that could explain many of our results is stronger for individual stocks than delegated accounts like mutual funds, and by Dorn and Weber (2013), who find that German retail brokerage customers tended to pull out of mutual funds during the crisis. Barrot et al. (2016) report a similar finding with data from a French retail brokerage.

Overall, the results do suggest that individuals disproportionately sold off assets in mutual funds during the crisis. Figure 12 depicts the share of total individual sales (for any asset class subject to 1099-B reporting) in either individual stocks or mutual funds from 2008 to 2009. We observe that the share of sales of mutual fund assets increases substantially during the financial crisis, from roughly 30 percent of all sales to roughly 50 percent, and then falls gradually during the latter three quarters of 2009. Consistent with this observation, we report

\footnotetext{
${ }^{29}$ Note that mutual funds that are not stock funds are not included in our main analysis, but they are included here. Relatedly, the shares depicted visually here are shares of total individual taxpayer sales on Form 1099-B (as in the next-to-last line of Table 1), which includes sales of assets that are neither mutual funds nor stocks. Mutual funds and stocks are by far the largest asset types appearing on the Form 1099-B.
} 
regression estimates in Table 13 suggesting that direct sales of stocks are less sensitive to market tumult than sales of mutual fund assets. The difference is significant at the 5 percent significance level using just one day of lagged differences of logged VIX, but not statistically different from zero when we use 10 days of lagged differences. ${ }^{30}$

These results are consistent with findings from the literature suggesting that many investors were reluctant to sell stocks that were losing money due to the disposition effect or lost trust in financial intermediation and sold their assets in mutual funds. The results could also be related to the types of individuals who trade in individual stocks rather than mutual funds. Individuals trading in mutual funds as opposed to individual stocks are likely more risk-averse and thus more prone to reduce the risk in their portfolio during the crisis by moving their wealth from mutual funds to something safer. Mutual fund investors could also be less confident in their own ability to pick winning stocks, which could make them more likely to sell off in tumultuous times than investors who are confident enough to pick individual stocks.

\section{Conclusions}

In this paper we have investigated which types of individuals sell stocks, and which kind of stocks are sold, during periods of turmoil in stock markets. To do this we use administrative data from the Internal Revenue Service consisting of billions of third-party reports on all sales of stock in United States taxable individual accounts, to understand which individuals sold out during the tumultuous market events of 2008 and 2009. On many dimensions, this data set is vastly superior to the kinds of data that have been brought to bear heretofore on these questions.

We begin by developing a statistical model that frames to what extent we can use data from tax returns on gross sales (which may include trades that reshuffle the portfolio between

\footnotetext{
${ }^{30}$ Differences in the effect of tumult on sales volume between stocks and mutual funds fade much more quickly than in the by-taxpayer-group analysis, with the effect beyond two days of lagged differences being approximately zero. This explains why the 10-day effect here is more difficult to distinguish from zero statistically than the 1-day effect.
} 
different stocks) to infer unobserved net sales (sales minus purchases, i.e., the overall reduction in stock holdings). We confirm, based on a supplementary data set on brokerage accounts from Barber and Odean (2000) and an analysis of the relationship of gross sales to changes in dividends received, that gross sales are indeed strongly related to net sales. The model further clarifies that data on sales can only identify differences between investor groups in their tendency to reduce stock holdings in response to turmoil. After all, the average investor can neither buy nor sell on net. For this reason, the objective in our study is to uncover differences between taxpayers and the investor population as a whole and differences between groups of taxpayers.

The unique advantage of our data is that we can identify for each sale exactly who sold what security on each day, and characterize the sellers by the demographic information available on income tax returns and matched Social Security data. We see that, starting in September 2008, the share of sales volume attributed to the top 0.1 percent of income recipients rises sharply until the beginning of 2009. The same is true of the share of sales by those over the age of 60 . These observations are confirmed by regression analyses that show that the relationship of volume to lagged volatility, as measured by VIX, is higher for the top 95-99, 99-99.9, and 99.9-100 income percentiles over the period 2008 to 2009. In multi-dimensional analysis, both income and age are separately related to volatility sensitivity of sales volume. The separate association with volatility sensitivity also arises if we replace age with receipt of Social Security income. Other aspects of investors-gender, marital status, region and state of residence, presence and amount of a mortgage interest deduction, and 2007 zip-code-level house price growth-are not related to the volatility sensitivity of stock sales. Although sales in financial stocks clearly respond to specific 
events, we find no evidence that sales in finance responded more strongly to changes in the VIX than sales in other sectors.

Overall, our results show that there is substantial heterogeneity in investors' responses to market tumult. An explanation of market movements during these episodes likely needs to take into account these shifts in risk-bearing capacity. The data support theories that emphasize willingness to take risk among investors close to or in retirement. More difficult to explain is the tendency of high-income investors to sell in response to bursts in volatility. Perceived markettiming skills of financially more sophisticated investors, or their relatively high use of margin trading, could play a role. There could also be a connection to the disposition effect- the tendency of investors to hold on to stocks with accumulated losses - as the groups that we find are less likely to sell are also those that previous research has identified as having stronger disposition effects. We encourage future research to further examine why individuals at the very top of the income distribution are especially prone to sell stock during tumultuous times. 


\section{References}

Adrian, T., and H. S. Shin. 2010. Liquidity and leverage. Journal of Financial Intermediation 19 (3). Risk Transfer Mechanisms and Financial Stability: 418-437.

Anderson, A. M., and E. A. Dyl. 2007. Trading Volume: NASDAQ and the NYSE. Financial Analysts Journal 63 (3): 79-86.

Barber, B. M., and T. Odean. 2000. Trading Is Hazardous to Your Wealth: The Common Stock Investment Performance of Individual Investors. The Journal of Finance 55 (2): 773806.

Barrot, J.-N., R. Kaniel, and D. Sraer. 2016. Are retail traders compensated for providing liquidity? Journal of Financial Economics 120 (1): 146-168.

Ben-David, I., F. Franzoni, and R. Moussawi. 2012. Hedge Fund Stock Trading in the Financial Crisis of 2007-2009. Review of Financial Studies 25 (1): 1-54.

Bollerslev, T., and V. Todorov. 2011. Tails, Fears, and Risk Premia. The Journal of Finance 66 (6): 2165-2211.

Bricker, J., B. K. Bucks, A. Kennickell, T. L. Mach, and K. Moore. 2011. Drowning or Weathering the Storm? Changes in Family Finances from 2007 to 2009. Working Paper. National Bureau of Economic Research.

Calvet, L. E., J. Y. Campbell, and P. Sodini. 2009. Measuring the Financial Sophistication of Households. American Economic Review 99 (2): 393-398.

Cella, C., A. Ellul, and M. Giannetti. 2013. Investors' Horizons and the Amplification of Market Shocks. Review of Financial Studies: hht023.

Chai, J., W. Horneff, R. Maurer, and O. S. Mitchell. 2011. Optimal Portfolio Choice over the Life Cycle with Flexible Work, Endogenous Retirement, and Lifetime Payouts. Review of Finance 15 (4): 875-907.

Chang, T. Y., D. H. Solomon, and M. M. Westerfield. 2016. Looking for Someone to Blame: Delegation, Cognitive Dissonance, and the Disposition Effect. The Journal of Finance 71 (1): 267-302.

Cooper, M., J. McClelland, J. Pearce, R. Prisinzano, J. Sullivan, D. Yagan, O. Zidar, and E. Zwick. 2015. Business in the United States: Who Owns it and How Much Tax Do They Pay? Working Paper. National Bureau of Economic Research.

Dhar, R., and N. Zhu. 2006. Up Close and Personal: Investor Sophistication and the Disposition Effect. Management Science 52 (5): 726-740.

Dorn, D., and M. Weber. 2013. Individual Investors' Trading in Times of Crisis: Going It Alone or Giving Up? Working Paper.

Griffin, J. M., J. H. Harris, T. Shu, and S. Topaloglu. 2011. Who Drove and Burst the Tech Bubble? The Journal of Finance 66 (4): 1251-1290.

Guiso, L., P. Sapienza, and L. Zingales. 2013. The Determinants of Attitudes toward Strategic Default on Mortgages. The Journal of Finance 68 (4): 1473-1515.

Hoffmann, A. O. I., T. Post, and J. M. E. Pennings. 2013. Individual Investor Perceptions and Behavior During the Financial Crisis. Journal of Banking \& Finance 37 (1): 60-74.

Hoopes, J. L., D. H. Reck, and J. Slemrod. 2015. Taxpayer Search for Information: Implications for Rational Attention. American Economic Journal: Economic Policy 7 (3): 177-208.

Hudomiet, P., G. Kézdi, and R. J. Willis. 2011. Stock Market Crash and Expectations of American Households. Journal of Applied Econometrics 26 (3): 393-415.

K. Brunnermeier, M., and S. Nagel. 2004. Hedge Funds and the Technology Bubble. The Journal of Finance 59 (5): 2013-2040. 
Karpoff, J. M. 1987. The Relation Between Price Changes and Trading Volume: A Survey. The Journal of Financial and Quantitative Analysis 22 (1): 109-126.

Kimball, M. S., M. D. Shapiro, T. Shumway, and J. Zhang. 2011. Portfolio Rebalancing in General Equilibrium. Working Paper.

Longstaff, F. A. 2010. The Subprime Credit Crisis and Contagion in Financial Markets. Journal of Financial Economics 97 (3): 436-450.

Mackenzie, M. 2009. High-frequency trading under scrutiny. Financial Times, July 28.

Martin, I. 2015. What is the Expected Return on the Market? Working Paper.

Moreira, A., and T. Muir. 2016. Volatility Managed Portfolios. Working Paper.

Nagel, S. 2012. Evaporating Liquidity. Review of Financial Studies 25 (7): 2005-2039.

Odean, T. 1998. Are Investors Reluctant to Realize Their Losses? The Journal of Finance 53 (5): 1775-1798.

Poterba, J. M., and S. J. Weisbenner. 2001. Capital Gains Tax Rules, Tax-Loss Trading, and Turn-of-the-Year Returns. The Journal of Finance 56 (1): 353-368.

Shefrin, H., and M. Statman. 1985. The Disposition to Sell Winners Too Early and Ride Losers Too Long: Theory and Evidence. The Journal of Finance 40 (3): 777-790.

Shiller, R. J. 1987. Investor Behavior in the October 1987 Stock Market Crash: Survey Evidence. Working Paper. National Bureau of Economic Research.

Sicherman, N., G. Loewenstein, D. J. Seppi, and S. P. Utkus. 2016. Financial Attention. Review of Financial Studies 29 (4): 863-897.

Weber, M., E. U. Weber, and A. Nosić. 2012. Who Takes Risks When and Why: Determinants of Changes in Investor Risk Taking. Review of Finance 17: 847-883.

Wilson, J., and P. Liddell. 2013. Sales of Capital Assets Reported on Individual Tax Returns, 2008-2009. Statistics of Income Bulletin, Spring 2013. Internal Revenue Service. 


\section{Table I. Sample Selection}

Sample Restriction

All 1099-Bs in 2008-2009

Non-trading and partial days eliminated

Eliminate negative and trades over $\$ 2$ billion

Individual Taxpayers

Taxpayers age over 17
Transactions

Dollar Volume
$1,427,880,785 \$ 37,101,171,401,512$

$1,411,432,043 \quad \$ 36,283,816,476,155$

$870,141,589 \quad \$ 9,574,862,035,508$

$861,220,943 \quad \$ 9,547,946,596,246$

Stocks and Stock Mutual Funds $\quad 273,524,098 \quad \$ 6,793,511,903,794$

Notes. Full trading days are defined as days with positive CRSP trading volume, less days marked as partial trading days. Age of the taxpayer is determined as of December 31, 2008. Stocks are defined as assets where the first two characters of US_CFI_CODE from the cusip.issue database on WRDS are ES (common equity) or EP (preferred shares). 


\section{Table II. Overall Sales Response to Market Tumult}

\begin{tabular}{lcccc}
\hline \multirow{4}{*}{ Dependent variable: $\log 1099-\mathrm{B}$ sales volume, USD } \\
\cline { 2 - 5 } & \multicolumn{5}{c}{ Sample Period } \\
\cline { 2 - 5 } Number of 1-day lagged differences: & 1 & 10 & 1 & 10 \\
\cline { 2 - 5 } & $(1)$ & $(2)$ & $(3)$ & $(4)$ \\
\hline Change in log VIX & $0.346^{* *}$ & $4.964^{* * *}$ & $0.349^{* * *}$ & $7.183^{* * *}$ \\
Observations & $(0.135)$ & $(1.115)$ & $(0.131)$ & $(1.179)$ \\
R-squared & 498 & 498 & 62 & 62 \\
\hline
\end{tabular}

Notes: 1-day lagged difference is the difference between the lagged and twice lagged value (t-1 and $t-2)$. Columns 2 and 4 report sums of 10 1-day lagged differences (for $\mathrm{t}-1$ and $\mathrm{t}-2, \mathrm{t}-2$ and $\mathrm{t}-3, \ldots, \mathrm{t}-10$ and $\mathrm{t}-11$ ). Newey-West standard errors (10-day lag) in parentheses. $* * * \mathrm{p}<0.01, * * \mathrm{p}<0.05, * \mathrm{p}<0.1$ 


\section{Table III. Heterogeneity by Income in Sales Response to Market Tumult}

\begin{tabular}{lcccc}
\hline \multirow{2}{*}{ Dependent variable: log 1099-B sales volume, USD } \\
Reported coefficient: interaction between change in log VIX and average AGI percentile indicator \\
\cline { 2 - 5 } & \multicolumn{4}{c}{ Sample Period } \\
\cline { 2 - 5 } Number of 1-day lagged differences: & \multicolumn{4}{c}{ September - November } \\
& \multicolumn{2}{c}{$2008-2009$} & \multicolumn{3}{c}{2008} \\
\cline { 2 - 5 } & $(1)$ & $(2)$ & $(3)$ & $(4)$ \\
\hline$[99.9,100]$ & $0.327^{* * *}$ & $3.798^{* * *}$ & $0.224^{* *}$ & $2.640^{* * *}$ \\
& $(0.110)$ & $(1.408)$ & $(0.103)$ & $(0.666)$ \\
{$[99,99.9)$} & $0.255^{* * *}$ & $2.310^{* * *}$ & $0.147^{* *}$ & $1.500^{* * *}$ \\
& $(0.072)$ & $(0.884)$ & $(0.072)$ & $(0.501)$ \\
{$[95,99)$} & $0.146^{* *}$ & $1.895^{* *}$ & $0.152^{*}$ & $1.427^{* * *}$ \\
& $(0.071)$ & $(0.865)$ & $(0.080)$ & $(0.504)$ \\
{$[75,95)$} & 0.076 & 0.732 & 0.100 & $1.223^{* *}$ \\
& $(0.077)$ & $(0.955)$ & $(0.066)$ & $(0.495)$ \\
Group-day observations & 2,490 & 2,490 & 310 & 310 \\
R-squared & 0.91 & 0.92 & 0.96 & 0.97 \\
\hline All
\end{tabular}

Notes: All regressions include day and income-group fixed effects. 1-day lagged difference is the difference between the lagged and twice lagged value (t-1 and t-2). Columns 2 and 4 report sums of 10 1-day lagged differences (for $\mathrm{t}-1$ and $\mathrm{t}-2, \mathrm{t}-2$ and $\mathrm{t}-3, \ldots, \mathrm{t}-10$ and $\mathrm{t}-11$ ). Omitted category is taxpayers with average income in $[0$, 75). Newey-West standard errors (10-day lag) in parentheses. ${ }^{* * *} \mathrm{p}<0.01, * * \mathrm{p}<0.05,{ }^{*} \mathrm{p}<0.1$ 


\section{Table IV. Heterogeneity by Age in Sales Response to Market Tumult}

\begin{tabular}{|c|c|c|c|c|}
\hline \multicolumn{5}{|c|}{$\begin{array}{l}\text { Dependent variable: } \log 1099-\mathrm{B} \text { sales volume, USD } \\
\text { Reported coefficient: interaction between change in log VIX and age group indicator }\end{array}$} \\
\hline \multirow{4}{*}{ Number of 1-day lagged differences: } & \multicolumn{4}{|c|}{ Sample Period } \\
\hline & \multicolumn{2}{|c|}{ 2008-2009 } & \multicolumn{2}{|c|}{$\begin{array}{l}\text { September - November } \\
2008\end{array}$} \\
\hline & 1 & 10 & 1 & 10 \\
\hline & (1) & (2) & (3) & (4) \\
\hline $60+$ & $\begin{array}{c}0.314 * * * \\
(0.091)\end{array}$ & $\begin{array}{l}1.839 * \\
(1.029)\end{array}$ & $\begin{array}{c}0.304 * * * \\
(0.111)\end{array}$ & $\begin{array}{r}2.062 * * * \\
(0.498)\end{array}$ \\
\hline $50-59$ & $\begin{array}{c}0.063 \\
(0.059)\end{array}$ & $\begin{array}{c}0.243 \\
(0.640)\end{array}$ & $\begin{array}{c}0.053 \\
(0.089)\end{array}$ & $\begin{array}{c}0.91 * * * \\
(0.278)\end{array}$ \\
\hline $40-49$ & $\begin{array}{c}0.010 \\
(0.066)\end{array}$ & $\begin{array}{c}0.148 \\
(0.709)\end{array}$ & $\begin{array}{l}-0.037 \\
(0.094)\end{array}$ & $\begin{array}{l}-0.530 \\
(0.413)\end{array}$ \\
\hline Group-day observations & 1,992 & 1,992 & 248 & 248 \\
\hline R-squared & 0.96 & 0.96 & 0.98 & 0.98 \\
\hline
\end{tabular}

Notes: All regressions include day and income-group fixed effects. 1-day lagged difference is the difference between the lagged and twice lagged value ( $\mathrm{t}-1$ and $\mathrm{t}-2$ ). Columns 2 and 4 report sums of 10 1-day lagged differences (for $\mathrm{t}-1$ and $\mathrm{t}-2, \mathrm{t}-2$ and $\mathrm{t}-3, \ldots, \mathrm{t}-10$ and $\mathrm{t}-11$ ). Omitted category is taxpayers age 18-39. Newey-West standard errors (10-day lag) in parentheses. $* * * \mathrm{p}<0.01, * * \mathrm{p}<0.05, * \mathrm{p}<0.1$ 
Table V. Heterogeneity by Social Security Income Receipt in Sales Response to Market Tumult

\begin{tabular}{|c|c|c|c|c|}
\hline \multicolumn{5}{|c|}{$\begin{array}{c}\text { Dependent variable: log 1099-B sales volume, USD } \\
\text { Reported coefficient: interaction between change in log VIX and indicator for contemporaneous } \\
\text { receipt of social security income }\end{array}$} \\
\hline \multirow{4}{*}{ Number of 1-day lagged differences: } & \multicolumn{4}{|c|}{ Sample Period } \\
\hline & \multicolumn{2}{|c|}{$2008-2009$} & \multicolumn{2}{|c|}{$\begin{array}{c}\text { September - November } \\
2008\end{array}$} \\
\hline & 1 & 10 & 1 & 10 \\
\hline & $(1)$ & $(2)$ & (3) & $(4)$ \\
\hline Receipt of Social Security Income & $\begin{array}{l}0.306^{* * *} \\
(0.074)\end{array}$ & $\begin{array}{l}1.206^{*} \\
(0.696)\end{array}$ & $\begin{array}{c}0.349 * * * \\
(0.110)\end{array}$ & $\begin{array}{c}1.755 * * * \\
(0.581)\end{array}$ \\
\hline Group-day observations & 996 & 996 & 124 & 124 \\
\hline R-squared & 0.99 & 0.99 & 0.99 & 0.99 \\
\hline
\end{tabular}

Notes: All regressions include day and income-group fixed effects. 1-day lagged difference is the difference between the lagged and twice lagged value (t-1 and t-2). Columns 2 and 4 report sums of 10 1-day lagged differences (for $\mathrm{t}-1$ and $\mathrm{t}-2, \mathrm{t}-2$ and $\mathrm{t}-3, \ldots, \mathrm{t}-10$ and $\mathrm{t}-11$ ). The omitted category consists of taxpayers not receiving social security income. Newey-West standard errors (10-day lag) in parentheses. ${ }^{* * *} \mathrm{p}<0.01, * * \mathrm{p}<0.05,{ }^{*} \mathrm{p}<0.1$ 


\section{Table VI. Heterogeneity by Average Dividend Receipt in Sales Response to Market Tumult}

\begin{tabular}{lcccc}
\hline \multirow{2}{*}{ Dependent variable: $\log$ 1099-B sales volume, USD } \\
& \multicolumn{5}{c}{ Sample Period } \\
\cline { 2 - 5 } & \multicolumn{2}{c}{ September - November } \\
Number of 1-day lagged differences: & 1 & 10 & 1 & 10 \\
\cline { 2 - 5 } & $(1)$ & $(2)$ & $(3)$ & $(4)$ \\
\hline$[99,100]$ & $0.567^{* * *}$ & $6.076^{* * *}$ & $0.482^{* * *}$ & $5.524^{* * *}$ \\
& $(0.163)$ & $(1.920)$ & $(0.136)$ & $(0.958)$ \\
{$[95,99)$} & $0.458^{* * *}$ & $5.077^{* * *}$ & $0.421^{* * *}$ & $4.921^{* * *}$ \\
& $(0.137)$ & $(1.547)$ & $(0.106)$ & $(0.821)$ \\
{$[75,95)$} & $0.222^{*}$ & $3.399^{* *}$ & $0.204^{*}$ & $2.758^{* * *}$ \\
& $(0.134)$ & $(1.545)$ & $(0.115)$ & $(0.781)$ \\
Group-day observations & 1,992 & 1,992 & 248 & 248 \\
R-squared & 0.91 & 0.92 & 0.97 & 0.98 \\
\hline
\end{tabular}

Notes: All regressions include day and income-group fixed effects. 1-day lagged difference is the difference between the lagged and twice lagged value ( $\mathrm{t}-1$ and $\mathrm{t}-2$ ). Columns 2 and 4 report sums of 10 1-day lagged differences (for $\mathrm{t}-1$ and $\mathrm{t}-2, \mathrm{t}-2$ and $\mathrm{t}-3, \ldots, \mathrm{t}-10$ and $\mathrm{t}-11$ ). Dividends refer to the average of qualifying taxable dividends. Omitted category is taxpayers with average dividends in $[0,75)$. Newey-West standard errors (10-day lag) in parentheses. $* * * \mathrm{p}<0.01, * * \mathrm{p}<0.05, * \mathrm{p}<0.1$ 


\section{Table VII. Heterogeneity by Receipt of Partnership/S-Corp Income in Response to Market Tumult}

\begin{tabular}{lcccc}
\hline & \multicolumn{3}{c}{$\begin{array}{c}\text { Dependent variable: log 1099-B sales volume, USD } \\
\text { Reported coefficient: interaction between change in log VIX and dummy for receipt of } \\
\text { positive partnership or S-corporation income }\end{array}$} \\
\cline { 2 - 5 } & \multicolumn{4}{c}{ Sample Period } \\
\hline Number of 1-day lagged differences: & 1 & \multicolumn{3}{c}{ September - November } \\
& $(1)$ & 10 & 1 & 10 \\
\hline Receipt of Partnership/S-corp Income & $0.170 * * *$ & $1.547 * * *$ & 0.054 & 0.444 \\
Group-day observations & $(0.041)$ & $(0.582)$ & $(0.044)$ & $(0.282)$ \\
R-squared & 996 & 996 & 124 & 124 \\
\hline
\end{tabular}

Notes: All regressions include day and income-group fixed effects. 1-day lagged difference is the difference between the lagged and twice lagged value (t-1 and t-2). Columns 2 and 4 report sums of 10 1-day lagged differences (for $\mathrm{t}-1$ and $\mathrm{t}-2, \mathrm{t}-2$ and $\mathrm{t}-3, \ldots, \mathrm{t}-10$ and $\mathrm{t}-11$ ). Omitted category is taxpayers not receiving positive partnership or S-corporation income. Newey-West standard errors (10-day lag) in parentheses. $* * * \mathrm{p}<0.01, * *$ $\mathrm{p}<0.05, * \mathrm{p}<0.1$ 


\section{Table VIII. Heterogeneity by Income and Age in Sales Response to Market Tumult}

\begin{tabular}{|c|c|c|c|c|c|c|}
\hline \multicolumn{7}{|c|}{$\begin{array}{l}\text { Dependent variable: } \log 1099-\mathrm{B} \text { sales volume, USD } \\
\text { Reported coefficient: interaction between change in VIX and two-way group indicator }\end{array}$} \\
\hline \multicolumn{7}{|c|}{ A. $2008-2009,1$ day lagged difference of $\log$ VIX } \\
\hline \multicolumn{7}{|c|}{ Age: } \\
\hline & $80+$ & $70-79$ & $60-69$ & $50-59$ & $40-49$ & $<40$ \\
\hline \multicolumn{7}{|l|}{ Average AGI: } \\
\hline$[99.9,100]$ & $\begin{array}{c}0.813 * * * \\
(0.285)\end{array}$ & $\begin{array}{c}0.800 * * * \\
(0.158)\end{array}$ & $\begin{array}{c}0.559 * * * \\
(0.153)\end{array}$ & $\begin{array}{c}0.382 * * * \\
(0.139)\end{array}$ & $\begin{array}{c}0.370 * * \\
(0.146)\end{array}$ & $\begin{array}{l}0.270 \\
(0.203)\end{array}$ \\
\hline \multirow[t]{2}{*}{$99,99.9$} & $0.781 * * *$ & $0.665 * * *$ & $0.505^{* * *}$ & $0.396 * * *$ & $0.312 * *$ & $0.441 * * *$ \\
\hline & $(0.166)$ & $(0.137)$ & $(0.125)$ & $(0.117)$ & $(0.129)$ & $(0.137)$ \\
\hline \multirow[t]{2}{*}{95,99} & $0.624 * * *$ & $0.608 * * *$ & $0.418 * * *$ & $0.206^{*}$ & $0.223^{*}$ & $0.351^{* *}$ \\
\hline & $(0.145)$ & $(0.126)$ & $(0.120)$ & $(0.118)$ & $(0.130)$ & $(0.151)$ \\
\hline \multirow[t]{2}{*}{85,95} & $0.580 * * *$ & $0.587 * * *$ & $0.357 * * *$ & 0.201 & 0.100 & $0.221 *$ \\
\hline & $(0.136)$ & $(0.127)$ & $(0.115)$ & $(0.130)$ & $(0.136)$ & $(0.133)$ \\
\hline \multirow[t]{2}{*}{75,85} & $0.537 * * *$ & $0.553 * * *$ & $0.320 * * *$ & $0.227 *$ & 0.152 & 0.109 \\
\hline & $(0.141)$ & $(0.125)$ & $(0.123)$ & $(0.132)$ & $(0.142)$ & $(0.150)$ \\
\hline \multirow[t]{2}{*}{0,75} & $0.615 * * *$ & $0.566 * * *$ & $0.337 * * *$ & 0.215 & 0.007 & (omitted) \\
\hline & $(0.133)$ & $(0.123)$ & $(0.126)$ & $(0.132)$ & $(0.155)$ & \\
\hline \multicolumn{7}{|c|}{ B. September-November 2008, 1 day lagged difference of log VIX } \\
\hline \multicolumn{7}{|l|}{ Average AGI: } \\
\hline$[99.9,100]$ & $\begin{array}{l}0.955^{*} \\
(0.575)\end{array}$ & $\begin{array}{c}0.570 * * * \\
(0.189)\end{array}$ & $\begin{array}{c}0.472 * * * \\
(0.157)\end{array}$ & $\begin{array}{c}0.308^{* *} \\
(0.137)\end{array}$ & $\begin{array}{c}0.214 \\
(0.161)\end{array}$ & $\begin{array}{l}0.333^{*} \\
(0.174)\end{array}$ \\
\hline \multirow[t]{2}{*}{$99,99.9$} & $0.760 * * *$ & $0.513 * * *$ & $0.388 * * *$ & $0.342 * * *$ & 0.202 & $0.305^{* *}$ \\
\hline & $(0.164)$ & $(0.139)$ & $(0.110)$ & $(0.100)$ & $(0.129)$ & $(0.136)$ \\
\hline \multirow[t]{2}{*}{95,99} & $0.643^{* * *}$ & $0.677 * * *$ & $0.405 * * *$ & $0.223 * *$ & $0.262 *$ & 0.335 \\
\hline & $(0.153)$ & $(0.120)$ & $(0.102)$ & $(0.109)$ & (0.158) & $(0.212)$ \\
\hline \multirow[t]{2}{*}{85,95} & $0.629 * * *$ & $0.634 * * *$ & $0.458 * * *$ & $0.216^{* *}$ & 0.086 & $0.256^{*}$ \\
\hline & $(0.141)$ & $(0.121)$ & $(0.110)$ & $(0.107)$ & (0.123) & (0.137) \\
\hline \multirow[t]{2}{*}{75,85} & $0.712 * * *$ & $0.678 * * *$ & $0.365 * * *$ & $0.285^{* *}$ & 0.145 & 0.138 \\
\hline & (0.164) & $(0.122)$ & $(0.104)$ & $(0.113)$ & $(0.136)$ & $(0.142)$ \\
\hline \multirow[t]{2}{*}{0,75} & $0.717 * * *$ & $0.669 * * *$ & $0.339 * * *$ & $0.249 * *$ & -0.017 & (omitted) \\
\hline & $(0.136)$ & $(0.128)$ & $(0.117)$ & $(0.108)$ & $(0.150)$ & \\
\hline
\end{tabular}

Notes: Each panel reports the results of a separate regression. The reported coefficients are interactions between a change in VIX and an income-group-by-age fixed effect. All regressions include day and income-group-by-age fixed effects. 1 day lagged difference is the difference between the lagged and twice lagged value ( $\mathrm{t}-1$ and $\mathrm{t}-2)$. Newey-West standard errors (10-day lag) in parentheses. ${ }^{* * *} \mathrm{p}<0.01,{ }^{* *} \mathrm{p}<0.05,{ }^{*} \mathrm{p}<0.1$ 


\section{Table IX. Gross and Net Sales in the Barber-Odean Discount Brokerage Data}

\begin{tabular}{|c|c|c|c|c|c|c|}
\hline & \multicolumn{5}{|c|}{ Dependent variable: } & \multirow[b]{2}{*}{$\begin{array}{c}\text { Log gross } \\
\text { sales } \\
\text { volume, } \\
\text { taxable } \\
\text { accounts, } \\
\text { large } \\
\text { portfolios } \\
(6) \\
\end{array}$} \\
\hline & $\begin{array}{c}\text { Log gross } \\
\text { sales } \\
\text { volume, } \\
\text { taxable } \\
\text { accounts } \\
(1) \\
\end{array}$ & $\begin{array}{l}\text { Net sales } \\
\text { volume } \\
\text { (\% of } \\
\text { portfolio } \\
\text { value), } \\
\text { taxable } \\
\text { accounts } \\
(2) \\
\end{array}$ & $\begin{array}{c}\text { Gross sales } \\
\text { volume (\% } \\
\text { of portfolio } \\
\text { value), } \\
\text { taxable } \\
\text { accounts } \\
(3)\end{array}$ & $\begin{array}{c}\text { Net sales } \\
\text { volume (\% } \\
\text { of } \\
\text { portfolio } \\
\text { value), } \\
\text { taxable } \\
\text { accounts } \\
(4)\end{array}$ & $\begin{array}{l}\text { Log gross } \\
\text { sales } \\
\text { volume, } \\
\text { non- } \\
\text { taxable } \\
\text { accounts } \\
(5) \\
\end{array}$ & \\
\hline Contemp. 1 day diff. of $\log$ VIX & $\begin{array}{c}1.010 * * * \\
(0.176)\end{array}$ & & $\begin{array}{c}0.526 * * * \\
(0.086)\end{array}$ & $\begin{array}{c}0.171 * * * \\
(0.058)\end{array}$ & $\begin{array}{c}1.140 * * * \\
(0.239)\end{array}$ & $\begin{array}{c}1.087 * * * \\
(0.226)\end{array}$ \\
\hline Lagged 1 day diff. of $\log$ VIX & $\begin{array}{c}0.414 * * * \\
(0.189)\end{array}$ & & $\begin{array}{c}0.228 * * \\
(0.093)\end{array}$ & $\begin{array}{l}0.116^{*} \\
(0.070)\end{array}$ & $\begin{array}{l}0.606^{* *} \\
(0.241)\end{array}$ & $\begin{array}{l}0.531 * * \\
(0.224)\end{array}$ \\
\hline $\begin{array}{l}\text { Contemp. gross sales volume } \\
\text { (\% of portfolio value) }\end{array}$ & & $\begin{array}{c}0.342 * * * \\
(0.029)\end{array}$ & & & & \\
\hline Adj. $\mathrm{R}^{2}$ & $2.51 \%$ & $26.85 \%$ & $4.11 \%$ & $1.10 \%$ & $1.53 \%$ & $1.93 \%$ \\
\hline Observations & 1496 & 1475 & 1474 & 1474 & 1496 & 1474 \\
\hline
\end{tabular}

Notes: Large portfolios in the last column are those above the $80^{\text {th }}$ percentile by the total value of all positions at the end of the previous month. Newey-West standard errors (10 day lag) in parentheses. $* * * \mathrm{p}<0.01, * * \mathrm{p}<0.05,{ }^{*} \mathrm{p}<0.1$ 
Table X. Gross Sales and Changes in Dividend Income

Dependent Variable: Dividends in $t+1$ minus Dividends in $t-1$

\begin{tabular}{|c|c|c|c|c|}
\hline & $\begin{array}{c}\mathrm{t}=2008 \\
(1)\end{array}$ & $\begin{array}{c}\mathrm{t}=2009 \\
(2)\end{array}$ & $\begin{array}{c}\mathrm{t}=2008 \\
(3)\end{array}$ & $\begin{array}{c}t=2009 \\
(4)\end{array}$ \\
\hline \multirow[t]{2}{*}{ Gross Sales } & $-0.0065 * * *$ & $-0.0068 * * *$ & $-0.0049 * * *$ & $-0.043 * * *$ \\
\hline & $(0.000041)$ & $(0.000051)$ & $(0.000086)$ & $(0.000094)$ \\
\hline \multirow[t]{2}{*}{ Gross Sales x AGI percentile $[75,95]$} & & & $-0.0004 * * *$ & $-0.0008 * * *$ \\
\hline & & & $(0.00011)$ & $(0.00013)$ \\
\hline \multirow[t]{2}{*}{ Gross Sales x AGI percentile $[95,99]$} & & & $-0.0005 * * *$ & $-0.0012 * * *$ \\
\hline & & & $(0.00012)$ & $(0.00014)$ \\
\hline \multirow[t]{2}{*}{ Gross Sales x AGI percentile $[99,99.9]$} & & & $-0.0006 * * *$ & $-0.0017 * * *$ \\
\hline & & & $(0.00013)$ & $(0.00015)$ \\
\hline \multirow[t]{2}{*}{ Gross Sales x AGI percentile $[99.9,100]$} & & & $-0.0004 * * *$ & $-0.0017 * * *$ \\
\hline & & & $(0.00022)$ & $(0.00027)$ \\
\hline AGI group fixed effects & $\mathrm{NO}$ & NO & YES & YES \\
\hline R-square & $9.41 \%$ & $6.48 \%$ & $11.47 \%$ & $8.69 \%$ \\
\hline Observations & $1,888,174$ & $1,885,874$ & $1,888,174$ & $1,885,874$ \\
\hline
\end{tabular}


Table XI. Net Sales in Taxable Accounts and Total Net Sales, 2007-2009

Dependent Variable: Net Purchases (Negative Sales) from 2007 to 2009

(1)

(2)

Net Taxable Purchases (or Sales)

$0.925 * * * \quad 0.908 * * *$

$(0.075)$

$(0.123)$

Net Taxable Purchases x HH income percentile [75,95]

0.146

(0.139)

Net Taxable Purchases x HH income percentile [95,99]

0.030

Net Taxable Purchases x HH income percentile [99,100]

0.015

AGI group fixed effects

(0.153)

R-square

$\mathrm{NO}$

YES

Observations

$0.772 \quad 0.728$

$3,857 \quad 3,857$

Notes: Household (HH) income percentiles are based on the SCF. Observations weighted by SCF survey weights. White standard errors, adjusted for multiple imputations in the survey data, are reported in parentheses. $* * * \mathrm{p}<0.01$, $* * \mathrm{p}<0.05, * \mathrm{p}<0.1$. 


\section{Table XII. Which Stocks Were Sold? Heterogeneity by Fama-French 12-Industry Stock Classification}

\begin{tabular}{|c|c|c|c|c|}
\hline \multicolumn{5}{|c|}{$\begin{array}{l}\text { Dependent variable: logged individual 1099-b volume by industry, USD } \\
\text { Reported coefficient: interaction between change in log VIX and asset type indicator }\end{array}$} \\
\hline & \multicolumn{2}{|c|}{$2008-2009$} & \multicolumn{2}{|c|}{$\begin{array}{l}\text { September - November } \\
2008\end{array}$} \\
\hline Number of 1-day lagged differences & 1 & 10 & 1 & 10 \\
\hline & $(1)$ & $(2)$ & (3) & (4) \\
\hline Business Equipment & $\begin{array}{c}0.282 \\
(0.237)\end{array}$ & $\begin{array}{c}6.465 * * * \\
(2.334)\end{array}$ & $\begin{array}{c}0.240 \\
(0.340)\end{array}$ & $\begin{array}{c}0.949 \\
(2.380)\end{array}$ \\
\hline Chemicals & $\begin{array}{r}0.577 * * \\
(0.277)\end{array}$ & $\begin{array}{c}7.203 * * * \\
(2.371)\end{array}$ & $\begin{array}{c}0.694 \\
(0.453)\end{array}$ & $\begin{array}{c}2.525 \\
(2.457)\end{array}$ \\
\hline Consumer Nondurables & $\begin{array}{c}0.329 \\
(0.230)\end{array}$ & $\begin{array}{c}7.118 * * * \\
(1.910)\end{array}$ & $\begin{array}{c}0.553 \\
(0.354)\end{array}$ & $\begin{array}{r}4.718^{* *} \\
(2.346)\end{array}$ \\
\hline Energy & $\begin{array}{l}0.424^{*} \\
(0.344)\end{array}$ & $\begin{array}{c}6.943 * * * \\
(2.106)\end{array}$ & $\begin{array}{c}0.092 \\
(0.334)\end{array}$ & $\begin{array}{l}3.105 \\
(2.361)\end{array}$ \\
\hline Finance & $\begin{array}{c}0.345 \\
(0.255)\end{array}$ & $\begin{array}{c}7.222 * * * \\
(2.447)\end{array}$ & $\begin{array}{c}0.069 \\
(0.349)\end{array}$ & $\begin{array}{c}0.522 \\
(2.474)\end{array}$ \\
\hline Healthcare & $\begin{array}{c}0.299 \\
(0.233)\end{array}$ & $\begin{array}{c}3.152 \\
(2.041)\end{array}$ & $\begin{array}{c}0.486 \\
(0.328)\end{array}$ & $\begin{array}{c}1.974 \\
(2.419)\end{array}$ \\
\hline Manufacturing & $\begin{array}{c}0.188 \\
(0.219)\end{array}$ & $\begin{array}{c}3.837 * * \\
(1.820)\end{array}$ & $\begin{array}{c}0.046 \\
(0.323)\end{array}$ & $\begin{array}{c}2.427 \\
(2.298)\end{array}$ \\
\hline Other & $\begin{array}{c}0.090 \\
(0.222)\end{array}$ & $\begin{array}{c}4.418 * * \\
(1.971)\end{array}$ & $\begin{array}{c}0.209 \\
(0.357)\end{array}$ & $\begin{array}{c}0.422 \\
(2.489)\end{array}$ \\
\hline Shops & $\begin{array}{c}0.154 \\
(0.227)\end{array}$ & $\begin{array}{c}4.786 * * \\
(1.856)\end{array}$ & $\begin{array}{c}0.292 \\
(0.342)\end{array}$ & $\begin{array}{c}1.047 \\
(2.428)\end{array}$ \\
\hline Telecommunications & $\begin{array}{c}0.293 \\
(0.226)\end{array}$ & $\begin{array}{c}4.854 * * \\
(1.905)\end{array}$ & $\begin{array}{c}0.295 \\
(0.341)\end{array}$ & $\begin{array}{c}0.921 \\
(2.385)\end{array}$ \\
\hline Utilities & $\begin{array}{c}0.547 \text { ** } \\
(0.242)\end{array}$ & $\begin{array}{c}7.879 * * * \\
(2.021)\end{array}$ & $\begin{array}{c}0.608 \\
(0.344)\end{array}$ & $\begin{array}{l}4.279 * \\
(2.333)\end{array}$ \\
\hline Sectors & 12 & 12 & 12 & 12 \\
\hline Days & 505 & 505 & 63 & 63 \\
\hline Sector-Days & 6,060 & 6,060 & 756 & 756 \\
\hline R-squared & 0.957 & 0.958 & 0.981 & 0.983 \\
\hline
\end{tabular}

Notes: All regressions include day and sector fixed effects. 1-day lagged difference is the difference between the lagged and twice lagged value ( $\mathrm{t}-1$ and $\mathrm{t}-2$ ). Columns 2 and 4 report sums of 101 -day lagged differences (for $\mathrm{t}-1$ and $\mathrm{t}-2, \mathrm{t}-2$ and $\mathrm{t}-3, \ldots, \mathrm{t}-10$ and $\mathrm{t}-11$ ). Sectors are defined using the Fama-French 12-industry classification system. The omitted category is consumer durables. Newey-West standard errors (10-day lag) in parentheses. *** $\mathrm{p}<0.01$, ** $\mathrm{p}<0.05, * \mathrm{p}<0.1$. 


\section{Table XIII. Sales of Stock versus Sales of Mutual Funds}

Dependent variable: logged individual 1099-b volume in either stocks or mutual funds, USD Reported coefficient: interaction between change in log VIX and asset type indicator

\begin{tabular}{lcccc} 
& \multicolumn{4}{c}{ Sample Period } \\
\cline { 2 - 5 } Number of 1-day lagged differences & \multicolumn{3}{c}{ September - } \\
& \multicolumn{2}{c}{$2008-2009$} & \multicolumn{2}{c}{ November 2008 } \\
\cline { 2 - 5 } & 1 & 10 & 1 & 10 \\
\hline Stock & $-0.396^{* *}$ & -1.92 & -0.112 & 2.113 \\
& $(0.171)$ & $(2.259)$ & $(0.425)$ & $(3.014)$ \\
Days & 505 & 505 & 63 & 63 \\
Asset-type-day observations & 1,010 & 1,010 & 126 & 126 \\
R-squared & 0.754 & 0.754 & 0.119 & 0.465 \\
\hline
\end{tabular}

Notes: All regressions include day and asset type fixed effects. 1-day lagged difference is the difference between the lagged and twice lagged value (t-1 and t-2). Columns 2 and 4 report sums of 101 -day lagged differences (for t- 1 and $\mathrm{t}-2, \mathrm{t}-2$ and $\mathrm{t}-3, \ldots, \mathrm{t}-10$ and $\mathrm{t}-11$ ). The omitted category is mutual funds. Assets are classified as stocks or mutual funds based on the reported CUSIP number. Newey-West standard errors (10-day lag) in parentheses. *** p<0.01, $* * \mathrm{p}<0.05, * \mathrm{p}<0.1$. 
Figure I

Stock Market Volatility (VIX S\&P 500) Over Time

Panel A. 2008-2009

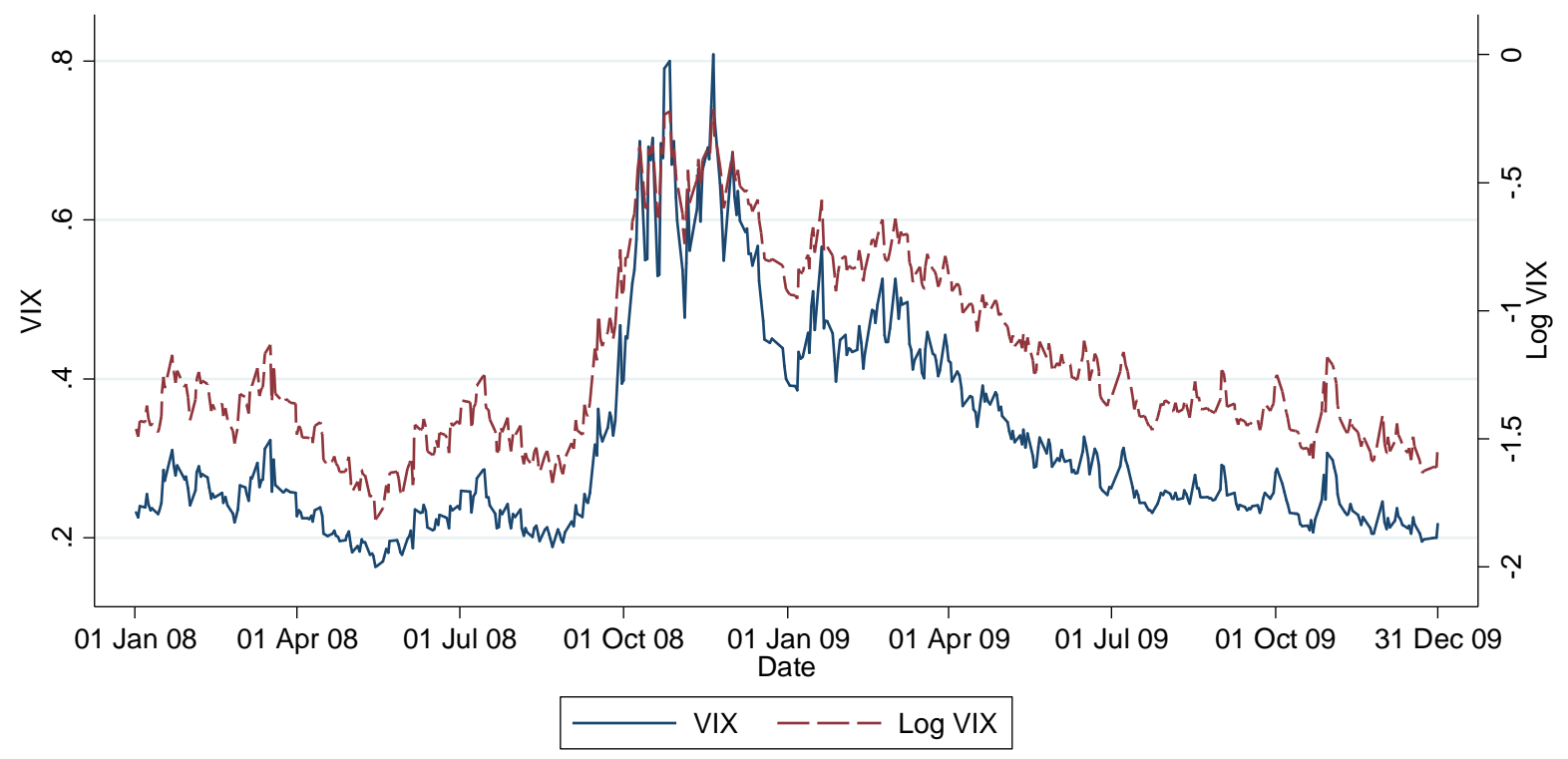

Panel B. September-November 2008

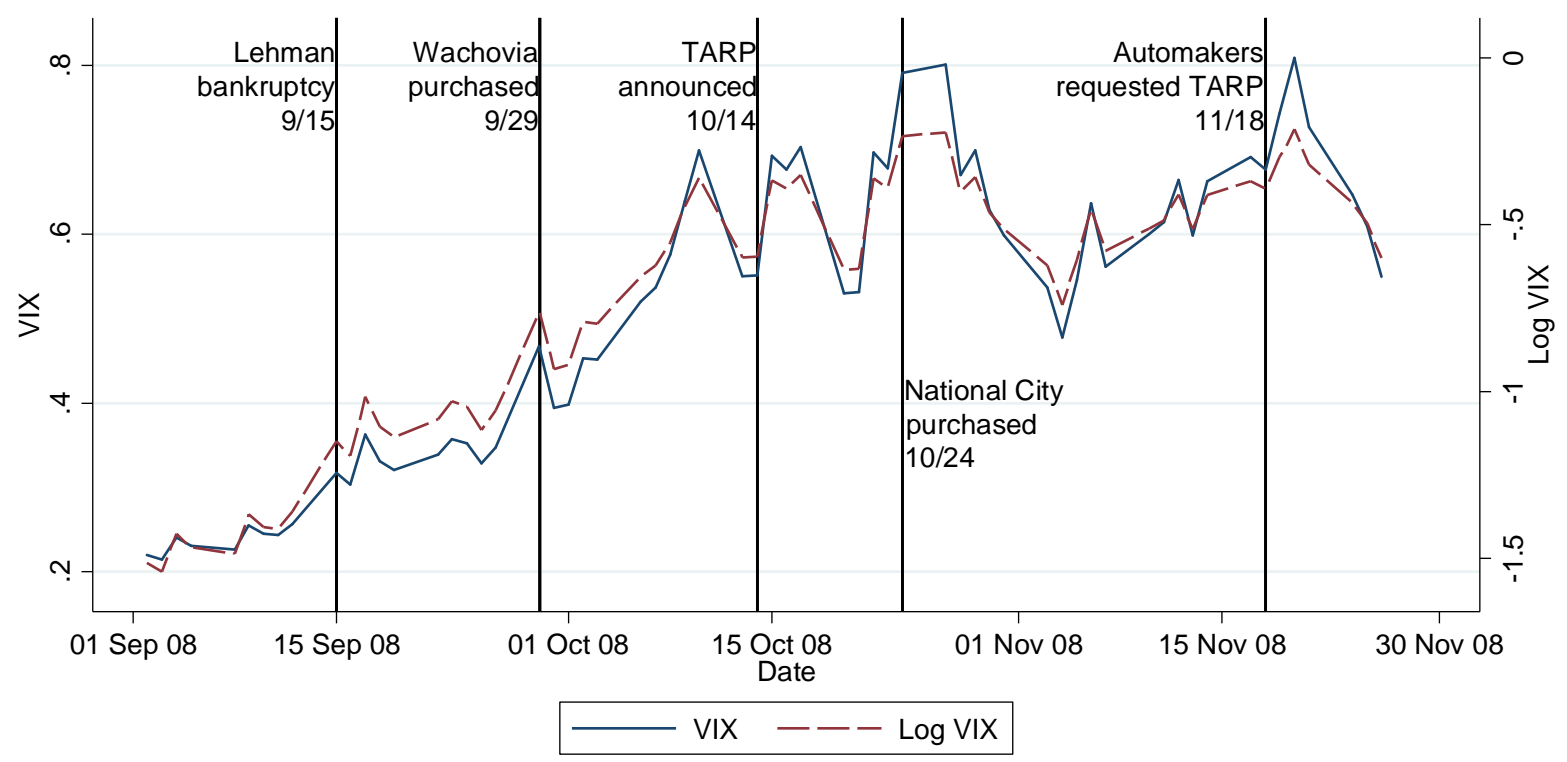


Figure II

Sales and Trading Volume from Matched 1099-B's and CRSP

Panel A. Log Sales Volume, Matched 1099-B's and Universe of Stocks on CRSP

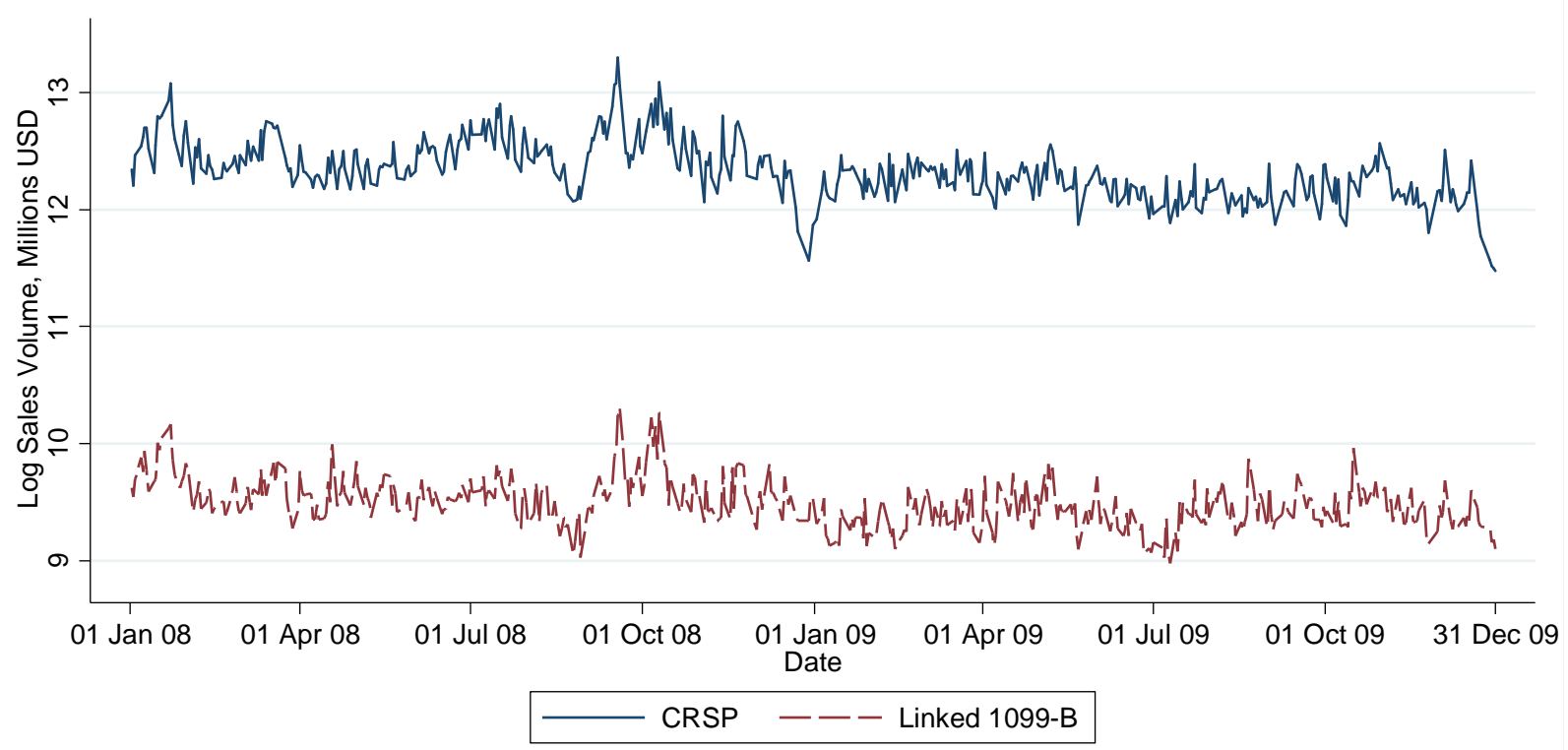

Panel B. Fraction of Total Sales Volume Represented by Matched 1099-B’s

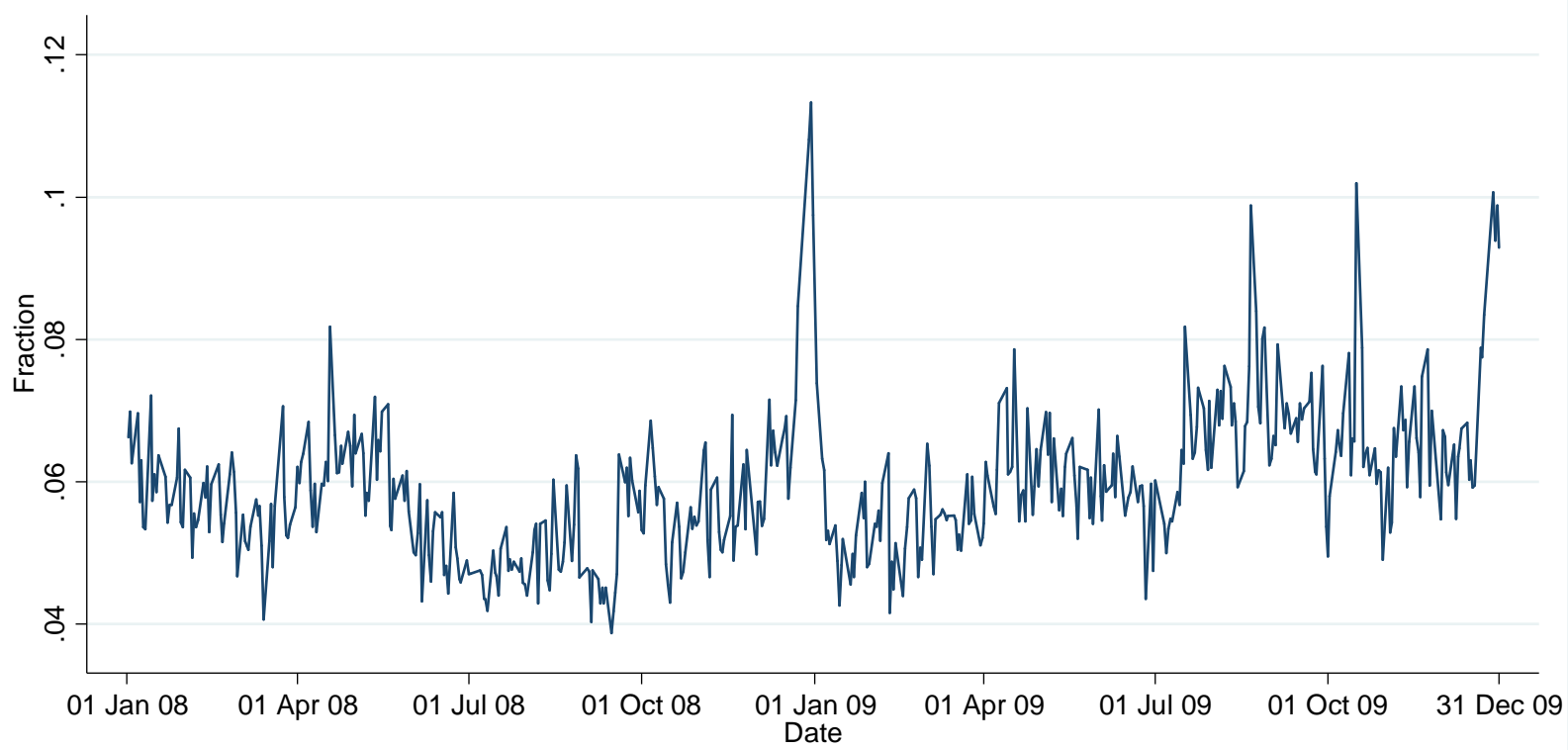

Notes: Total sales volume equals ending price per share times number of shares traded for the universe of stocks on CRSP. We divide the trading volume of NASDAQ stocks by two because it is a dealer market (see Anderson and Dyl 2007). The mean and median of the depicted share is 0.059 . 
Figure III

Sales Volume and Number of Transactors

Panel A. Sales Volume and Number of Transactors, Matched Form 1099-B's

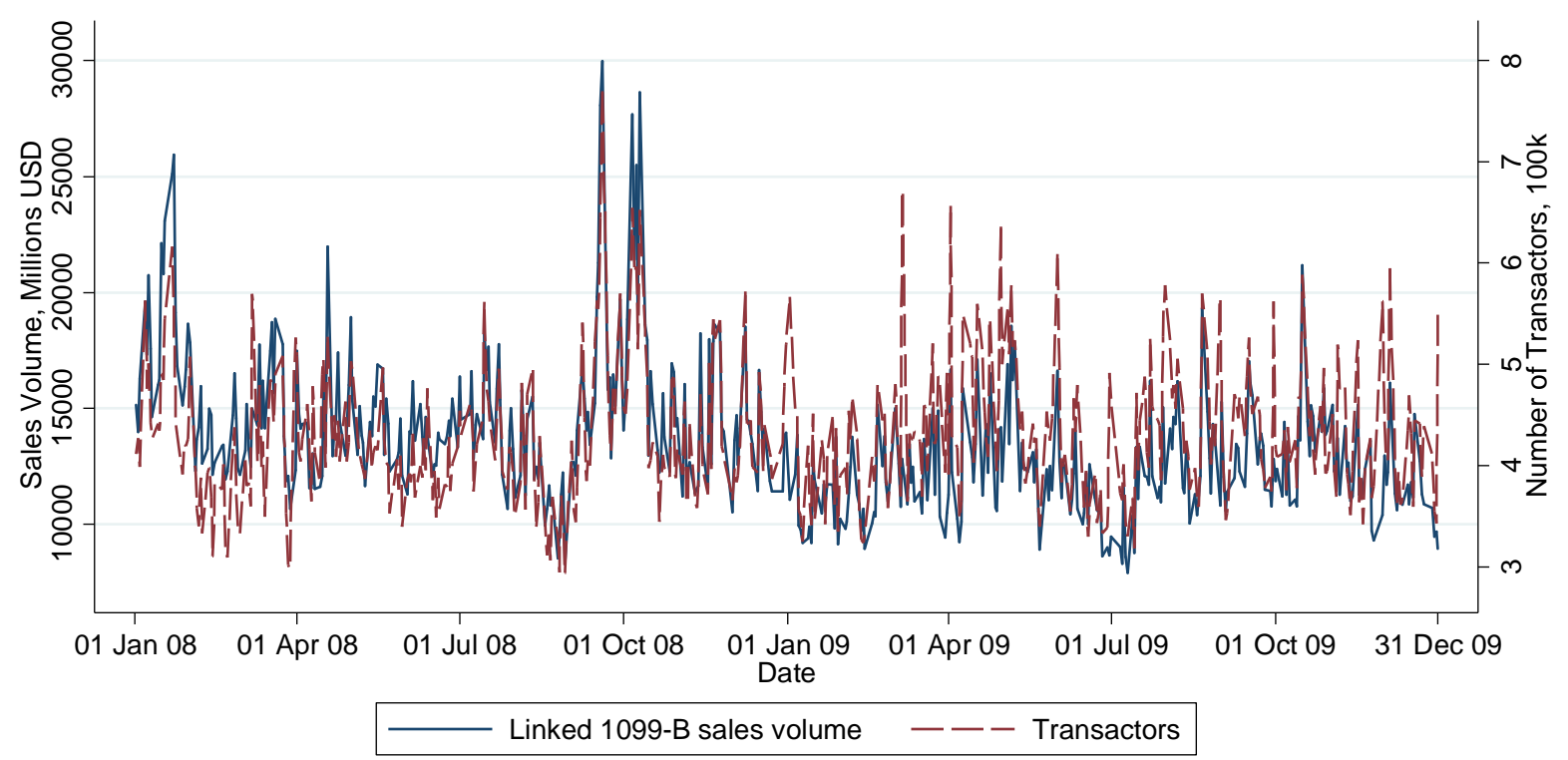

Panel B. Average Sales Volume per Transactor, Matched Form 1099-B's

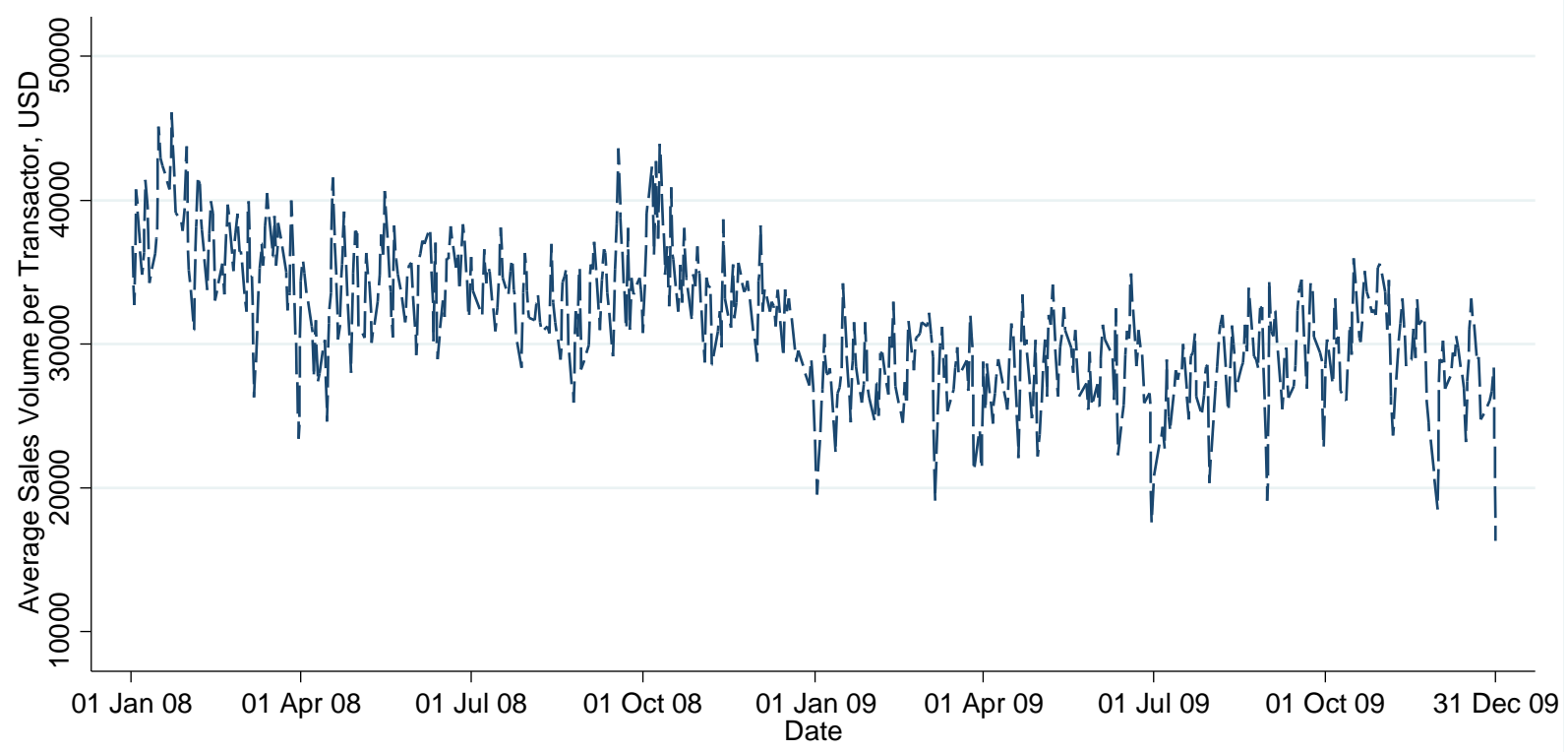




\section{Figure IV}

\section{Shares of 1099-B Sales Volume by Average Adjusted Gross Income Percentiles}

Panel A. 2008-2009

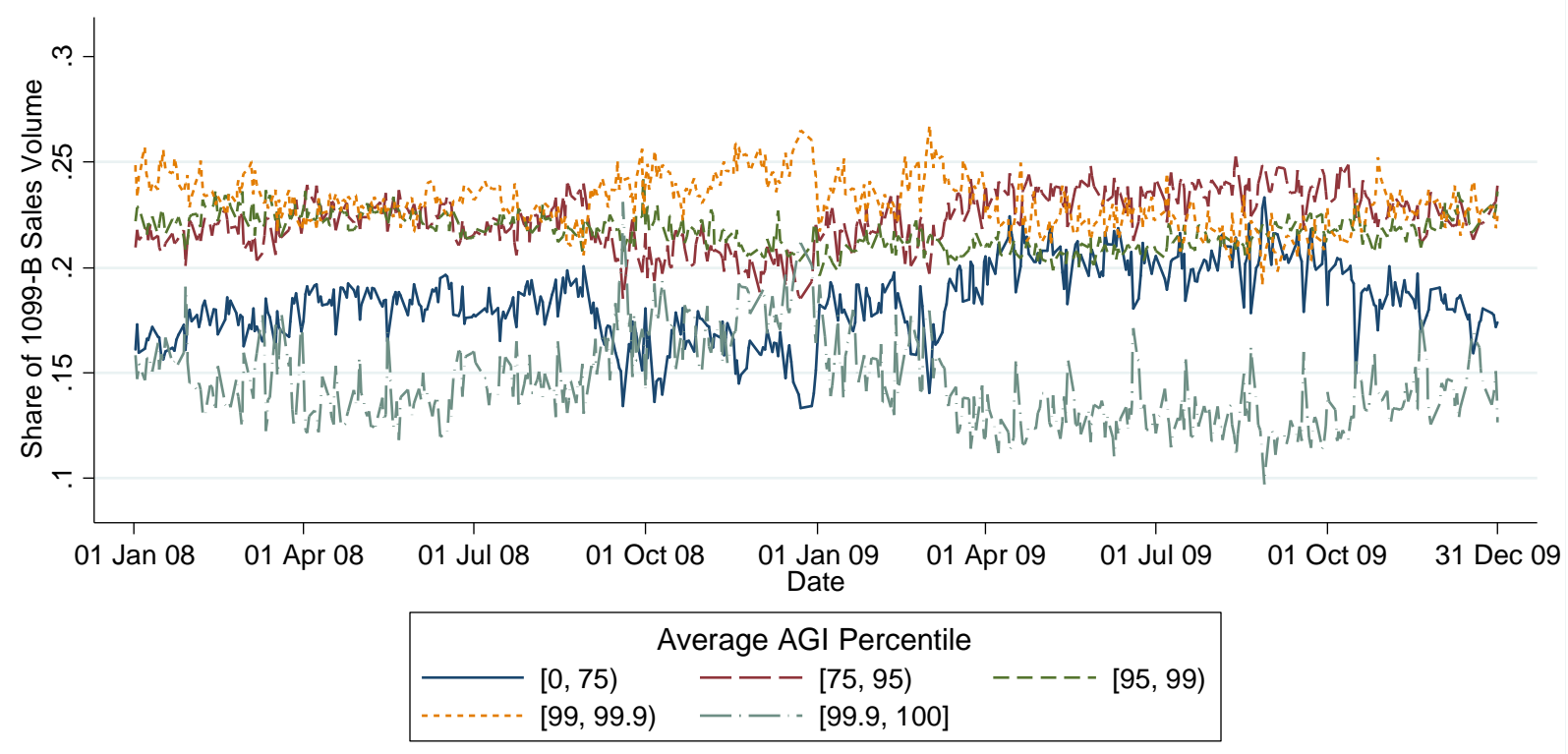

Panel B. 2008-2009, Normalized by Average Share of Trading Volume from 2008-2009

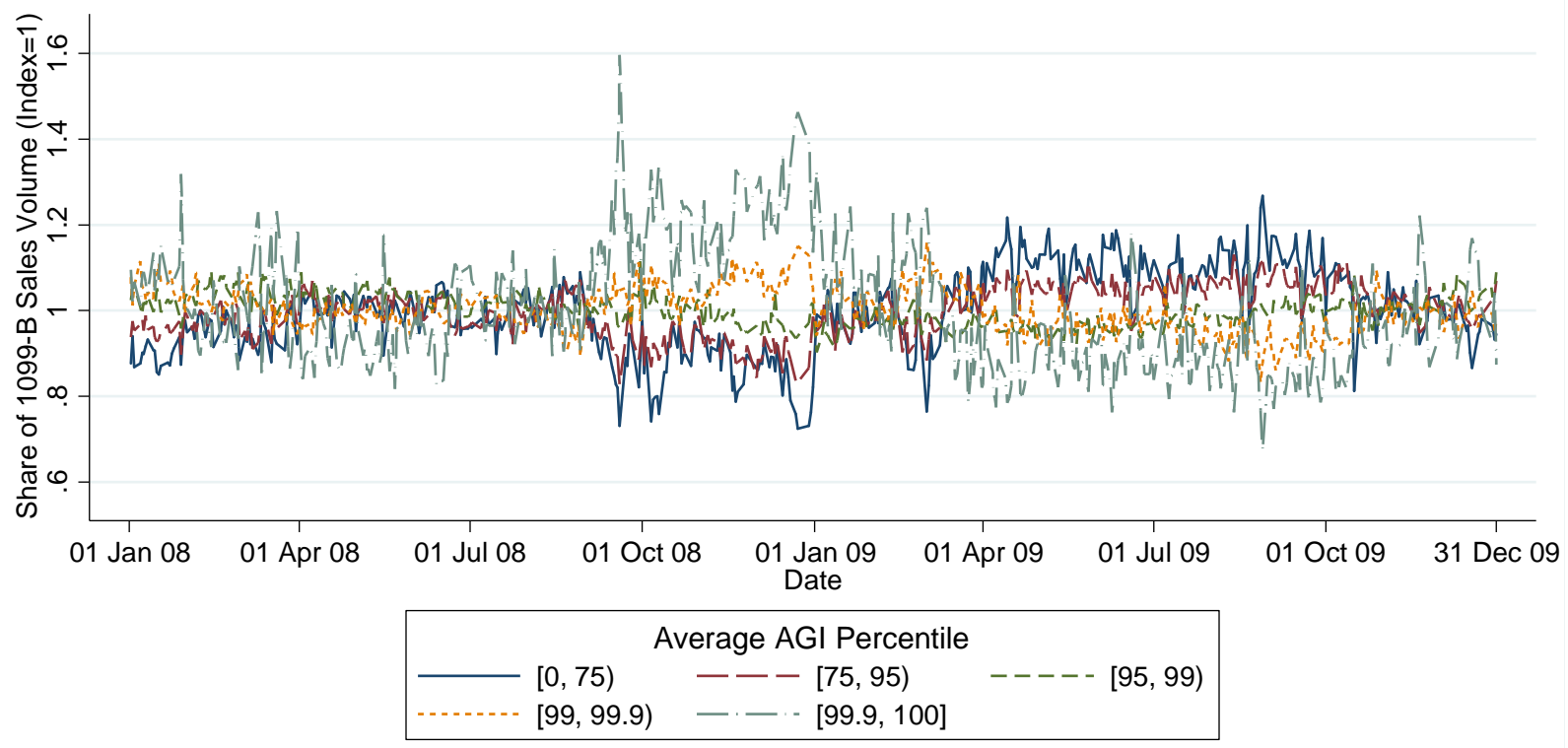


Figure V

Shares of 1099-B Sales Volume by Age

Panel A. 2008-2009

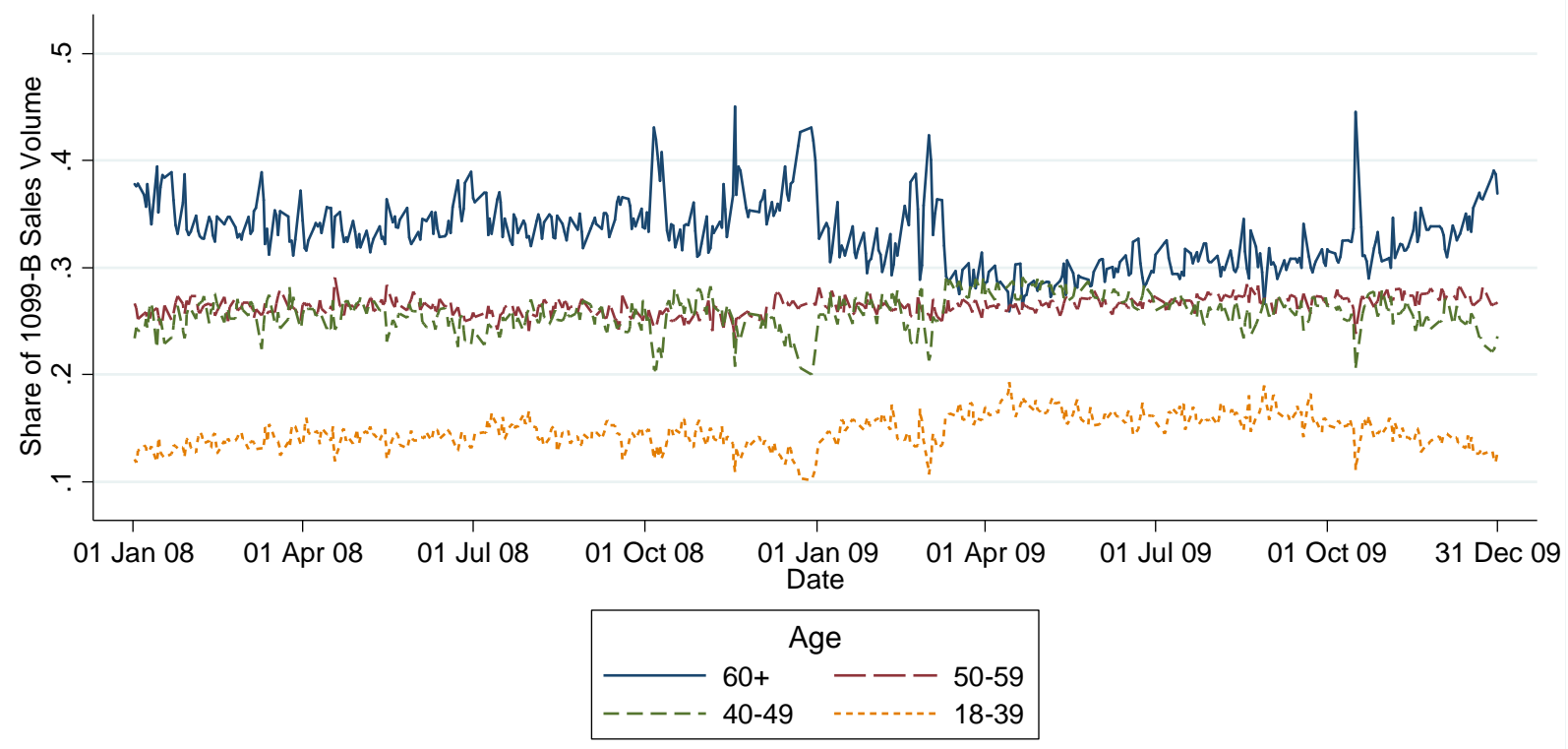

Panel B. 2008-2009, Normalized by Average Share of Trading Volume from 2008-2009

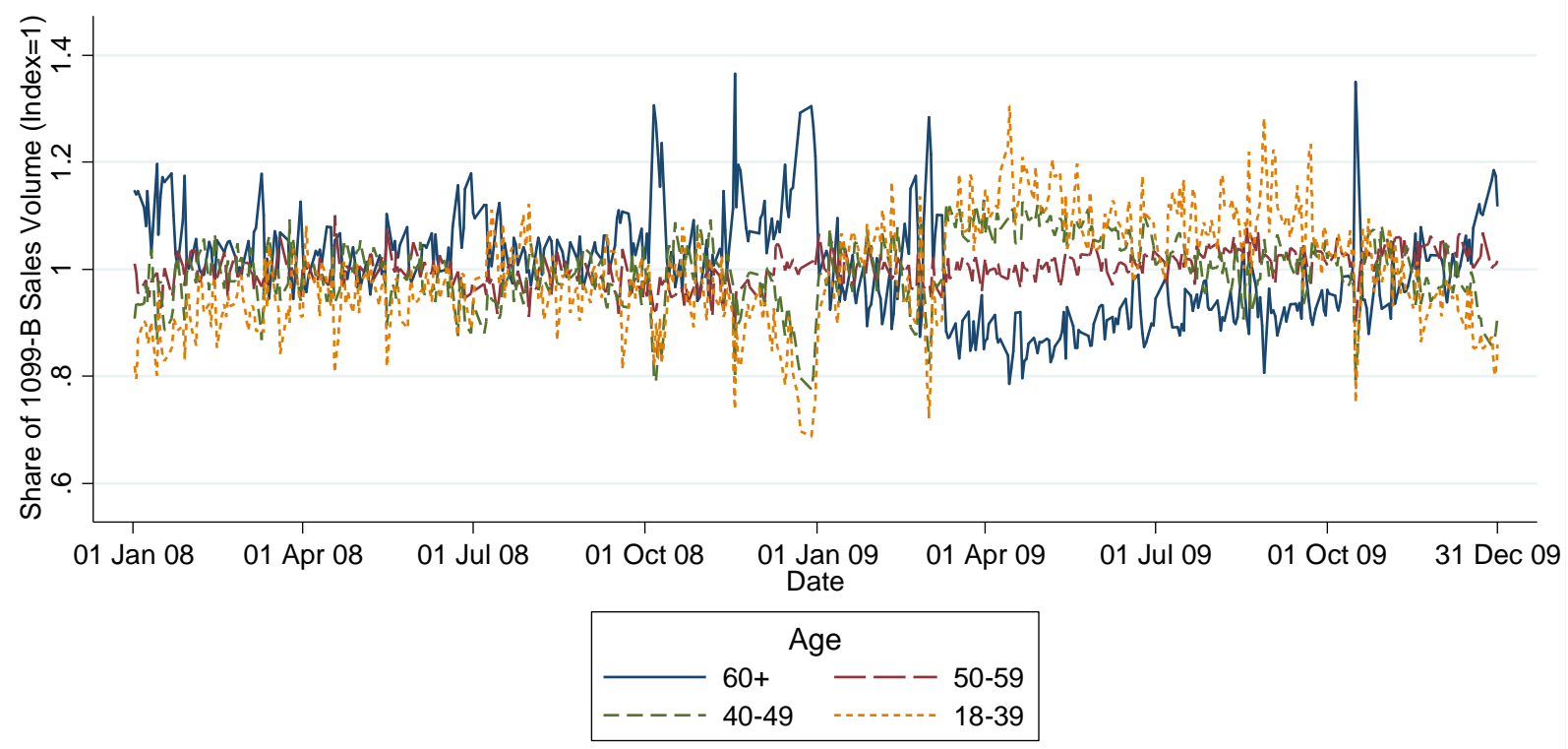


Figure VI

Share of 1099-B Sales Volume, Taxpayers Receiving Social Security Income, 2008-2009

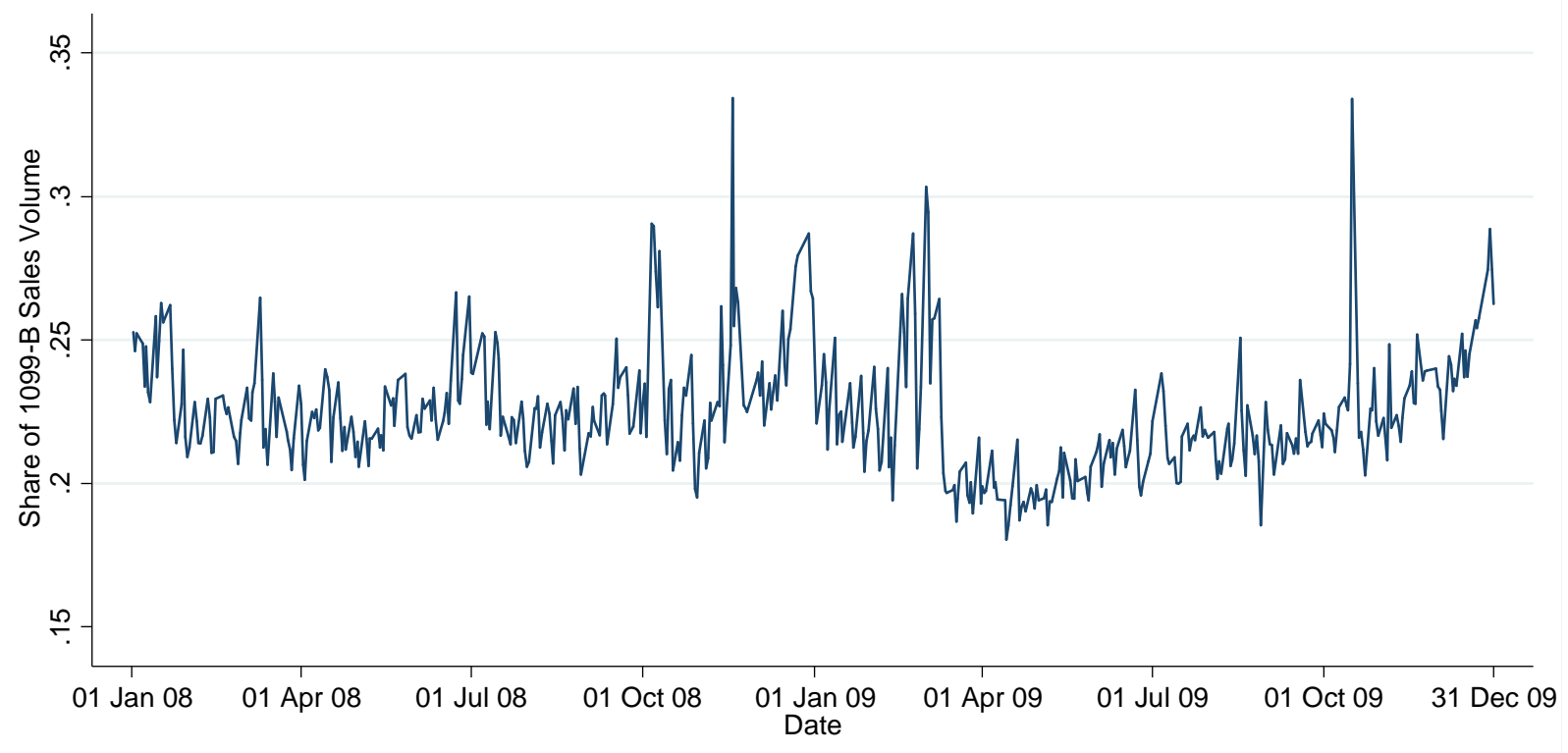


Figure VII

Shares of 1099-B Sales Volume by Average Dividend Income Percentiles

Panel A. 2008-2009

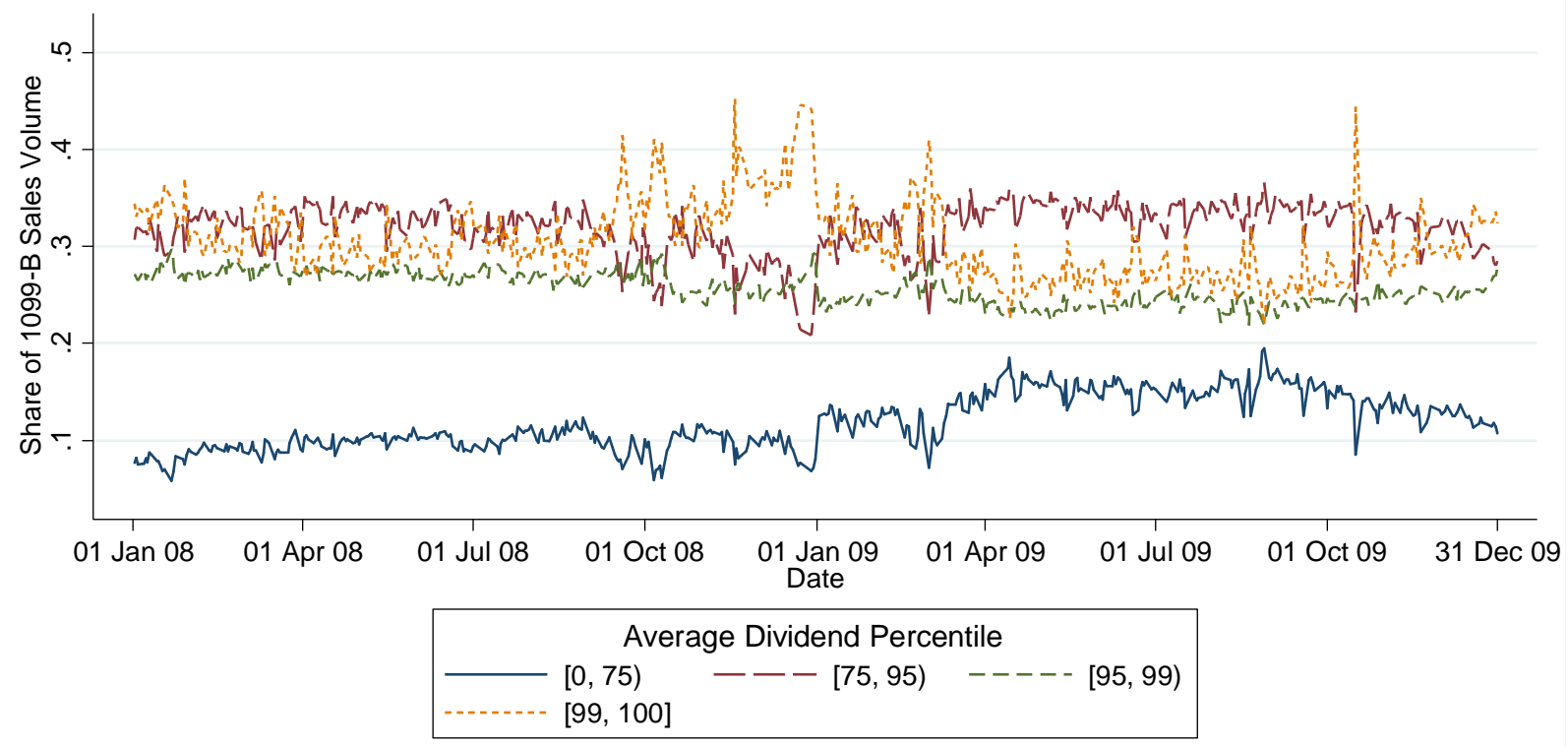

Panel B. 2008-2009, Normalized by Average Share of Trading Volume from 2008-2009

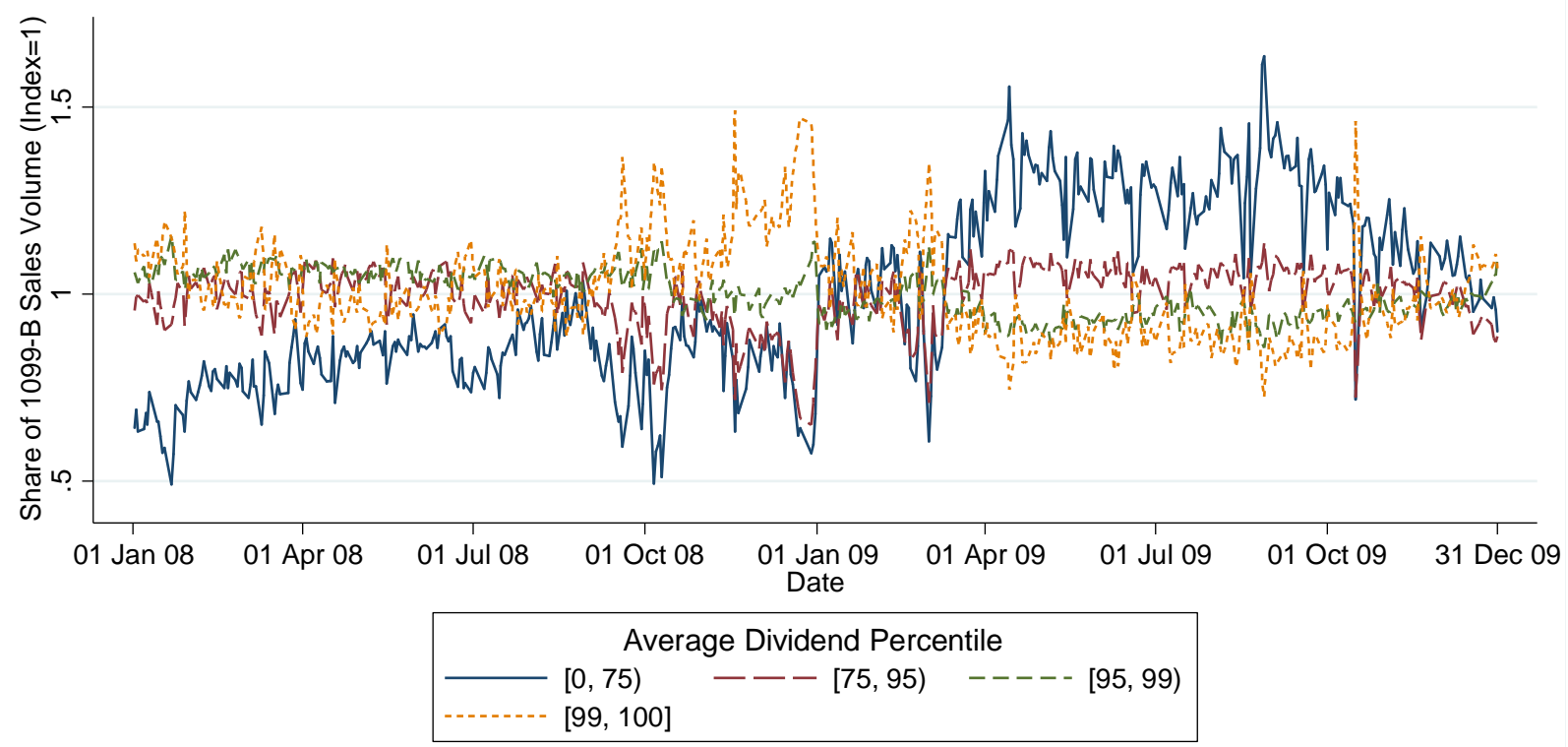


Figure VIII

Share of 1099-B Sales Volume, Taxpayers Receiving Positive Partnership or S-Corporation Income before 2008

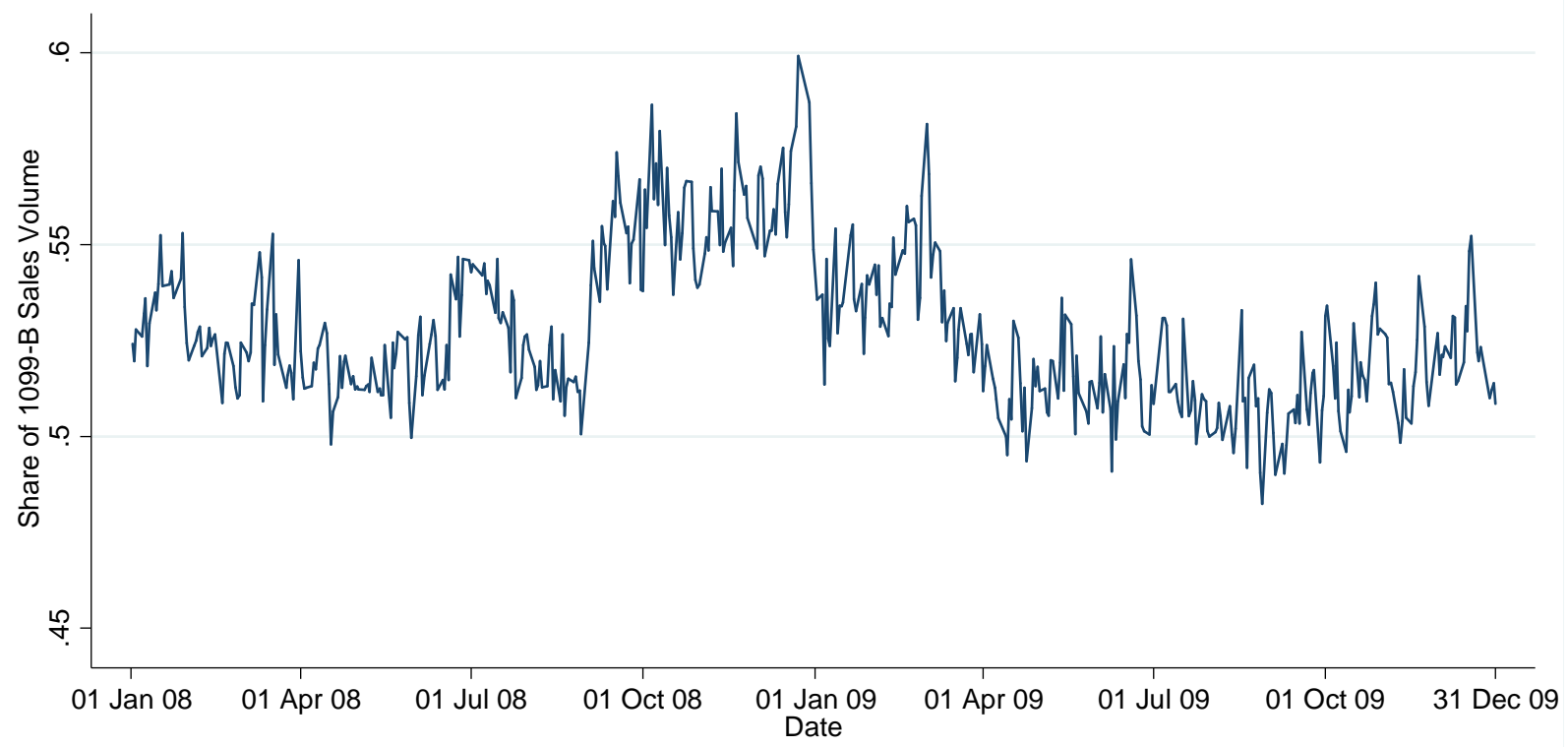




\section{Figure IV}

Heterogeneity by Income and Age in Sales Response to Market Tumult

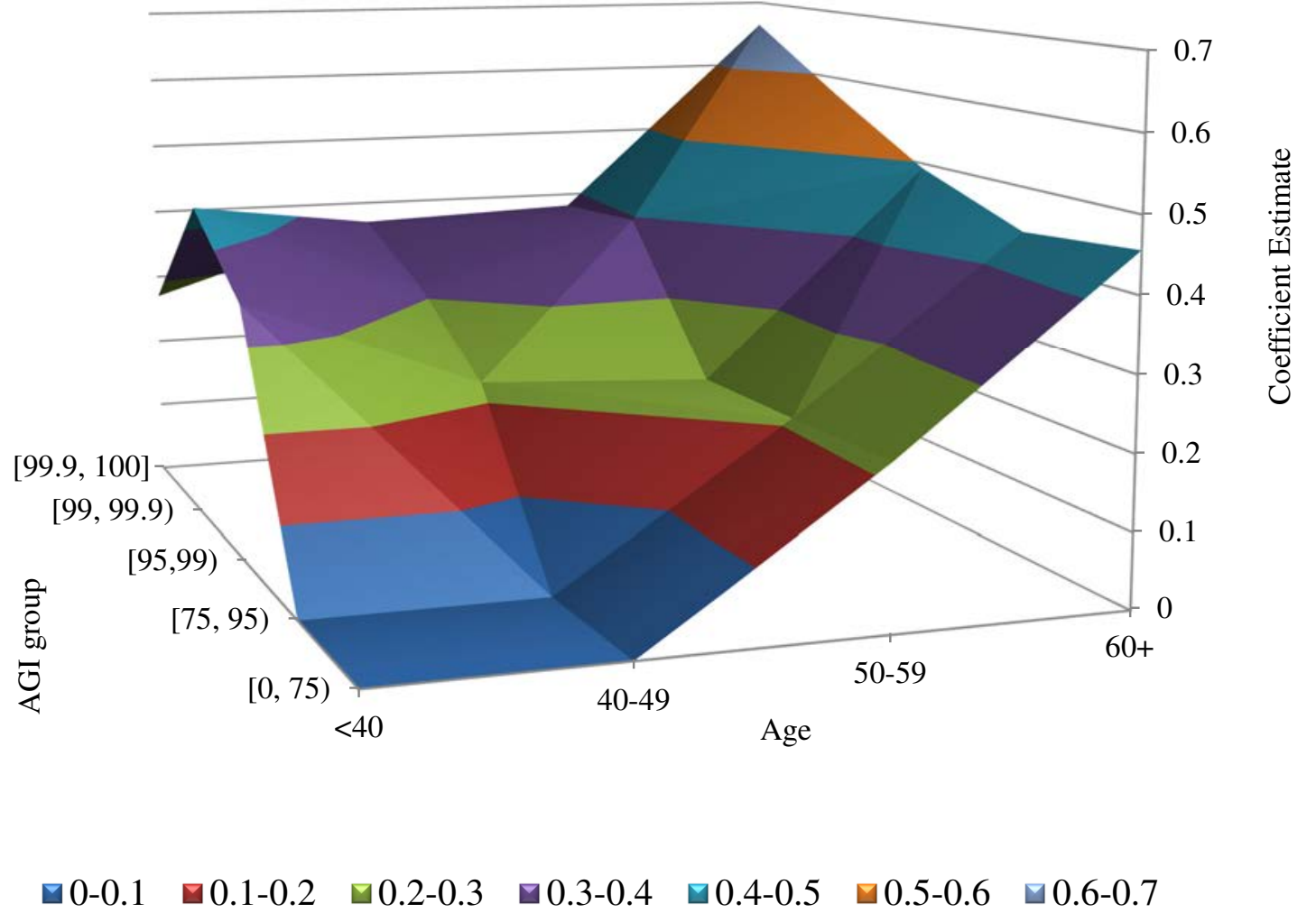

Notes. This graph depicts the coefficients in the regressions documented in Panel A of Table VIII. 
Figure $\mathrm{X}$

Share of Wealth in Taxable Accounts by Income and Age

Panel A. By Income Group

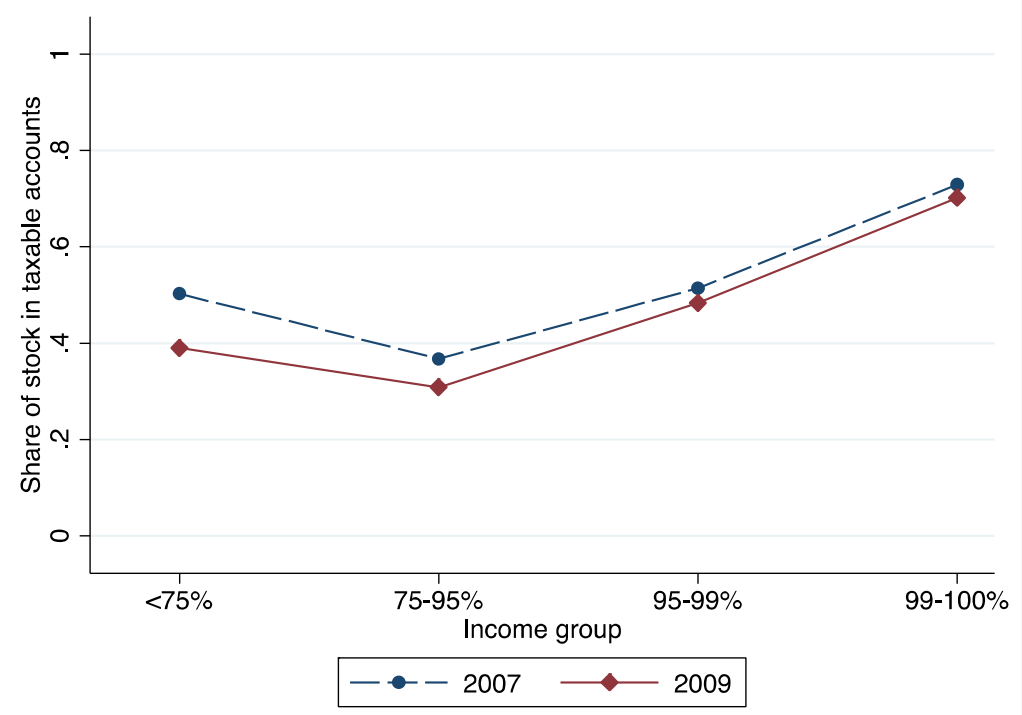

Panel B. By Age Group

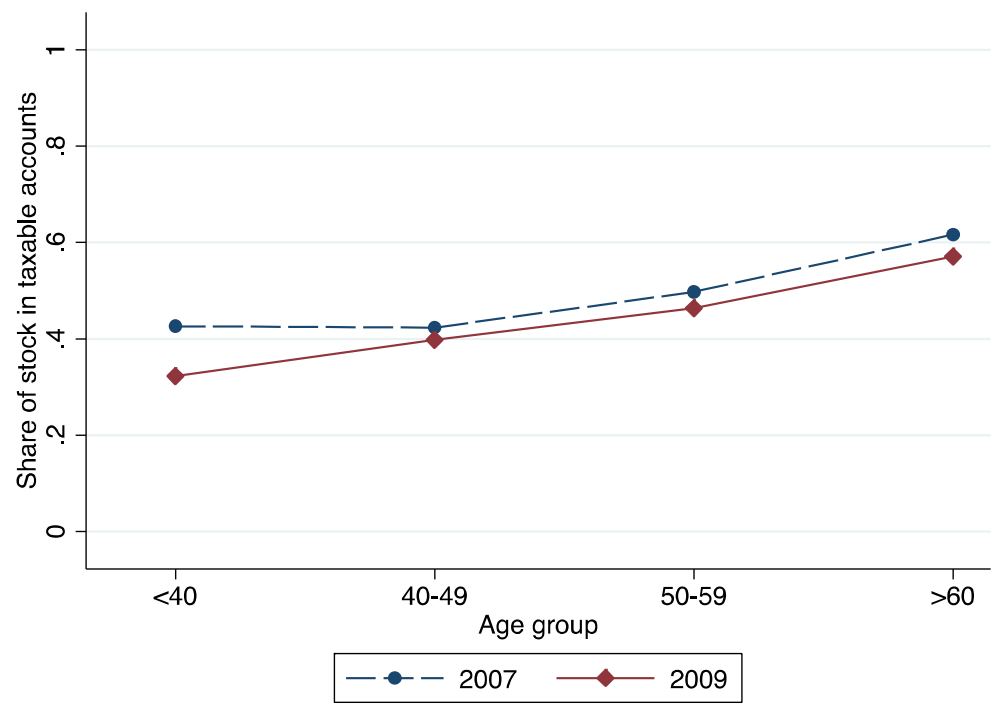

Notes. The data for this analysis come from the 2007-2009 panel of the Survey of Consumer Finance. Income groups and age groups are defined based on income and age reported in the 2007 wave of the survey. We calculate the shares by dividing the total equities (stocks and mutual funds) held in taxable accounts in each group by the total equities held in any account in the same group. 


\section{Figure 11}

\section{Shares of Individual 1099-B Stock Sales by Sector}

Panel A. Shares in Fama-French 12-Industry Classification of Stocks, 2008-2009

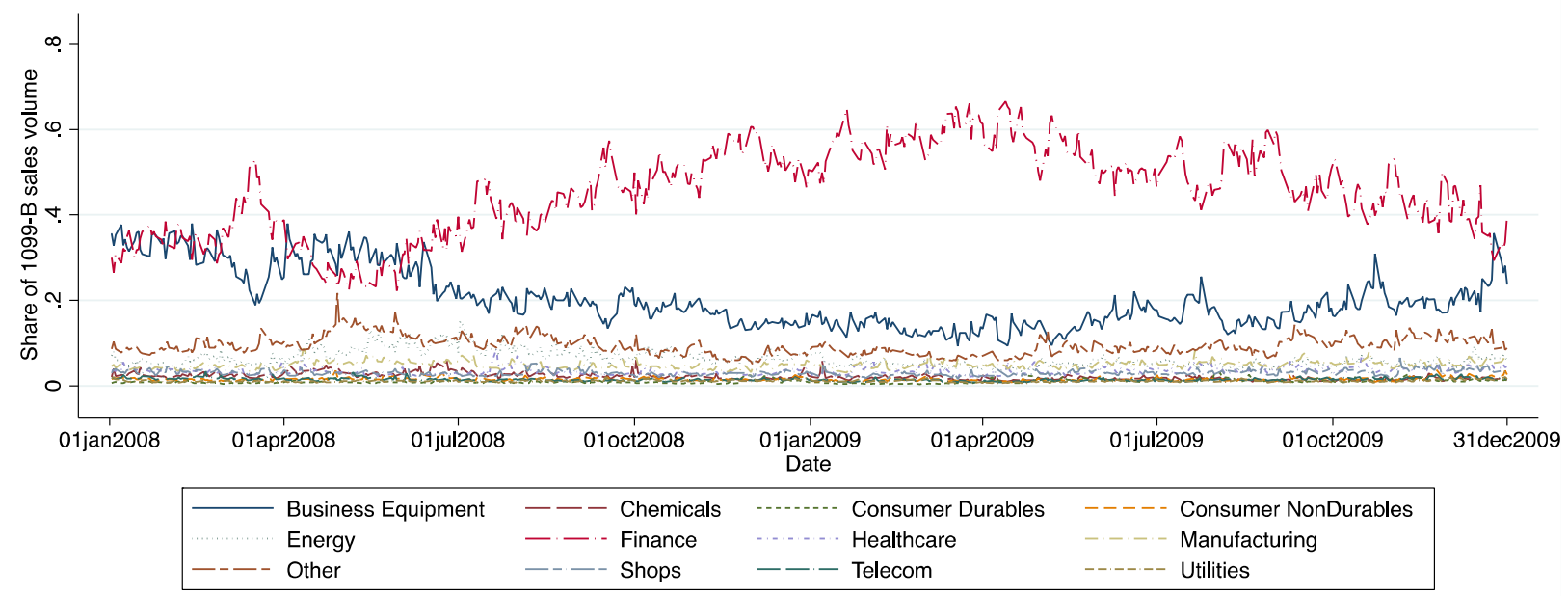

Panel B. Shares in Financial Sectors and Selected Non-Finance Sectors, 2008-2009

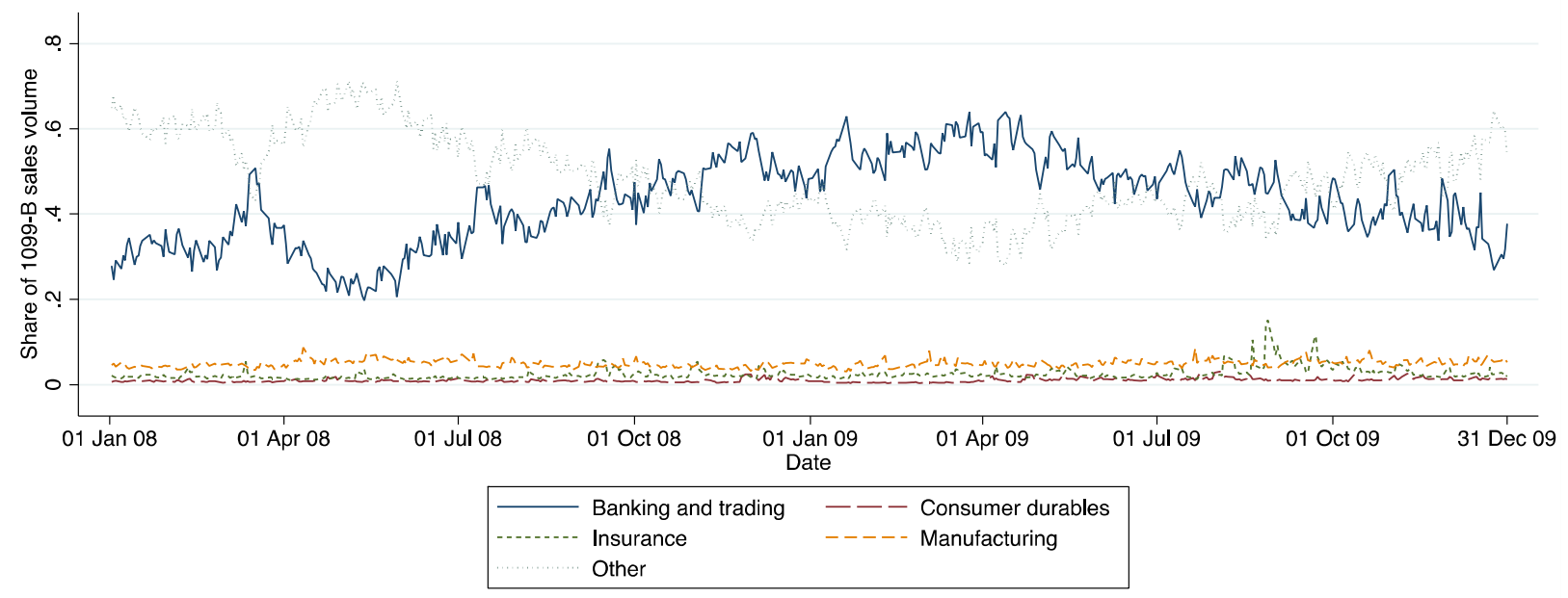


Panel C. Shares in Financial Sectors and Selected Non-Finance Sectors, 2008-2009, Normalized

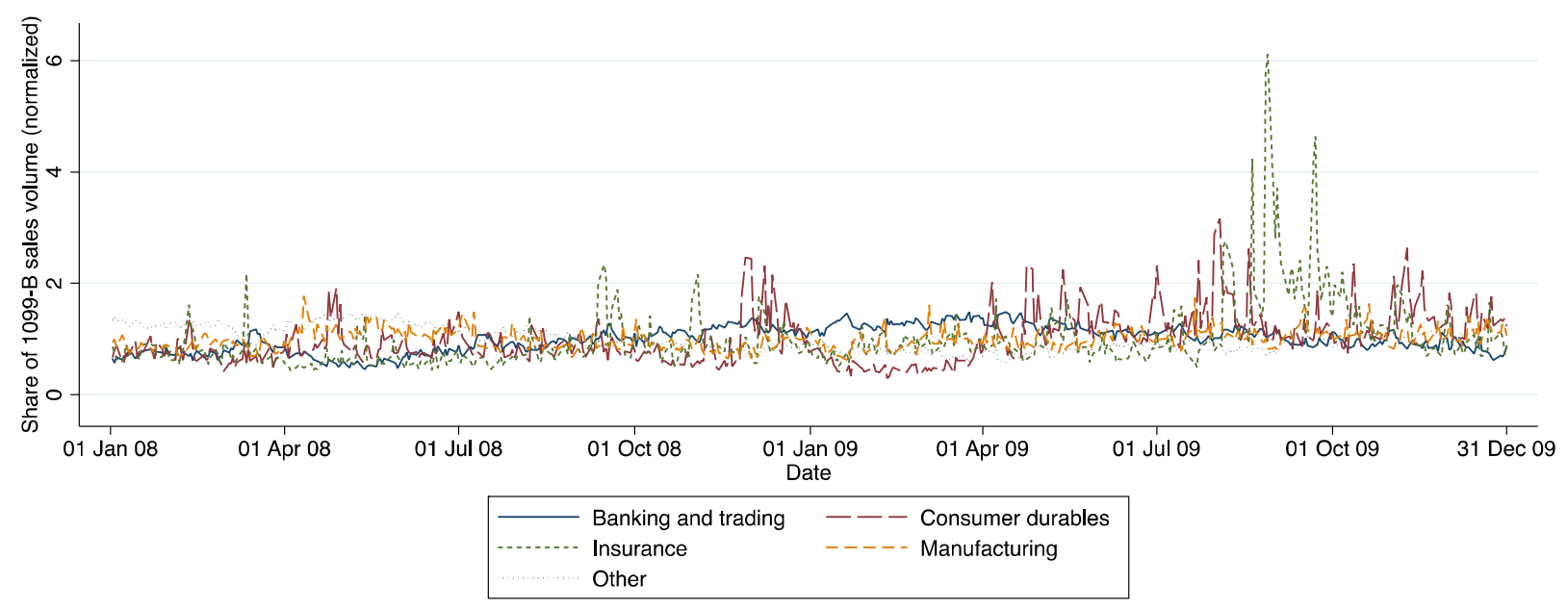


Figure XII. Sales of Stock versus Sales of Mutual Funds

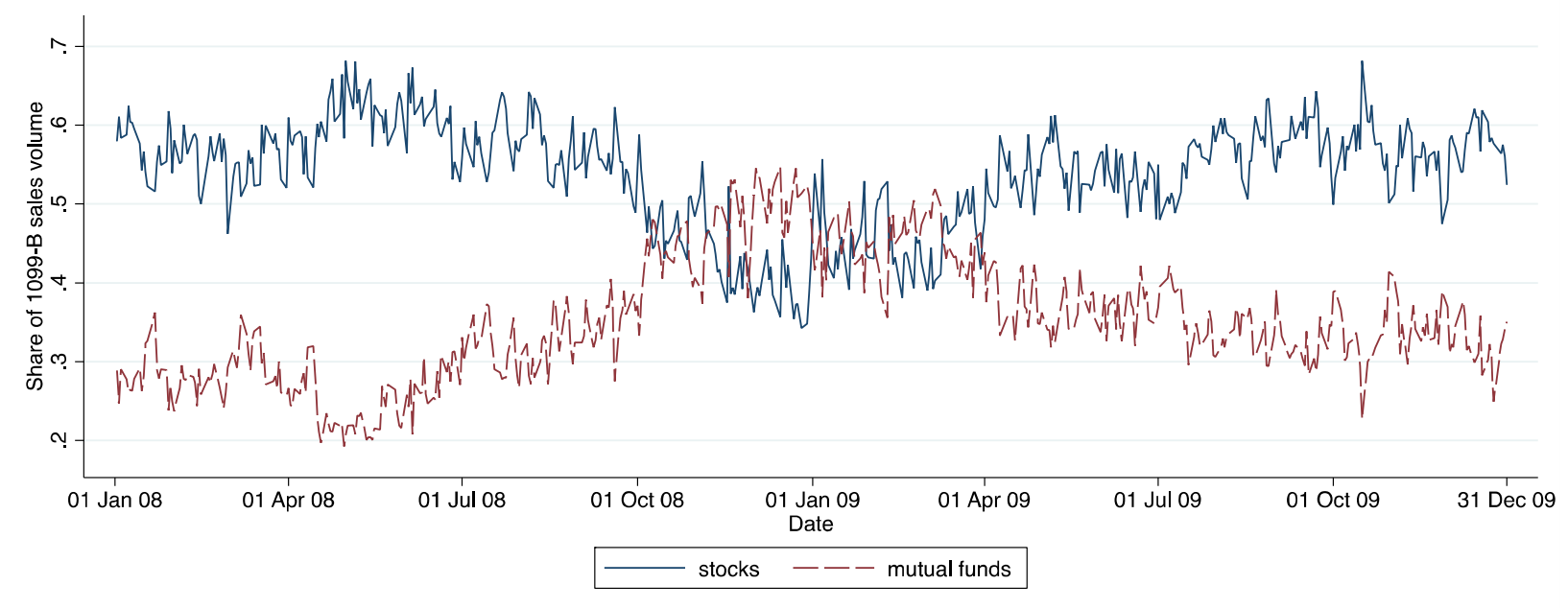




\section{Online Appendix - Not for Publication \\ Figure A.1}

\section{Shares of 1099-B Sales Volume by Average Pre-Tax Income Percentiles}

Panel A. Daily Shares, 2008-2009

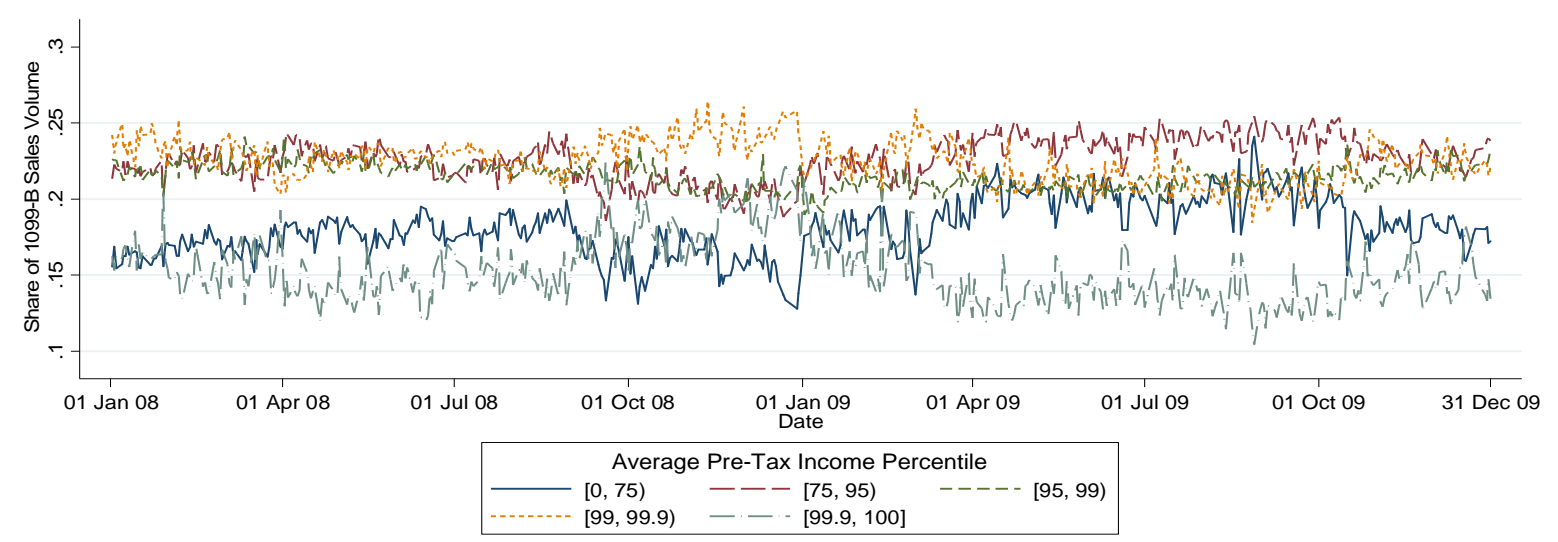

Panel B. Daily Shares, 2008-2009, Normalized by Average Share of Trading Volume from 20082009

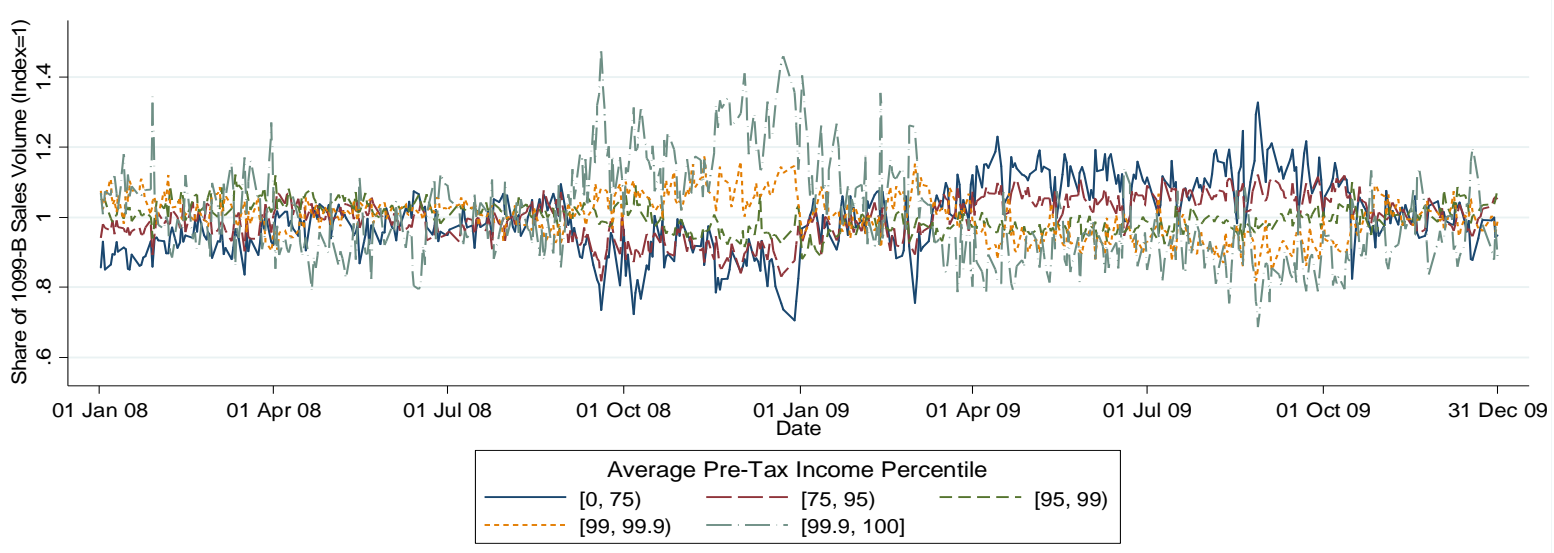


Table A.1. Summary Statistics

\begin{tabular}{|c|c|c|c|c|c|c|c|c|}
\hline & \multicolumn{4}{|c|}{$2008-2009$} & \multicolumn{4}{|c|}{ September-November 2008} \\
\hline & Mean & SD & Minimum & Maximum & Mean & $\mathrm{SD}$ & Minimum & Maximum \\
\hline Log sales volume, CRSP, millions USD & 12.330 & 0.250 & 11.477 & 13.300 & 12.598 & 0.245 & 12.069 & 13.300 \\
\hline Log sales volume, 1099-B, millions USD & 9.491 & 0.206 & 8.976 & 10.308 & 9.661 & 0.240 & 9.326 & 10.308 \\
\hline Log number of transactors, $100 \mathrm{k}$ & 1.444 & 0.151 & 1.078 & 2.045 & 1.511 & 0.181 & 1.236 & 2.045 \\
\hline Log average volume per transactor, USD & 10.350 & 0.153 & 9.700 & 10.738 & 10.453 & 0.098 & 10.260 & 10.690 \\
\hline Log ratio, 1099-B to CRSP volume & -2.839 & 0.163 & -3.253 & -2.178 & -2.937 & 0.139 & -3.253 & -2.667 \\
\hline Ratio, 1099-B to CRSP volume & 0.059 & 0.010 & 0.039 & 0.113 & 0.054 & 0.007 & 0.039 & 0.069 \\
\hline Log sales volume, average AGI & 21.678 & 0.285 & 20.676 & 22.701 & 21.854 & 0.284 & 21.308 & 22.701 \\
\hline Log sales volume, average income & 21.679 & 0.282 & 20.725 & 22.706 & 21.853 & 0.289 & 21.290 & 22.706 \\
\hline Log sales volume, age & 21.877 & 0.366 & 20.852 & 23.202 & 22.038 & 0.407 & 21.128 & 23.202 \\
\hline Log sales volume, social security & 22.430 & 0.662 & 21.215 & 23.853 & 22.613 & 0.656 & 21.636 & 23.853 \\
\hline Log sales volume, average dividend receipt & 21.840 & 0.470 & 20.474 & 23.243 & 21.979 & 0.562 & 20.749 & 23.243 \\
\hline Log sales volume, partnership and S-corporation income & 22.610 & 0.216 & 22.072 & 23.544 & 22.776 & 0.263 & 22.332 & 23.544 \\
\hline 1 day lagged difference, log VIX & 0.000 & 0.068 & -0.283 & 0.296 & 0.018 & 0.114 & -0.283 & 0.296 \\
\hline 1 day lagged difference, VIX & 0.000 & 0.029 & -0.174 & 0.165 & 0.007 & 0.063 & -0.174 & 0.165 \\
\hline Log VIX & -1.208 & 0.359 & -1.814 & -0.212 & -0.737 & 0.389 & -1.540 & -0.212 \\
\hline VIX & 0.321 & 0.132 & 0.163 & 0.809 & 0.512 & 0.174 & 0.214 & 0.809 \\
\hline
\end{tabular}


Table A.2. Total Sales Volume, Coverage Rates, Number of Transactors, and Market Tumult

\begin{tabular}{|c|c|c|c|c|c|}
\hline & \multicolumn{5}{|c|}{ Dependent variable: } \\
\hline & $\begin{array}{l}\text { Log sales } \\
\text { volume, } \\
\text { CRSP, } \\
\text { millions } \\
\text { USD } \\
\quad(1)\end{array}$ & $\begin{array}{l}\text { Log sales } \\
\text { volume, } \\
\text { 1099-B, } \\
\text { millions } \\
\text { USD } \\
\quad(2)\end{array}$ & $\begin{array}{l}\text { Ratio of } \\
\text { 1099-B to } \\
\text { CRSP sales } \\
\text { volume } \\
\quad(3)\end{array}$ & $\begin{array}{l}\text { Log } \\
\text { number of } \\
\text { transactors, } \\
\text { 100k } \\
\quad \text { (4) }\end{array}$ & $\begin{array}{l}\text { Log } \\
\text { average } \\
\text { volume per } \\
\text { transactor, } \\
\text { USD } \\
\quad(5)\end{array}$ \\
\hline $\begin{array}{l}1 \text { day lagged } \\
\text { difference of log VIX }\end{array}$ & $\begin{array}{c}0.541 * * * \\
(0.156)\end{array}$ & $\begin{array}{c}0.346 * * \\
(0.135)\end{array}$ & $\begin{array}{c}-0.013 * * \\
(0.005)\end{array}$ & $\begin{array}{c}0.132 \\
(0.090)\end{array}$ & $\begin{array}{l}0.214 * * * \\
(0.076)\end{array}$ \\
\hline Observations & 498 & 498 & 498 & 498 & 498 \\
\hline R-squared & 0.02 & 0.01 & 0.01 & 0.00 & 0.01 \\
\hline
\end{tabular}

Notes: The regressand in column 4 is the natural log of the number of transactors divided by 100,000 , i.e. $\log (\mathrm{N} / 100000)$. Newey-West standard errors with a maximum of 10 -day lag orders of autocorrelation are reported in parentheses. $* * * \mathrm{p}<0.01, * * \mathrm{p}<0.05, * \mathrm{p}<0.1$

Table A.3. Correlation of 1-day Lagged Log VIX Differences

\begin{tabular}{|c|c|c|c|c|c|c|c|c|c|c|}
\hline \multicolumn{11}{|c|}{ Correlation between 1-day lagged difference of log VIX } \\
\hline & 1 & 2 & 3 & 4 & 5 & 6 & 7 & 8 & 9 & 10 \\
\hline 1 & 1.000 & & & & & & & & & \\
\hline 2 & $-0.179 *$ & 1.000 & & & & & & & & \\
\hline 3 & -0.070 & $-0.178^{*}$ & 1.000 & & & & & & & \\
\hline 4 & 0.006 & -0.070 & $-0.178^{*}$ & 1.000 & & & & & & \\
\hline 5 & -0.054 & 0.006 & -0.069 & $-0.178^{*}$ & 1.000 & & & & & \\
\hline 6 & $0.108^{*}$ & -0.055 & 0.002 & -0.069 & $-0.178^{*}$ & 1.000 & & & & \\
\hline 7 & -0.060 & $0.108 *$ & -0.056 & 0.003 & -0.069 & $-0.176^{*}$ & 1.000 & & & \\
\hline 8 & -0.032 & -0.060 & $0.106^{*}$ & -0.056 & 0.003 & -0.068 & $-0.176^{*}$ & 1.000 & & \\
\hline 9 & 0.002 & -0.033 & -0.063 & $0.106^{*}$ & -0.057 & 0.008 & -0.064 & $-0.173^{*}$ & 1.000 & \\
\hline 10 & 0.020 & 0.002 & -0.031 & -0.063 & $0.106^{*}$ & -0.060 & 0.006 & -0.066 & $-0.173^{*}$ & 1.000 \\
\hline
\end{tabular}

Notes: The first column relates to the difference of days $\mathrm{t}-1$ and $\mathrm{t}-2$, the second column for days $\mathrm{t}-2$ and $\mathrm{t}-3$, and so on. Stars indicate significance at the 5 -percent level or better. 
Table A.4. Heterogeneity by Income in Sales Response to Market Tumult, Comparison of Log VIX and VIX

\begin{tabular}{|c|c|c|c|c|}
\hline \multicolumn{5}{|c|}{$\begin{array}{l}\text { Dependent variable: } \log 1099-\mathrm{B} \text { sales volume, USD } \\
\text { Reported coefficient: interaction between change in VIX and average AGI percentile indicator }\end{array}$} \\
\hline & \multicolumn{4}{|c|}{ Sample Period } \\
\hline \multirow{3}{*}{1 day lagged difference of: } & \multicolumn{2}{|c|}{$2008-2009$} & \multicolumn{2}{|c|}{ September - November 2008} \\
\hline & Log VIX & VIX & Log VIX & VIX \\
\hline & $(1)$ & (2) & (3) & (4) \\
\hline \multirow[t]{2}{*}[99.9,100]{} & $0.327 * * *$ & $0.707 * *$ & $0.224 * *$ & $0.509 * * *$ \\
\hline & $(0.110)$ & $(0.287)$ & $(0.103)$ & $(0.144)$ \\
\hline \multirow[t]{2}{*}{$99,99.9$} & $0.255^{* * *}$ & $0.536 * * *$ & $0.147 * *$ & $0.328 * * *$ \\
\hline & $(0.072)$ & $(0.187)$ & $(0.072)$ & $(0.108)$ \\
\hline \multirow[t]{2}{*}{95,99} & $0.146^{* *}$ & $0.353 *$ & $0.152 *$ & $0.293 * *$ \\
\hline & $(0.071)$ & $(0.182)$ & $(0.080)$ & $(0.128)$ \\
\hline \multirow[t]{2}{*}{75,95} & 0.076 & 0.201 & 0.100 & $0.199 *$ \\
\hline & $(0.077)$ & $(0.200)$ & $(0.066)$ & $(0.102)$ \\
\hline Group-day observations & 2,490 & 2,490 & 310 & 310 \\
\hline R-squared & 0.91 & 0.91 & 0.96 & 0.96 \\
\hline
\end{tabular}

Notes: All regressions include day and income-group fixed effects. The 1-day lagged difference is the difference between the lagged and twice lagged value (t-1 and $\mathrm{t}-2)$. Omitted category is taxpayers with an average income in $[0,75)$. Newey-West standard errors (10-day lag) in parentheses. $* * * \mathrm{p}<0.01, * * \mathrm{p}<0.05, *$ $\mathrm{p}<0.1$ 
Table A.5. Heterogeneity by Income in Sales Response to Market Tumult, Comparison of 1 day lagged difference in Log VIX with Negative Market Return

\begin{tabular}{|c|c|c|c|c|c|c|}
\hline \multicolumn{7}{|c|}{ Dependent variable: $\log 1099-\mathrm{B}$ sales volume, USD } \\
\hline & \multicolumn{6}{|c|}{ Sample Period } \\
\hline & \multicolumn{3}{|c|}{$2008-2009$} & \multicolumn{3}{|c|}{ September - November 2008} \\
\hline & (1) & (2) & (3) & (4) & (5) & (6) \\
\hline \multicolumn{7}{|c|}{1 day lagged difference of log VIX (normalized) } \\
\hline$[99.9,100]$ & $\begin{array}{c}0.022 * * * * \\
(0.008)\end{array}$ & & $\begin{array}{l}-0.023 \\
(0.014)\end{array}$ & $\begin{array}{c}0.015^{* *} \\
(0.007)\end{array}$ & & $\begin{array}{l}-0.008 \\
(0.014)\end{array}$ \\
\hline$[99,99.9)$ & $\begin{array}{c}0.017 * * * \\
(0.005)\end{array}$ & & $\begin{array}{l}-0.009 \\
(0.010)\end{array}$ & $\begin{array}{c}0.010^{* *} \\
(0.005)\end{array}$ & & $\begin{array}{l}-0.001 \\
(0.012)\end{array}$ \\
\hline$[95,99)$ & $\begin{array}{c}0.010 * * \\
(0.005)\end{array}$ & & $\begin{array}{l}-0.013 \\
(0.009)\end{array}$ & $\begin{array}{l}0.010^{*} \\
(0.005)\end{array}$ & & $\begin{array}{l}-0.001 \\
(0.011)\end{array}$ \\
\hline$[75,95)$ & $\begin{array}{c}0.005 \\
(0.005)\end{array}$ & & $\begin{array}{l}-0.006 \\
(0.010)\end{array}$ & $\begin{array}{c}0.007 \\
(0.005)\end{array}$ & & $\begin{array}{l}-0.004 \\
(0.011)\end{array}$ \\
\hline \multicolumn{7}{|c|}{ Negative 1 day lagged market return (normalized) } \\
\hline$[99.9,100]$ & & $\begin{array}{c}0.038 * * * \\
(0.008)\end{array}$ & $\begin{array}{c}0.056 * * * \\
(0.016)\end{array}$ & & $\begin{array}{c}0.017 * * * \\
(0.006)\end{array}$ & $\begin{array}{l}0.023^{*} \\
(0.012)\end{array}$ \\
\hline$[99,99.9)$ & & $\begin{array}{c}0.026 * * * \\
(0.006)\end{array}$ & $\begin{array}{c}0.033 * * * \\
(0.011)\end{array}$ & & $\begin{array}{c}0.010^{* *} \\
(0.004)\end{array}$ & $\begin{array}{c}0.011 \\
(0.010)\end{array}$ \\
\hline$[95,99)$ & & $\begin{array}{c}0.018 * * * \\
(0.005)\end{array}$ & $\begin{array}{c}0.029 * * * \\
(0.010)\end{array}$ & & $\begin{array}{c}0.010^{* *} \\
(0.005)\end{array}$ & $\begin{array}{c}0.011 \\
(0.009)\end{array}$ \\
\hline$[75,95)$ & & $\begin{array}{c}0.009 \\
(0.006)\end{array}$ & $\begin{array}{c}0.014 \\
(0.012)\end{array}$ & & $\begin{array}{l}0.007 * \\
(0.004)\end{array}$ & $\begin{array}{c}0.010 \\
(0.009)\end{array}$ \\
\hline Group-day observations & 2,490 & 2,490 & 2,490 & 310 & 310 & 310 \\
\hline R-squared & 0.91 & 0.92 & 0.92 & 0.96 & 0.96 & 0.96 \\
\hline
\end{tabular}

Notes: Both the 1-day lagged difference of log VIX and the negative 1-day lagged market return are normalized to have mean zero and standard deviation one over 2008-2009. All regressions include day and income-group fixed effects. Omitted category is taxpayers with average AGI in [0, 75). Newey-West standard errors (10-day lag) in parentheses. $* * * \mathrm{p}<0.01, * * \mathrm{p}<0.05, * \mathrm{p}<0.1$ 
Table A.6. Lag Structure of Heterogeneity by Income in Sales Response to Market Tumult, 2008-2009

\begin{tabular}{|c|c|c|c|c|c|}
\hline \multicolumn{6}{|c|}{$\begin{array}{c}\text { Dependent variable: } \log 1099 \text {-B sales volume, USD } \\
\text { Reported coefficient: interaction between lagged difference of log VIX and } \\
\text { average AGI percentile indicator }\end{array}$} \\
\hline & & {$[75,95)$} & {$[95,99)$} & {$[99,99.9)$} & {$[99.9,100]$} \\
\hline \multirow[t]{10}{*}{ Leads } & $(t+5)-(t+4)$ & 0.002 & 0.036 & 0.009 & 0.114 \\
\hline & & $(0.091)$ & $(0.080)$ & $(0.084)$ & $(0.131)$ \\
\hline & $(t+4)-(t+3)$ & 0.024 & 0.027 & -0.013 & 0.109 \\
\hline & & $(0.102)$ & $(0.090)$ & $(0.093)$ & $(0.151)$ \\
\hline & $(\mathrm{t}+3)-(\mathrm{t}+2)$ & 0.002 & 0.006 & -0.050 & -0.046 \\
\hline & & (0.109) & $(0.096)$ & $(0.101)$ & $(0.157)$ \\
\hline & $(t+2)-(t+1)$ & -0.002 & 0.042 & 0.007 & 0.029 \\
\hline & & $(0.115)$ & (0.104) & $(0.110)$ & $(0.168)$ \\
\hline & $(\mathrm{t}+1)-(\mathrm{t})$ & -0.001 & 0.017 & -0.002 & -0.047 \\
\hline & & $(0.120)$ & (0.109) & $(0.114)$ & $(0.173)$ \\
\hline \multirow[t]{15}{*}{ Lags } & $(\mathrm{t})-(\mathrm{t}-1)$ & 0.061 & $0.249 * *$ & $0.395 * * *$ & $0.422 * *$ \\
\hline & & $(0.115)$ & $(0.106)$ & $(0.111)$ & $(0.164)$ \\
\hline & $(\mathrm{t}-1)-(\mathrm{t}-2)$ & 0.098 & $0.222 * *$ & $0.370 * * *$ & $0.448 * * *$ \\
\hline & & (0.118) & $(0.107)$ & (0.111) & $(0.166)$ \\
\hline & $(\mathrm{t}-2)-(\mathrm{t}-3)$ & 0.113 & $0.220 *$ & $0.289 * *$ & 0.396 ** \\
\hline & & (0.129) & (0.114) & $(0.118)$ & $(0.190)$ \\
\hline & $(\mathrm{t}-3)-(\mathrm{t}-4)$ & 0.057 & $0.192 *$ & $0.223^{*}$ & $0.329 *$ \\
\hline & & $(0.130)$ & $(0.117)$ & $(0.122)$ & $(0.188)$ \\
\hline & $(t-4)-(t-5)$ & 0.079 & $0.207 *$ & $0.257 * *$ & $0.419^{* *}$ \\
\hline & & $(0.136)$ & $(0.122)$ & $(0.125)$ & $(0.205)$ \\
\hline & $(t-5)-(t-6)$ & 0.060 & 0.169 & $0.255^{* *}$ & $0.390^{* *}$ \\
\hline & & $(0.124)$ & $(0.112)$ & $(0.117)$ & $(0.178)$ \\
\hline & $(\mathrm{t}-6)-(\mathrm{t}-7)$ & 0.072 & 0.150 & $0.174^{*}$ & $0.319^{*}$ \\
\hline & & $(0.111)$ & $(0.103)$ & (0.104) & $(0.169)$ \\
\hline & $(\mathrm{t}-7)-(\mathrm{t}-8)$ & 0.030 & 0.138 & 0.153 & $0.304^{* *}$ \\
\hline
\end{tabular}




\begin{tabular}{|c|c|c|c|c|}
\hline & $(0.101)$ & $(0.092)$ & $(0.093)$ & $(0.153)$ \\
\hline \multirow[t]{2}{*}{$(\mathrm{t}-8)-(\mathrm{t}-9)$} & 0.074 & $0.182^{*}$ & $0.196^{* *}$ & $0.405^{* * *}$ \\
\hline & $(0.103)$ & $(0.094)$ & $(0.097)$ & $(0.156)$ \\
\hline \multirow[t]{2}{*}{$(\mathrm{t}-9)-(\mathrm{t}-10)$} & 0.054 & $0.170^{*}$ & $0.162^{*}$ & $0.288^{*}$ \\
\hline & $(0.107)$ & $(0.096)$ & $(0.098)$ & $(0.157)$ \\
\hline \multirow[t]{2}{*}{$(\mathrm{t}-10)-(\mathrm{t}-11)$} & 0.084 & $0.194 * *$ & $0.197 * *$ & $0.337 * *$ \\
\hline & $(0.093)$ & $(0.086)$ & $(0.089)$ & $(0.136)$ \\
\hline \multirow[t]{2}{*}{$(\mathrm{t}-11)-(\mathrm{t}-12)$} & 0.071 & $0.213^{* *}$ & $0.236 * *$ & $0.376^{* * * *}$ \\
\hline & $(0.101)$ & $(0.093)$ & $(0.096)$ & $(0.142)$ \\
\hline \multirow[t]{2}{*}{$(\mathrm{t}-12)-(\mathrm{t}-13)$} & 0.024 & 0.117 & 0.139 & $0.300 * *$ \\
\hline & $(0.092)$ & $(0.086)$ & $(0.089)$ & $(0.132)$ \\
\hline \multirow[t]{2}{*}{$(\mathrm{t}-13)-(\mathrm{t}-14)$} & 0.025 & 0.144 & $0.167^{*}$ & $0.362 * *$ \\
\hline & $(0.096)$ & $(0.088)$ & $(0.091)$ & $(0.141)$ \\
\hline \multirow[t]{2}{*}{$(\mathrm{t}-14)-(\mathrm{t}-15)$} & 0.047 & $0.165^{*}$ & $0.178^{*}$ & $0.391 * * *$ \\
\hline & $(0.100)$ & $(0.092)$ & $(0.094)$ & $(0.144)$ \\
\hline \multirow[t]{2}{*}{$(\mathrm{t}-15)-(\mathrm{t}-16)$} & 0.041 & $0.179 * *$ & $0.177 * *$ & $0.371 * * *$ \\
\hline & $(0.091)$ & $(0.084)$ & $(0.084)$ & $(0.135)$ \\
\hline \multirow[t]{2}{*}{$(\mathrm{t}-16)-(\mathrm{t}-17)$} & 0.055 & $0.186^{* *}$ & $0.148^{*}$ & $0.287 * *$ \\
\hline & $(0.092)$ & $(0.083)$ & $(0.086)$ & $(0.133)$ \\
\hline \multirow[t]{2}{*}{$(\mathrm{t}-17)-(\mathrm{t}-18)$} & 0.043 & $0.148^{*}$ & $0.152^{*}$ & $0.255^{* *}$ \\
\hline & $(0.092)$ & $(0.084)$ & $(0.087)$ & $(0.130)$ \\
\hline \multirow[t]{2}{*}{$(\mathrm{t}-18)-(\mathrm{t}-19)$} & 0.052 & 0.102 & 0.081 & 0.171 \\
\hline & $(0.097)$ & $(0.087)$ & $(0.088)$ & $(0.144)$ \\
\hline \multirow[t]{2}{*}{$(\mathrm{t}-19)-(\mathrm{t}-20)$} & 0.051 & $0.172 *$ & $0.155^{*}$ & $0.256^{*}$ \\
\hline & $(0.101)$ & $(0.089)$ & $(0.091)$ & $(0.149)$ \\
\hline \multirow[t]{2}{*}{$(\mathrm{t}-20)-(\mathrm{t}-21)$} & 0.051 & $0.150^{*}$ & $0.153^{*}$ & $0.361 * * *$ \\
\hline & $(0.095)$ & $(0.087)$ & $(0.091)$ & $(0.131)$ \\
\hline \multirow[t]{2}{*}{$(\mathrm{t}-21)-(\mathrm{t}-22)$} & 0.051 & $0.165^{* *}$ & $0.206^{* *}$ & $0.379 * * *$ \\
\hline & $(0.091)$ & $(0.082)$ & $(0.082)$ & $(0.131)$ \\
\hline$(\mathrm{t}-22)-(\mathrm{t}-23)$ & 0.004 & 0.083 & 0.130 & 0.197 \\
\hline
\end{tabular}




$\begin{array}{ccccc} & (0.097) & (0.089) & (0.089) & (0.141) \\ (t-23)-(t-24) & 0.011 & 0.140 & 0.190^{*} & 0.285^{*} \\ & (0.107) & (0.097) & (0.100) & (0.150) \\ (t-24)-(t-25) & 0.063 & 0.164^{*} & 0.218^{* *} & 0.235 \\ & (0.104) & (0.097) & (0.100) & (0.148) \\ (t-25)-(t-26) & 0.061 & 0.166^{*} & 0.211^{* *} & 0.302^{* *} \\ & (0.101) & (0.091) & (0.093) & (0.148) \\ (t-26)-(t-27) & 0.033 & 0.136 & 0.177^{*} & 0.191 \\ & (0.106) & (0.097) & (0.099) & (0.154) \\ (t-27)-(t-28) & 0.051 & 0.152 & 0.163 & 0.204 \\ & (0.107) & (0.099) & (0.103) & (0.153) \\ (t-28)-(t-29) & 0.088 & 0.178^{*} & 0.174^{*} & 0.258^{*} \\ & (0.103) & (0.095) & (0.097) & (0.148) \\ (t-29)-(t-30) & 0.026 & 0.118 & 0.161^{*} & 0.218 \\ & (0.092) & (0.085) & (0.085) & (0.138) \\ (t-30)-(t-31) & 0.036 & 0.098 & 0.097 & 0.172 \\ & (0.089) & (0.082) & (0.085) & (0.128)\end{array}$

Notes: Results come from a single regression, estimated on data from 2008-2009. The regression includes day and income-group fixed effects. The omitted category is taxpayers with average AGI in $[0,75)$. Newey-West standard errors (10-day lag) in parentheses. $* * * \mathrm{p}<0.01,{ }^{* *} \mathrm{p}<0.05,{ }^{*} \mathrm{p}<0.1$ 
Table A.7. Heterogeneity by Gender in Sales Response to Market Tumult

Dependent variable: log 1099-B sales volume, USD

Reported coefficient: interaction between change in log VIX and male gender dummy Sample Period

\begin{tabular}{lcccc} 
& \multicolumn{4}{c}{ Sample Period } \\
\cline { 2 - 5 } Number of 1-day lagged differences: & \multicolumn{2}{c}{ September - November 2008 } \\
\cline { 2 - 5 } & 1 & 10 & 1 & $(4)$ \\
\hline & -0.010 & -0.411 & -0.060 & $-1.036^{* *}$ \\
Group-day observations & $(0.063)$ & $(0.742)$ & $(0.064)$ & $(0.465)$ \\
R-squared & 996 & 996 & 124 & 124 \\
\hline
\end{tabular}

Notes: All regressions include day and gender fixed effects. Omitted category is female taxpayers. See note to Table 3 for more details. Newey-West standard errors (10-day lag) in parentheses. $* * * \mathrm{p}<0.01, * * \mathrm{p}<0.05, * \mathrm{p}<0.1$

\section{Table A.8. Heterogeneity by Marital Status in Sales Response to Market Tumult}

Dependent variable: $\log$ 1099-B sales volume, USD

Reported coefficient: interaction between change in log VIX and dummy for being married

\begin{tabular}{|c|c|c|c|c|}
\hline \multirow{4}{*}{ Number of 1-day lagged differences: } & \multicolumn{4}{|c|}{ Sample Period } \\
\hline & \multicolumn{2}{|c|}{$2008-2009$} & \multicolumn{2}{|c|}{ September - November 2008} \\
\hline & 1 & 10 & 1 & 10 \\
\hline & (1) & (2) & (3) & (4) \\
\hline \multirow[t]{2}{*}{ Married } & -0.016 & 0.235 & 0.005 & 0.105 \\
\hline & $(0.024)$ & $(0.149)$ & $(0.040)$ & $(0.258)$ \\
\hline Group-day observations & 996 & 996 & 124 & 124 \\
\hline R-squared & 1.00 & 1.00 & 1.00 & 1.00 \\
\hline
\end{tabular}

Notes: All regressions include day and marital status fixed effects. Omitted category is unmarried taxpayers. See note to Table 3 for more details. Newey-West standard errors (10-day lag) in parentheses. $* * * \mathrm{p}<0.01, * * \mathrm{p}<0.05,{ }^{*} \mathrm{p}<0.1$ 


\section{Table A.9. Heterogeneity by Mortgage Interest Deduction Receipt in Sales Response to Market Tumult}

Dependent variable: $\log 1099$-B sales volume, USD

Reported coefficient: interaction between change in log VIX and dummy for claiming mortgage

interest deduction in given year

\begin{tabular}{lcccc} 
& \multicolumn{4}{c}{ Sample Period } \\
\cline { 2 - 5 } 1 day lagged difference of: & \multicolumn{2}{c}{ September - November } \\
& Log VIX & VIX & Log VIX & VIX \\
\cline { 2 - 5 } & $(1)$ & $(2)$ & $(3)$ & $(4)$ \\
\hline & $-0.086^{* *}$ & 0.008 & -0.084 & -0.289 \\
Group-day observations & $(0.036)$ & $(0.384)$ & $(0.072)$ & $(0.340)$ \\
R-squared & 996 & 996 & 124 & 124 \\
\hline
\end{tabular}

Notes: All regressions include day and mortgage interest receipt fixed effects. Omitted category is taxpayers not claiming a mortgage interest deduction. See note to Table 3 for more details. Newey-West standard errors (10-day lag) in parentheses. $* * * p<0.01, * * p<0.05, * p<0.1$ 


\section{Table A.10. Heterogeneity by Amount of Mortgage Interest Deduction Receipt in Sales Response to Market Tumult}

\section{Dependent variable: $\log$ 1099-B sales volume, USD}

Reported coefficient: interaction between change in log VIX and dummy for decile of mortgage interest

deduction amount in given year

\begin{tabular}{lcccc} 
& \multicolumn{4}{c}{ Sample Period } \\
\cline { 2 - 5 } Number of 1-day lagged differences: & \multicolumn{2}{c}{ September - November 2008 } \\
\cline { 2 - 4 } & 1 & 10 & 1 & 10 \\
\hline$[80,100]$ & 0.009 & $1.382^{* *}$ & $-0.105^{* *}$ & 0.107 \\
& $(0.053)$ & $(0.632)$ & $(0.052)$ & $(0.306)$ \\
{$[50,80)$} & 0.011 & 0.479 & 0.022 & $1.004 * * *$ \\
{$[30,50)$} & $(0.046)$ & $(0.521)$ & $(0.070)$ & $(0.261)$ \\
& $0.165^{* * *}$ & $1.740^{* *}$ & 0.039 & $1.334 * * *$ \\
Group-day observations & $(0.060)$ & $(0.754)$ & $(0.088)$ & $(0.332)$ \\
R-squared & 1,992 & 1,992 & 248 & 248 \\
\hline
\end{tabular}

Notes: All regressions include day and mortgage interest receipt group fixed effects. The omitted category consists of taxpayers with a mortgage interest deduction amount in $[0,30)$. See note to Table 3 for more details. Newey-West standard errors $(10$-day lag) in parentheses. $* * * p<0.01, * * \mathrm{p}<0.05, * \mathrm{p}<0.1$ 
Table A.11. Heterogeneity by Region in Sales Response to Market Tumult

\begin{tabular}{|c|c|c|c|c|}
\hline \multirow{5}{*}{ Number of 1-day lagged differences: } & $\begin{array}{l}\text { 1099-B sa } \\
\text { ange in lo }\end{array}$ & $\begin{array}{l}\text { s volume, } \\
\text { VIX and d }\end{array}$ & $\begin{array}{l}\text { D } \\
\text { Imy for Cen }\end{array}$ & ion \\
\hline & \multicolumn{4}{|c|}{ Sample Period } \\
\hline & \multicolumn{2}{|c|}{ 2008-2009 } & \multicolumn{2}{|c|}{ September - November 2008} \\
\hline & 1 & 10 & 1 & 10 \\
\hline & (1) & $(2)$ & (3) & (4) \\
\hline \multirow[t]{2}{*}{ Midwest } & -0.025 & $-1.010 * *$ & $-0.091 * *$ & -0.583 \\
\hline & $(0.050)$ & $(0.416)$ & $(0.038)$ & $(0.443)$ \\
\hline \multirow[t]{2}{*}{ South } & 0.022 & -0.297 & $-0.094 * *$ & -0.569 \\
\hline & $(0.042)$ & $(0.292)$ & $(0.045)$ & $(0.379)$ \\
\hline \multirow[t]{2}{*}{ West } & -0.008 & $-0.553 *$ & $-0.100 * *$ & -0.318 \\
\hline & $(0.042)$ & $(0.322)$ & $(0.043)$ & $(0.371)$ \\
\hline Group-day observations & 1,992 & 1,992 & 248 & 248 \\
\hline R-squared & 0.99 & 0.99 & 0.99 & 0.99 \\
\hline
\end{tabular}

Notes: All regressions include day and region fixed effects. Omitted category is the Northeast region. See note to Table 3 for more details. Newey-West standard errors (10-day lag) in parentheses. $* * * \mathrm{p}<0.01, * * \mathrm{p}<0.05, * \mathrm{p}<0.1$ 
Table A.12. Heterogeneity by State in Sales Response to Market Tumult

Dependent variable: log 1099-B sales volume, USD

Reported coefficient: interaction between change in log VIX and dummy for state

Sample Period

\begin{tabular}{|c|c|c|c|c|}
\hline \multirow{4}{*}{ Number of 1-day lagged differences: } & \\
\hline & \multicolumn{2}{|c|}{$2008-2009$} & \multicolumn{2}{|c|}{ September - November 2008} \\
\hline & 1 & 10 & 1 & 10 \\
\hline & $(1)$ & $(2)$ & (3) & $(4)$ \\
\hline \multirow[t]{2}{*}{$\mathrm{AL}$} & 0.074 & 0.011 & -0.057 & 0.127 \\
\hline & $(0.100)$ & $(0.741)$ & $(0.071)$ & $(1.055)$ \\
\hline \multirow[t]{2}{*}{ AK } & 0.119 & -1.032 & -0.081 & -0.420 \\
\hline & $(0.117)$ & $(0.885)$ & $(0.204)$ & $(1.072)$ \\
\hline \multirow[t]{2}{*}{$\mathrm{AZ}$} & -0.037 & -0.330 & -0.060 & 0.872 \\
\hline & $(0.069)$ & $(0.885)$ & $(0.084)$ & $(0.598)$ \\
\hline \multirow[t]{2}{*}{ AR } & -0.154 & -0.790 & -0.214 & 0.070 \\
\hline & $(0.102)$ & $(0.765)$ & $(0.138)$ & $(0.801)$ \\
\hline \multirow[t]{2}{*}{$\mathrm{CO}$} & -0.024 & -0.108 & -0.020 & $0.606^{*}$ \\
\hline & $(0.062)$ & $(0.675)$ & $(0.062)$ & $(0.347)$ \\
\hline \multirow[t]{2}{*}{$\mathrm{CT}$} & 0.034 & 0.808 & -0.050 & $1.380 * * *$ \\
\hline & $(0.062)$ & $(0.681)$ & $(0.071)$ & $(0.447)$ \\
\hline \multirow[t]{2}{*}{$\mathrm{DE}$} & -0.060 & -0.701 & 0.235 & 0.932 \\
\hline & $(0.111)$ & $(0.848)$ & $(0.225)$ & $(0.886)$ \\
\hline \multirow[t]{2}{*}{ DC } & 0.123 & $1.945^{*}$ & -0.061 & 0.646 \\
\hline & $(0.148)$ & $(1.135)$ & $(0.190)$ & $(1.244)$ \\
\hline \multirow[t]{2}{*}{ FL } & $0.127 * *$ & $1.045^{*}$ & -0.030 & -0.490 \\
\hline & $(0.057)$ & $(0.611)$ & $(0.078)$ & $(0.354)$ \\
\hline \multirow[t]{2}{*}{ GA } & -0.084 & 0.289 & $-0.158 * *$ & 0.285 \\
\hline & $(0.063)$ & $(0.685)$ & $(0.076)$ & $(0.737)$ \\
\hline \multirow[t]{2}{*}{ HI } & 0.058 & 0.185 & $-0.271 * *$ & 0.548 \\
\hline & $(0.113)$ & $(0.821)$ & $(0.129)$ & $(1.029)$ \\
\hline \multirow[t]{2}{*}{ ID } & -0.002 & -1.273 & 0.059 & -1.005 \\
\hline & $(0.114)$ & (1.117) & $(0.158)$ & $(1.287)$ \\
\hline IL & 0.045 & -0.047 & -0.007 & -0.256 \\
\hline
\end{tabular}




$\begin{array}{lcccc} & (0.059) & (0.576) & (0.063) & (0.388) \\ \text { IN } & 0.063 & 0.248 & -0.043 & -0.349 \\ \text { IA } & (0.080) & (0.675) & (0.124) & (0.547) \\ & -0.114 & -1.179 & -0.029 & 2.299^{*} \\ \text { KS } & (0.089) & (0.856) & (0.130) & (1.241) \\ & -0.133 & -1.081 & -0.059 & 0.700^{*} \\ \text { KY } & (0.090) & (0.748) & (0.116) & (0.41) \\ & -0.025 & -0.539 & 0.109 & 2.709^{* * *} \\ \text { LA } & (0.068) & (0.62) & (0.094) & (0.742) \\ & -0.046 & -1.528^{*} & -0.103 & 1.469 \\ & (0.084) & (0.859) & (0.105) & (1.371) \\ \text { ME } & & & & \\ & & & & \\ \text { MD } & 0.193 * * & -1.142 & 0.276^{* * *} & 2.628^{* * *} \\ & (0.095) & (0.849) & (0.106) & (0.971) \\ \text { MA } & -0.079 & -0.389 & -0.001 & 1.870^{* * *} \\ & (0.061) & (0.644) & (0.062) & (0.46) \\ \text { MI } & -0.023 & 0.386 & -0.012 & -0.022 \\ & (0.067) & (0.6) & (0.067) & (0.337) \\ \text { MN } & -0.012 & -0.222 & -0.010 & 0.118 \\ & (0.065) & (0.587) & (0.095) & (0.457) \\ \text { MS } & -0.126^{* *} & -0.589 & -0.108^{*} & 2.304^{* * *} \\ & (0.063) & (0.628) & (0.062) & (0.466) \\ \text { MO } & 0.130 & 1.943 * * & -0.147 & 1.040 \\ & (0.117) & (0.971) & (0.154) & (0.915) \\ & 0.012 & -0.377 & -0.028 & 0.937 * * \\ & (0.078) & (0.885) & (0.090) & (0.467) \\ & -0.004 & 0.679 & 0.000 & 1.843^{* *} \\ & (0.107) & (0.958) & (0.154) & (0.913) \\ & -0.077 & -1.607 * * & -0.059 & -1.321^{* *} \\ & (0.099) & (0.728) & (0.128) & (0.562) \\ & 0.054 & 3.475^{* * *} & -0.135 & 8.156^{* * *} \\ & & & & \\ & & & & \\ & & & \end{array}$




$\begin{array}{lcccc} & (0.153) & (1.325) & (0.260) & (1.198) \\ \mathrm{NH} & -0.003 & -0.894 & 0.063 & 1.153 \\ \mathrm{NJ} & (0.101) & (1.011) & (0.099) & (1.405) \\ & -0.017 & 0.593 & -0.020 & 0.135 \\ \mathrm{NM} & (0.077) & (0.94) & (0.071) & (0.423) \\ & 0.227 * & 1.320 & 0.189 & 1.077 \\ \mathrm{NY} & (0.122) & (0.932) & (0.243) & (1.287) \\ & 0.026 & 1.035 & 0.116 * & 1.205 \\ \mathrm{NC} & (0.080) & (0.77) & (0.067) & (0.776) \\ & -0.006 & -0.186 & -0.062 & 0.637 \\ \mathrm{ND} & (0.059) & (0.577) & (0.056) & (0.415) \\ & -0.342^{* *} & -0.115 & -0.151 & 0.006 \\ \mathrm{OH} & (0.172) & (0.996) & (0.250) & (1.42) \\ & -0.039 & -0.710 & -0.073 & 0.930 \\ \text { OK } & (0.060) & (0.593) & (0.070) & (0.682) \\ & 0.085 & 0.289 & 0.008 & 1.903 \\ \text { OR } & (0.120) & (1.143) & (0.145) & (2.954) \\ & -0.017 & -0.624 & 0.024 & 2.080^{* * *} \\ \mathrm{PA} & (0.067) & (0.717) & (0.060) & (0.707) \\ & -0.007 & -0.364 & 0.092 & 2.091 * * * \\ \mathrm{RI} & (0.053) & (0.532) & (0.063) & (0.401) \\ & 0.114 & 0.762 & -0.078 & 3.222 * * * \\ \mathrm{NC} & (0.106) & (1.013) & (0.148) & (0.704) \\ & 0.033 & 0.090 & 0.051 & 0.802 * \\ & (0.067) & (0.575) & (0.057) & (0.485) \\ & -0.021 & -0.149 & 0.148 & 3.983 * * * \\ & (0.153) & (0.932) & (0.267) & (1.107) \\ & 0.048 & 0.682 & 0.085 & 2.037 * \\ & (0.077) & (0.713) & (0.098) & (1.132) \\ & -0.018 & -0.134 & -0.067 & 0.782 \\ & (0.068) & (0.685) & (0.107) & (0.709)\end{array}$




\begin{tabular}{lcccc} 
UT & -0.101 & -0.827 & -0.224 & $-1.565^{*}$ \\
& $(0.095)$ & $(0.789)$ & $(0.143)$ & $(0.817)$ \\
VT & 0.087 & 1.587 & 0.324 & $7.252^{* * *}$ \\
& $(0.141)$ & $(1.406)$ & $(0.249)$ & $(2.252)$ \\
VA & 0.005 & 0.412 & -0.058 & 0.203 \\
& $(0.062)$ & $(0.664)$ & $(0.065)$ & $(0.577)$ \\
WA & 0.034 & -0.657 & -0.132 & $1.188^{*}$ \\
& $(0.076)$ & $(0.7)$ & $(0.189)$ & $(0.63)$ \\
WV & -0.249 & -1.579 & 0.074 & $3.772 * * *$ \\
& $(0.167)$ & $(1.022)$ & $(0.329)$ & $(1.419)$ \\
WI & -0.102 & -0.810 & -0.092 & 0.810 \\
& $(0.066)$ & $(0.682)$ & $(0.065)$ & $(0.526)$ \\
WY & -0.289 & -1.788 & $-0.793 * * *$ & -0.198 \\
& $(0.191)$ & $(1.572)$ & $(0.291)$ & $(1.437)$ \\
p-value, joint significance test & 0.0742 & 0.000 & 0.0759 & 0.000 \\
Group-year observations & 25,398 & 25,398 & 3,162 & 3162.000 \\
R-squared & 0.99 & 0.99 & 0.99 & 0.99 \\
\hline include day and state fixed effects. The omitted category is California. See note to Table 3 for more details. Newey-West standard errors
\end{tabular}


Table A.13. Heterogeneity by 2007 House Price Growth in Sales Response to Market Tumult

\begin{tabular}{|c|c|c|c|c|}
\hline \multicolumn{5}{|c|}{$\begin{array}{c}\text { Dependent variable: } \log 1099-\mathrm{B} \text { sales volume, USD } \\
\text { Reported coefficient: interaction between change in log VIX and dummy for percentile of } 2007 \text { ZIP } \\
\text { code level house price growth }\end{array}$} \\
\hline \multirow{4}{*}{ Number of 1-day lagged differences: } & \multicolumn{4}{|c|}{ Sample Period } \\
\hline & \multicolumn{2}{|c|}{ 2008-2009 } & \multicolumn{2}{|c|}{$\begin{array}{c}\text { September - November } \\
2008\end{array}$} \\
\hline & 1 & 10 & 1 & 10 \\
\hline & $(1)$ & (2) & (3) & (4) \\
\hline$[80,100]$ & $\begin{array}{l}-0.053 \\
(0.044)\end{array}$ & $\begin{array}{l}-0.451 \\
(0.410)\end{array}$ & $\begin{array}{c}0.044 \\
(0.072)\end{array}$ & $\begin{array}{c}1.693 * * * \\
(0.285)\end{array}$ \\
\hline$[60,80)$ & $\begin{array}{l}-0.049 \\
(0.037)\end{array}$ & $\begin{array}{l}-0.381 \\
(0.294)\end{array}$ & $\begin{array}{c}0.098^{* * *} \\
(0.049)\end{array}$ & $\begin{array}{c}1.267 * * * \\
(0.251)\end{array}$ \\
\hline$[40,60)$ & $\begin{array}{c}-0.097 * * * \\
(0.034)\end{array}$ & $\begin{array}{l}-0.330 \\
(0.251)\end{array}$ & $\begin{array}{l}-0.015 \\
(0.046)\end{array}$ & $\begin{array}{c}1.266^{* * * *} \\
(0.230)\end{array}$ \\
\hline$[20,40)$ & $\begin{array}{l}-0.043 \\
(0.043)\end{array}$ & $\begin{array}{c}0.119 \\
(0.386)\end{array}$ & $\begin{array}{c}0.037 \\
(0.070)\end{array}$ & $\begin{array}{c}1.791 * * * \\
(0.249)\end{array}$ \\
\hline Group-day observations & 2,490 & 2,490 & 310 & 310 \\
\hline R-squared & 0.97 & 0.97 & 0.98 & 0.98 \\
\hline
\end{tabular}

Notes: All regressions include day and group fixed effects. Omitted category is $[0,20)$. See note to Table 3 for more details. Newey-West standard errors $(10-$ day lag) in parentheses. ${ }^{* *} \mathrm{p}<0.01, * * \mathrm{p}<0.05,{ }^{*} \mathrm{p}<0.1$ 